\title{
L'HABITAT ARISTOCRATIQUE FORTIFIÉ DE PAule (CôTes-D’ARMor)
}

\author{
Yves MeneZ* et Jean-Charles ArRAMOND**
}

\begin{abstract}
Mots-clés. Côles-d Armor, Paule, second Âge du Fer; ferme, forleresse de hauleur:
Key-words. Côtes-d Armor; Paule, second Iron Age, Farm, Hill-Fort.

Résumé. Les fouilles réalisées à Paule depuis 1988 permettent de suivre l'évolution de cet habitat sur une très longue durée, du V s. avant J.-C. au Irr s. après J.-C. La vaste ferme initiale, constituée de deux enclos, est arasée veers le début du III s. avaant J.-C. Lors de l'édification d'une forteresse privée qui sem abandomnée dans le courant du Ir s. avant J.-C. L'article s'achève par un examen des caractéristiques principales de cet habilat, el de son aptitude à définir un type de site, la "forteresse seigneuriale ", jusqu'ici non pris en compte lors de l'élaboration des schémas définissant l'organisation des territoires au second Âge du Fer.
\end{abstract}

\section{Abstract. The excavations carried out in Paule since 1988 allow to follow the evolution of this settlement during a very long period, from the $5^{\text {th }}$ century B.C. up to the $l^{\text {st }}$ century A.D. The large primary settlement, a farm, comprised two enclosures, which were leveled around the beginning of the $3^{\text {rd }}$ century B.C., when a private fortress was buill. This study is concluded by the examination of the main characteristics of this settlement, defined here as an "aristocratic fortress", a type of site zuhich is at the moment unknoum in territory models of the second Iron Age.}

En 1988, une fouille de sauvetage dirigée par C. Le Potier sur la fortification du camp de Saint-Symphorien à Paule a amené la mise au jour de structures ou de mobiliers jusqu'ici rarement rencontrés sur les habitats du second Âge du Fer armoricain, et notamment une statuette figurant un personnage tenant une "lyre ». Le caractère remarquable de ces découvertes a naturellement conduit les archéologues à s'interroger sur la nature de ce site, manifestement très différent des fermes ou des bourgades, fortifiées ou non, qui parsemaient le territoire de la Gaule indépendante. Plusieurs opérations de fouille programmée, dirigées de 1989 à 1990 par J.-C. Arramond, puis, depuis 1991, par Y. Menez, ont tenté de répondre à cette question. Elles y ont, dans une certaine mesure, réussi. Les éléments sont aujourd'hui rassemblés pour identifier un type de site jusqu'alors méconnu : un habitat aristocratique fortifié du second Âge du Fer.

De ces huit années de recherches, fort peu de données ont été jusqu'ici publiées (Le Potier, Arramond,

\footnotetext{
* Service régional de l'Archéologie de Bretagne, 6 rue du Chapitre, F-35044 Rennes cedex.

** Association pour les Fouilles Archéologiques Nationales, antenne sud-ouest, 12 rue Marcelin-Berthelot, F-33270 Floirac.
} 
1989 a et b, 1990 ; Arramond, le Potier, 1990 ; Vendries, Aumasson, 1990; Arramond et al., 1992). Il est donc temps, aujourd'hui, de livrer à la communauté scientifique une synthèse des principaux résultats de cette fouille, qui consistent en la mise en évidence de l'évolution de cet habitat entre le $V^{*}$ s. avant J.-C. et le I $I^{a t} s$ après J.-C. Ia découverte sur ce site de trois statuettes du second Âge du Fer ne sera ici que rapidement évoquéc. L'étude stylistique de ces sculptures, ainsi que celle des contextes où elles ont été mises au jour, feront l'objet d'un article spécilique qui sera proposé ultérieurement à Gallia.

\section{LE SITE}

Le camp de Saint-Symphorien se situe en plein coeur de la Bretagne, à proximité des limites des départements du Finistère et du Morbihan (fig. 1). Il occupe une position topographique remarquable, à l'extrémité d'une ligne de crêtes qui prolonge vers l'est les Montagnes Noires, barrière naturelle entre la Cornouaille, au sud, et le bassin de ('hateaulin, au nord. Malgré la modeste alti-

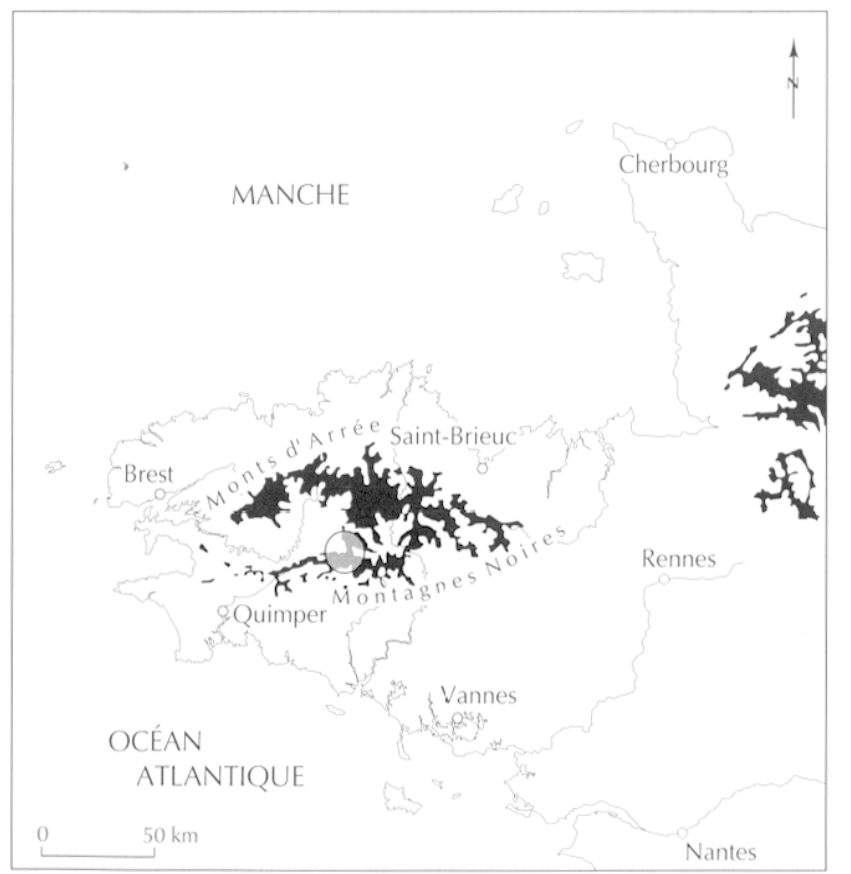

tude de ces sommets, qui culminent entre $270 \mathrm{~m}$ et $300 \mathrm{~m}$ NGF au voisinage du site, cet emplacement permet à la fortification de disposer d'une visibilité exceptionnelle sur le territoire avoisinant. Elle porte, en effet, jusqu’à une trentainc de kilomètres en direction du nord-ouest, vers les sommets des Monts d'Arrée (38.3 m NGF) qui sont les points culminants de la péninsule armoricaine.

Cette position topographique, sur des crêtes qui jouent également le rôle de barrières climatiques, explique la faible moyenne des températures $\left(9^{\circ}\right)$ ainsi que le fort volume des précipitations ammuclles, supérieures à $1300 \mathrm{~mm}$. Neige et gel sont ici bien plus fréquents qu'ailleurs en Bretagne. Deux sources au débit important sont connues à proximité du site : celle de Coat ar Scaon, à $800 \mathrm{~m}$ au nord-est, et surtout celle de Saint-Symphorien, localisée à moins de $100 \mathrm{~m}$ au nord de la fortification et qui alimente aujourd'hui les communes avoisinantes. I'examen géologique préliminaire du site, réalisé par P.-R. Giot, a montré que la fortification recoutvaait, pour la partic nord, un niveau à quartzites blancs et grès ferrugineux, pour la partie sud, des schistes phylliteux gris-vert fortement plissés par des phénomènes de cryoturbation. Ces matériaux, très altérés à proximité des grès, se présentent alors comme une « argile » blanchâtre

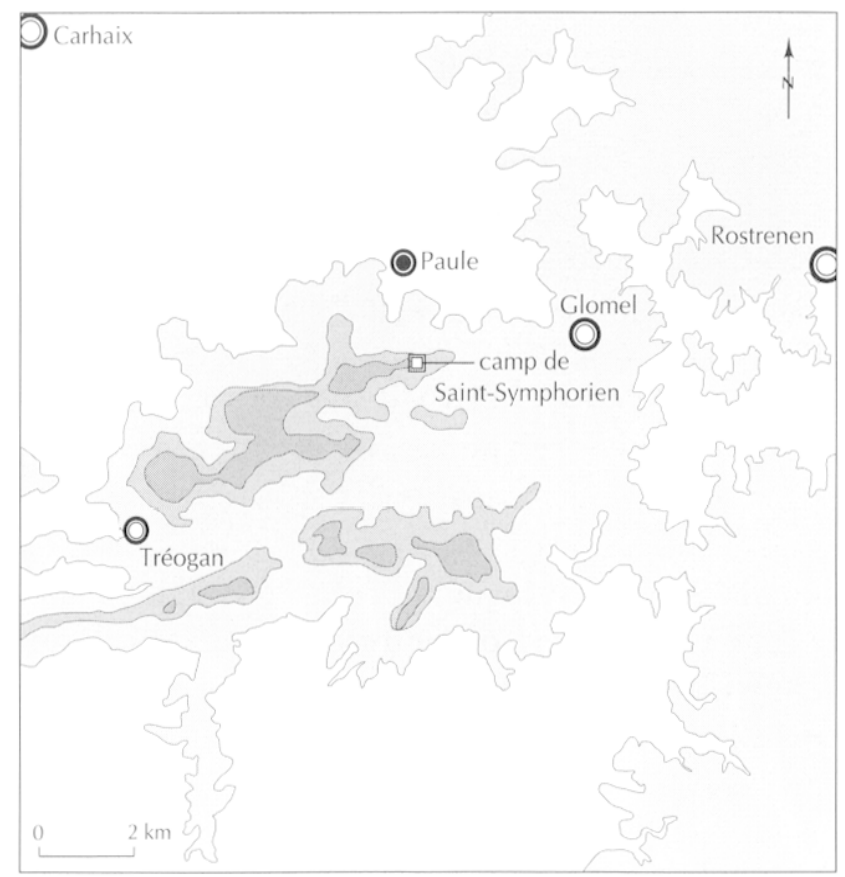

Fig. 1. I.ocalisation topographique du site. Seuls les reliefs d'une allitude supérieure à $200 \mathrm{~m} N(\mathrm{IF}$ somt indiqués en noir: Les trames grisées correspondent respectivement ia des allitudes supérieures à $200 \mathrm{~m}, 250 \mathrm{~m}$ et $270 \mathrm{~m}$ (dessin M. Dupré/AFAN). 
exploitée dès l'Âge du Fer, comme en témoignent de nombreuses petites carrières.

La première mention connue de cette fortification remonte à 1883, date à laquelle est signalée, dans une publication de J. Gaultier du Mottay, "l'enceinte fortifièe ou quadrilatère de Castel Odic, ayant soixante-quinze mètres de côté ". Cette indication, très succincte, scra ultérieurement reprise par ('. de la Chenelière (1884), puis par A.-I. Harmois (1909). Si le toponyme diffère de celui aujourd'hui utilisé, qui se réfère au hameau le plus proche, la description convient parfaitement à ce qui devait subsister de la fortification à la fin du XIX"s. : un champ délimité sur trois côtés par une puissante levée de terre, large de $10 \mathrm{~m}$ environ à la base et d'une hauteur conservée proche de $3 \mathrm{~m}$.

Les fouilles effectuées sur cette enceinte de 1988 à 1995 ont permis de décaper et d'étudier une superficic de $16600 \mathrm{~m}^{2}$, correspondant à l'emplacement de la nouvelle route départementale ainsi qu'à la parcelle située immédiatement au sud (fig. 2).

Les trous de poteaux et les fosses ont été fouillés de manière exhaustive. Il en a ćté de même des intersections de fossés, dont la compréhension est essenticlle pour la restitution de la chronologie relative du réseau de clôture. I.es autres sections de fossés n'ont été fouillées que lorsqu'elles paraissaient susceptibles de livrer quelques données nouvelles ou des précisions sur l'évolution du site, principalement lorsqu'un changement dans la stratigraphic ou une particulière abondance de mobilier était pressentie. Ces travaux ont été effectués en essayant de dissocier les différents niveaux d'accumulation stratigraphique dans ces fossés, le plus souvent manuellement ou, lorsqu'une plus grande rapidité s'avérait nécessaire, à l'aide d'un tractopelle.

Le plan obtenu à l'issue de ces sept années de fouille est relativement complexe. Hormis les restes d'un rempart, conservé sur ses parties nord et onest et qui constituait l'unique vestige de cette fortification discernable avant 1988 , on distingue un semis d'excavations plus ou moins vastes, cerné ou entrecoupé par des fossés aux dimensions parfois imposantes. Les très rares lambeaux de sols protohistoriques, piégés sous une voie ou la base de quelques remparts, ont montré que l'on se situait, de manière générale et en tenant compte des tassements, entre 40 et $80 \mathrm{~cm}$ sous les nivcaux de l'Âge du Fer. Malgré cette érosion, assez forte quoique comparable à celle constatée sur la plupart des sites laténiens fouillés en
Bretagne, les nombreux recoupements de structures ont permis de proposer une chronologie de l'évolution de cet établissement.

\section{L'HABITAT PRIMITIF (PHASE I)}

Les traces d'une première occupation sur le site ne semblent pas, pour le moment, remonter au-delà du V's. avant J.C. Elle se caractérise, d'cmblée, par la création d'un vaste enclos, d'une superficie proche de $9000 \mathrm{~m}^{2}$, auquel est venu s'accoler un second enclos que les fouilles commencent seulement à mettre au jour. Parmi les vestiges, probablement nombreux, qui doivent subsister de l'habitat primitif, fort peu ont pu ctre clairement identifiés grâce à l'étude des relations stratigraphiques ou du mobilier découvert dans les excavations. On peut néanmoins rattacher à cette première occupation, outre trois petits fossés, ultimes vestiges de partitions internes de l'enclos principal, un vaste édifice, deux ensembles de fosses-ateliers, ainsi que quatre vastes fosses ou souterrains (fig. 3).

Les fossés de cloture, dont de nombreuses sections ont été fouillées, présentent quasiment partout un comblement identique. Des matériaux éboulés des parois en tapissent le fond et sont recouverts d'un sédiment très fin, vestige des poussières et des boues qui ont achevé de combler ces excavations de section triangulaire et d'une profondeur conservée comprise entre $1 \mathrm{~m}$ et $2,50 \mathrm{~m}$ (fig. 4). Il s'agit donc bien de fossés qui devaient être bordés d'un talus édifié à l'aide des matériaux extraits lors de leur creusement. Une portion de ce talus, conservée sur une hauteur de $1,20 \mathrm{~m}$, soit la totalité de son élévation, a d'ailleurs été mise au jour en 1994, ensevelie sous l'un des remparts qui ont été édifiés ultérieurement. À cet emplacement, cette clôture était parementée de blocs de grès (fig. 5). L'entréc de l'enclos principal a pu être étudiée. L'ampleur de l'interruption du fossé sur la façade est $(17 \mathrm{~m})$ ainsi que l'absence de toute trace d'un quelconque système de fermeture montrent qu'il s'agit bien d'un habitat simplement clôturé, et non fortifié.

D'un vaste édifice adossé au milieu de la façade ouest de l'enclos, à l'abri des vents dominants, ne subsistent aujourd'hui que les fondations : une petite tranchée au profil régulier, à fond plat et parois presque verticales, large de $80 \mathrm{~cm}$ et d'une profondeur conservée de $50 \mathrm{~cm}$, 


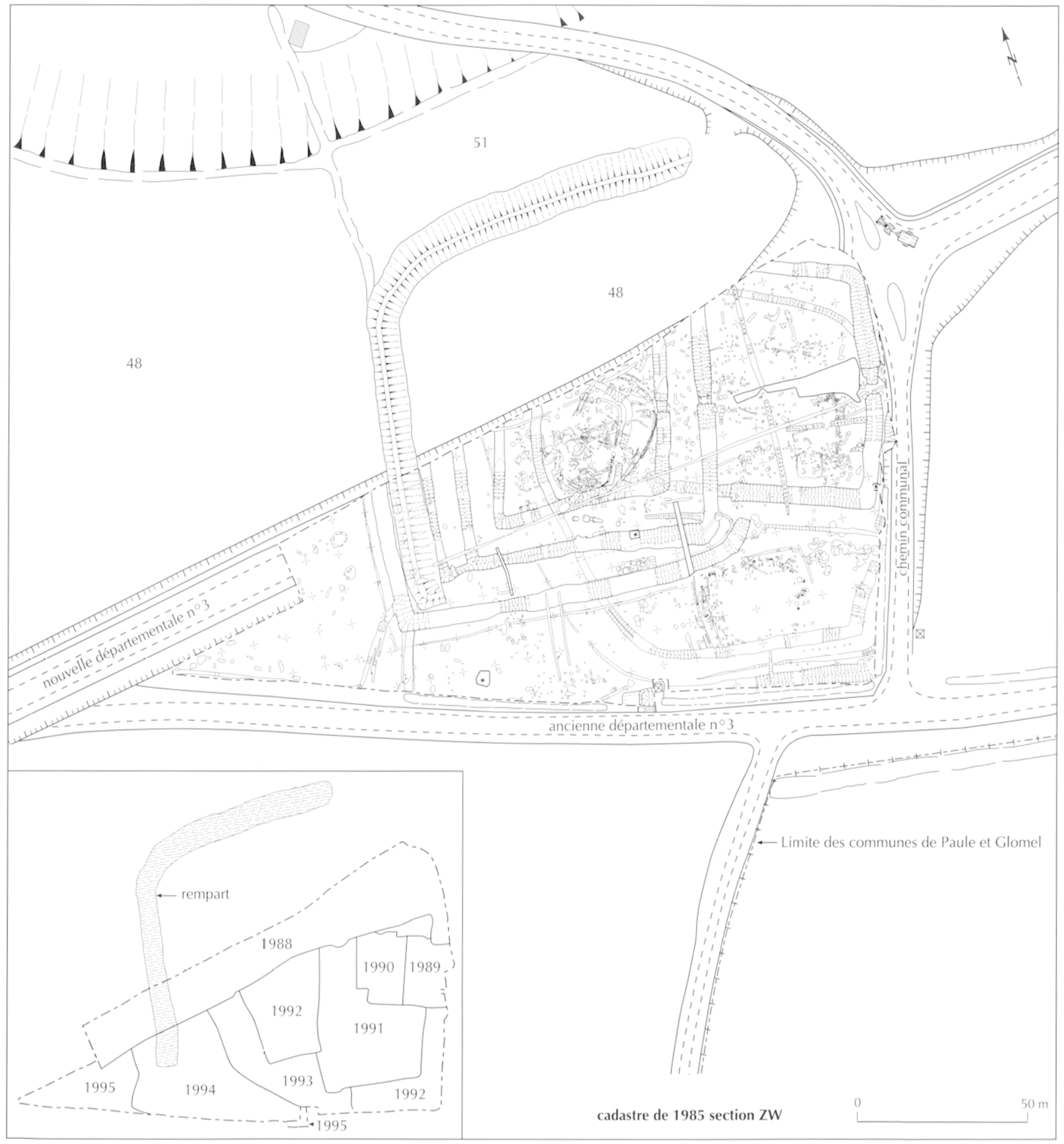

Fig. 2. Plan général des fouilles et localisation, année par année, des secteurs d'intervention (dessin M. Dupré). 


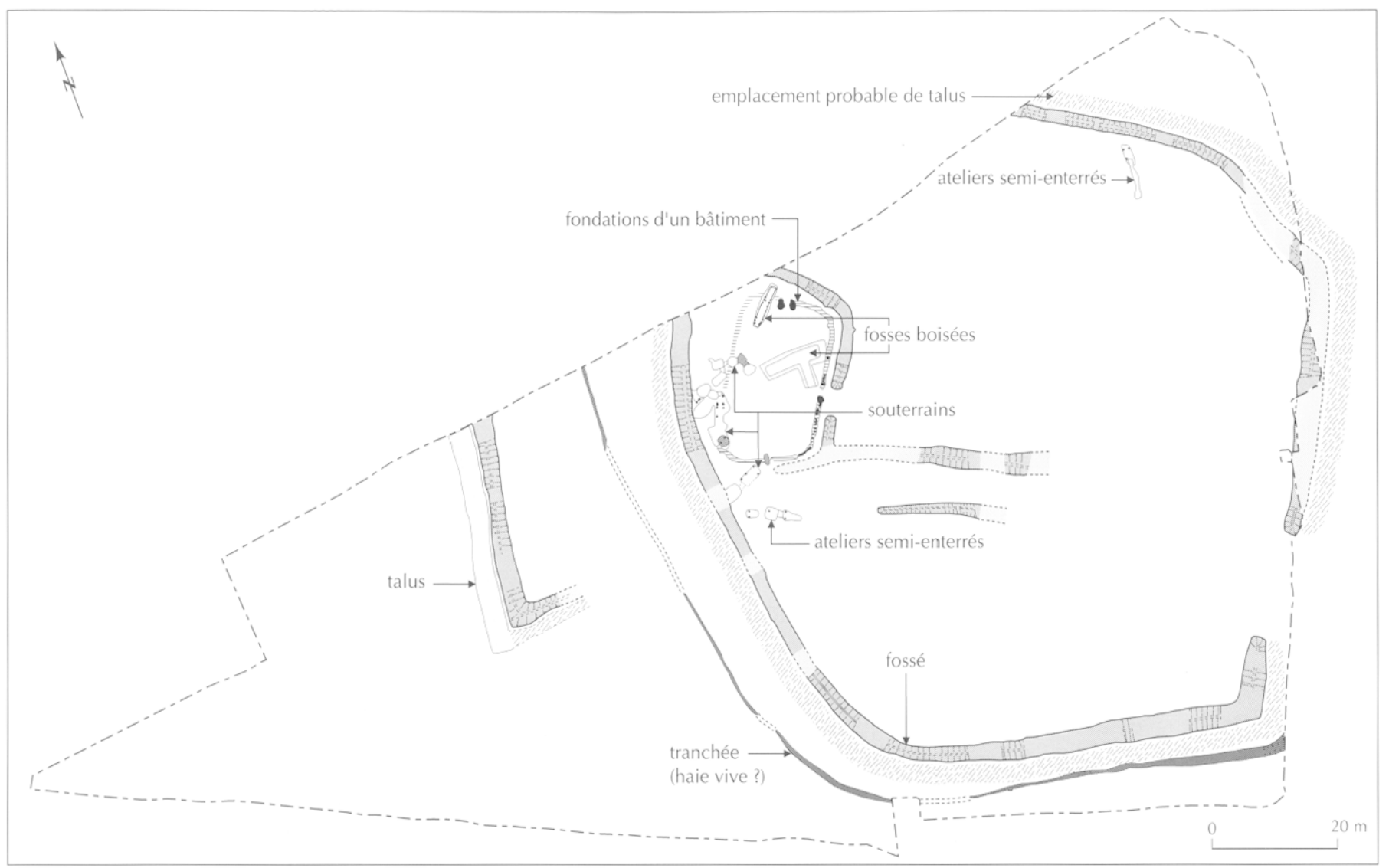

Fig. 3. Plan proposé pour le site primitif: $V^{k}$ et $V^{v}$ s. atant J.-C. (dessin M. Dupré).

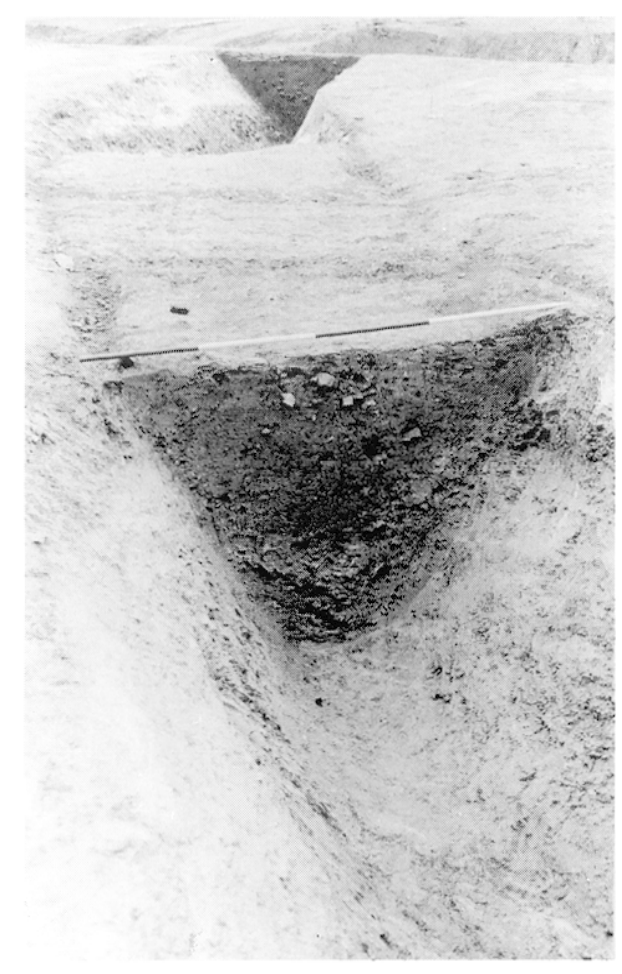

Fig. 4. Coupe dans le fossé de l'enclos primitif; le jalon mesure. $2 \mathrm{~m}$.

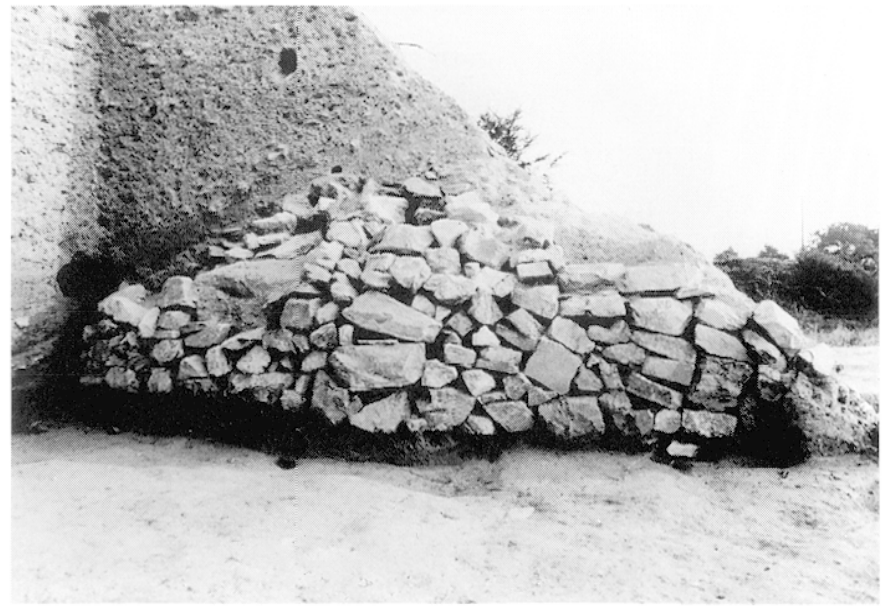

Fig. 5. Vestiges du talus de l'enclos primitif parementé de blocs de grès et scellé sous un des remparts édifiés ultérieurement. I a hauteur totale est de 1,20 menviron au-dessus du sol du $V^{r}$ s. avant J.-C., situé immédiatement sous la première assise (jalon $=2 \mathrm{~m}$, gradué tous les $50 \mathrm{~cm})$. 
au nord, et de $10 \mathrm{~cm}$, au sud. Lorsque cette tranchée a pu être fouillée par passes successives, et dans des conditions d'hygrométric favorables, on a pu y distinguer, au coxur d'un remblai de couleur brune, des taches plus foncées, d'un diamètre compris entre 20 et $40 \mathrm{~cm}$, ultimes traces de la base d'anciens poteaux. Cette excavation peut donc, sans aucun doute, être interprétée comme la fondation d'une paroi constituée de poteaux jointifs. En l'état actucl des données, cette tranchée délimite un espace quadrangulaire long de $25 \mathrm{~m}$ et large de $15 \mathrm{~m}$ environ, soit une superficie de $375 \mathrm{~m}^{2}$. Il est aujourd'hui difficile d'opter entre la restitution d'un unique bâtiment, proche par ses dimensions de la maison de Verberie, Oise (Blanchet et al., 1983), ou celle d'une palissade à laquelle seraient venues s'adosser des constructions de superficies plus modestes.

Deux séries de fosses peu profondes (environ $30 \mathrm{~cm}$ sous le niveau de décapage), aux parois faiblement inclinées, ont été mises au jour respectivement contre les façades nord et ouest de l'enclos principal. Ieur fond plat a systématiquement livré les empreintes d'un ou, le plus souvent, deux poteaux (lig. 6). I.e comblement, pratiquement stérile à l'exception de quelques tessons, était constitué de colluvions. L'aspect de ces fosses fait immédiatement penser à des constructions semienterrées de type "fond de cabane ". Leur position en enfilade permettait de couvrir plusieurs de ces excavations à l'aide d'une unique toiture posée sur les sols avoisinants. La position des couples de poteaux, seulement à l'une des extrémités de chaque fosse, ainsi que leur écartement régulier de $1 \mathrm{~m}$, suggèrent pour ces pieux la fonction de supports d'un métier à tisser. En faveur de cette hypothèse, on notera que de nombreux pesons de tisserand ont été mis au jour sur le site. Parfois en terre cuite, ils se présentent, le plus souvent, sous la forme de disques de schiste percés en leur centre, cette ouverture montrant les traces d'une usure provoquée par la tension des fils.

Deux autres fosses, localisées en partie ou en totalité sous l'édifíce précédemment décrit, étaient bien plus vastes.

I a première, de forme oblongue, avait pour dimensions $7 \mathrm{~m}$ de long, 1,10 $\mathrm{m}$ de large, pour une profondeur conservée de $2 \mathrm{~m}$ sous le niveau de décapage (fig. 7). L'intérêt architectural majeur de cette fosse vient du fait qu'au fond de celle-ci, creusés dans le sol naturcl sur son pourtour et attenant aux parois, trois groupes de trous de

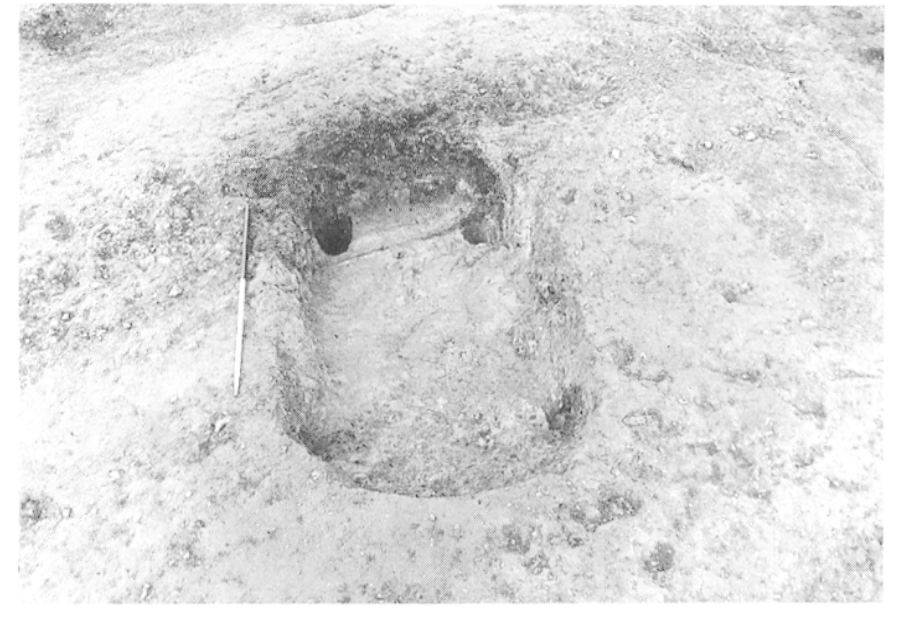

Fig. 6. Vue d'un des ateliers semi-enterrés. Les deux trous de poteaux correspondent probablement aux emplacements des supports d'un métier à tisser $($ jalon $=l \mathrm{~m})$.

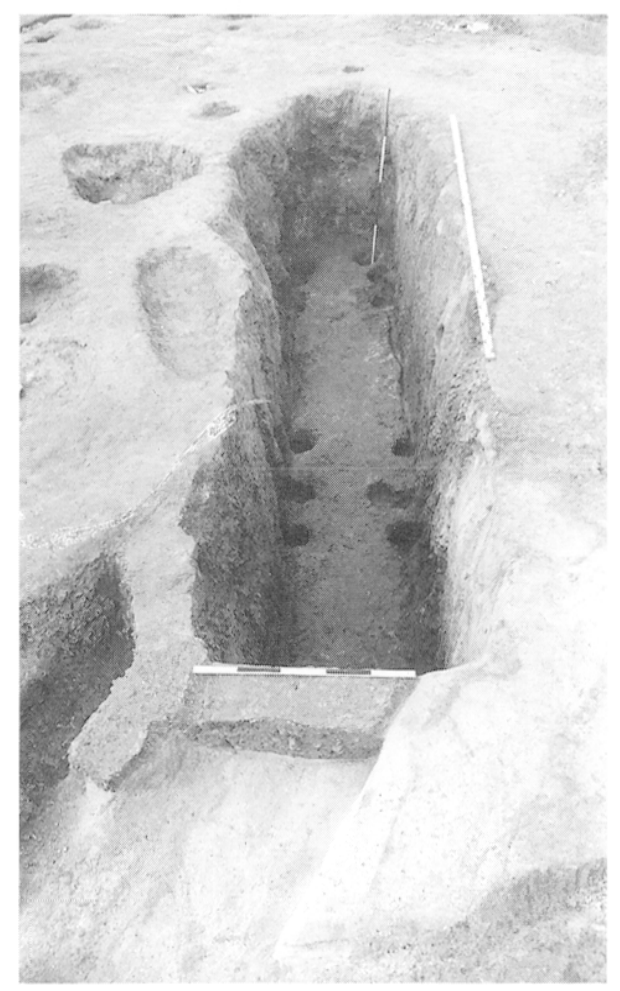

Fig. 7. Vue gémérale de la fosse oblongue (photo II. Paitier, M.C..).

poteaux ont céc découverts : deux d'entre cux aux extrémités de la fosse (six trous au sud-ouest, deux au nordest), le troisième étant composé de sept trous dans la partie médiane. 
Ces excavations ont servi à implanter des picux d'un diamètre voisin de $30 \mathrm{~cm}$ et d'une taille au moins équivalente à la hauteur conservée de la fosse puisque, dans plusieurs cas, les surcreusements de la paroi effectués pour y loger les poteaux étaient conserves. Ces pieux, légèrement inclinés vers l'extérieur, étaient reliés, pour certains d'entre eux, par un habillage de bois qui couvrait les parois de cette fosse. De cette sorte de lambris ne subsistait qu'une petite rigole localiséc à la jonction des parois et du fond. Le caractère « double" de ces boisages est évident. En effet, si l'on imagine que les ensembles de six trous de poteaux correspondent aux fondations de puits de descente au fond de la fosse, la structure peut être décrite comme constituée de deux puits auxquels serait adjointe, au nord-est, une salle souterraine lambrisséc d'environ $2 \mathrm{~m} \times 1 \mathrm{~m}$, pour aut moins $2 \mathrm{~m}$ de profondeur. L'existence de deux accès pour une salle souterraine à la surface somme toute modeste ne se conçoit que dans l'hypothèse d'une possibilité d'utilisation indépendante des deux espaces ainsi restitués, et donc d'une cloison étanche localisée à l'exact milieu de la fosse. Ia présence de très nombreux poteaux peut, certes, s'expliquer par la nature du substrat : une argile relativement instable. Mais il semble bien qu'elle ne justifie pas l'emploi de six poteaux d'un diamètre de $30 \mathrm{~cm}$ pour les probables puits d'accès. De fortes pressions, analogues à celles proroquées par le stockage de grains, pourraient sc révéler une explication plus convaincante. L'hypothèse de deux silos jumelés est donc celle qui est actucllement proposée.

Une deuxième fosse, localisée à environ $10 \mathrm{~m}$ de la précédente, a un plan en forme de " $T$ ». L'aile orientée est-ouest, qui correspond à la barre transversale, mesure $11 \mathrm{~m}$ de long, sa perpendiculaire se développant sur une distance de 4,50 m. La largeur, constante, est de $2 \mathrm{~m}$; la profondeur conservée sous le niveau de décapage n'excède pas $2,50 \mathrm{~m}$. Ces dimensions ainsi que la parfaite verticalité des parois et l'horizontalité du fond donnent à cette fosse un aspect extrêmement similaire à celle ćtudiée précédemment. Cette excavation ne présentait aucune trace d'aménagement conservée vers la base, mais uniquement dans la partie haute, à une vingtaine de centimètres sous le niveau de décapage. Il s'agit d'une échancrure, d'une sorte de corniche conservée sur $0,60 \mathrm{~m}$ de haut et $0,20 \mathrm{~m}$ à $0,30 \mathrm{~m}$ de large qui longe le pourtour de cette structure et peut être interprétée comme le support d'un plafond de traverses de bois. On peut donc être ici tout à fait certain, à la différence de la fosse précédente, de la présence d'une couverture localisée sous les sols de l'époque. Peut-être fautil donc voir, dans cette structure d'un volume estimé à $75 \mathrm{~m}^{3}$, un silo ou plus probablement une vaste cave.

Non loin de ces deux fosses, un souterrain a été découvert. Creusé dans un sous-sol très altéré, l'accès se présentait sous la forme d'un puits d'un diamètre de $1,30 \mathrm{~m}$ pour une profondeur conservée de $2,40 \mathrm{~m}$ sous le niveau de décapage, soit près de $3 \mathrm{~m}$ sous les sols de l'époque. Deux ensembles s'organisaient à partir de cette ouverture : à l'ouest, une succession de trois salles séparées par des chatières; au sud-est, une unique salle creusée dans le substrat. Toutes ces pièces souterraines avaient des dimensions voisines de $1,60 \mathrm{~m}$ pour la largeur et la hauteur maximale, les longueurs s'échelonnant entre 2 et $3 \mathrm{~m}$. Après l'effondrement particl d'au moins une des voutes de ce souterrain, une série de fosses a été creusée dans le prolongement des salles précédentes. Un nouveau puits, peu profond $(1,50 \mathrm{~m}$ sous le niveau de décapage), permettait d'accéder aux nouvelles salles souterraines.

À proximité immédiate de cette structure, un deuxième soutcrain a pu être fouillé en 1994. Un puits d'accès de section quadrangulaire a été creusé à une profondeur estimée à environ $2 \mathrm{~m}$ sous les sols de l'époque. Il permettait d'accéder, par l'intermédiaire d'une cha-

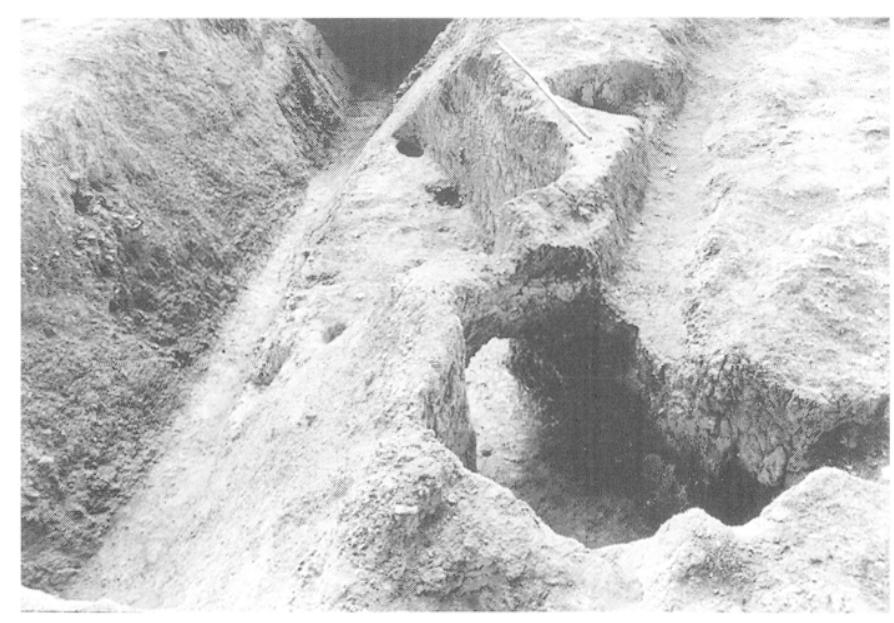

Fig. 8. Vue d'un souterrain. Au premier plan, le puits d'acrès qui permetlait d'accéder; pro la chatière, à une salle boisée dont on devime l'emplacement des potecaux, à l'aplomb du jalon. Cefle structure a élé ultérieurement recoupée par un profond fossé, creusé au débul de la phase II (jalon $=2 \mathrm{~m})$. 
tière taillée dans le substrat, à unc enfilade de deux salles de plan rectangulaire, aux parois lambrissées maintenues par des poteaux et couvertes d'un plafond de bois très probablement recouvert de terre (fig. 8).

L'usage de ces souterrains, très fréquents dans la péninsule armoricaine durant l'Âge du Fer, prête encore à discussion. À l'hypothèse de simples caves ou de silos, nous préférons celle de cachettes, non pour les hommes, mais pour les denrées pondéreuses (Menez, 1994).

Tous ces vestiges, épars, ne représentent très probatblement qu'une partic des constructions qui ont marqué la premicre phase d'occupation sur ce site; de surcroît, ils ne sont sûrement pas tous strictement contemporains, même s'ils appartiennent à la phase la plus ancienne.
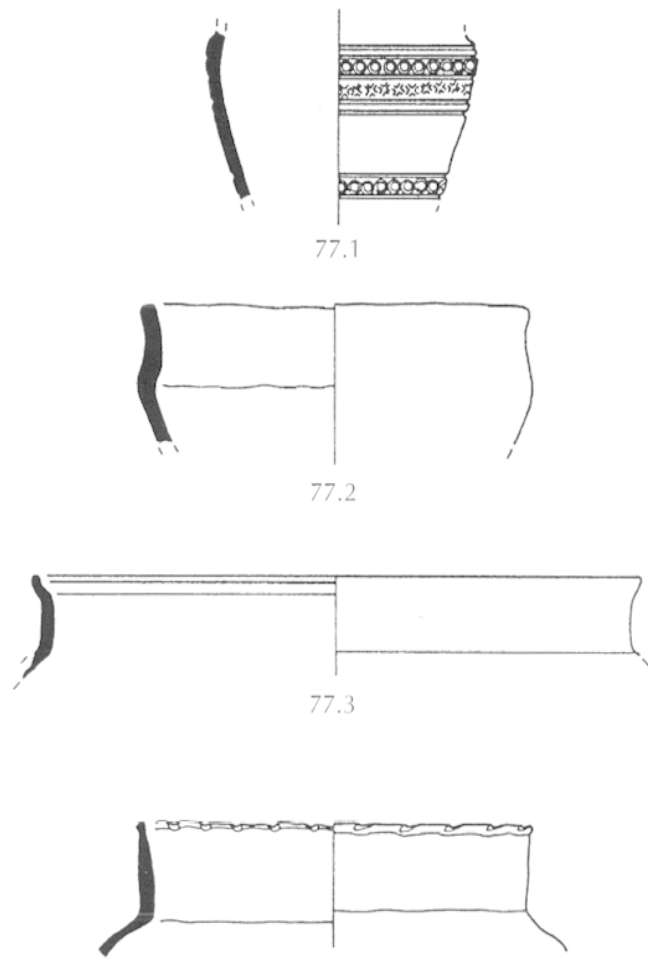

366.2
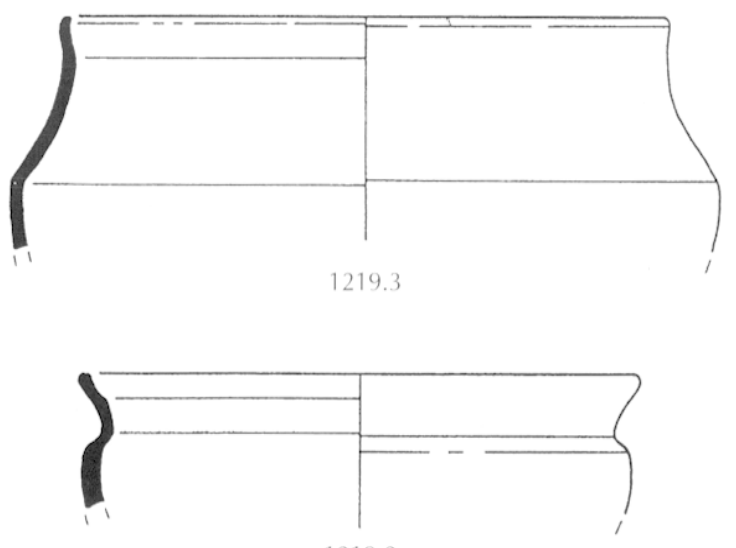

1219.2

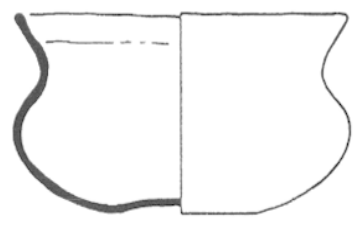

857.1
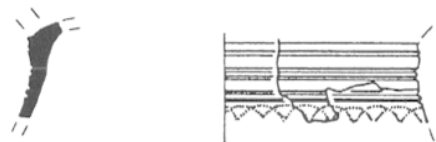

1219.7

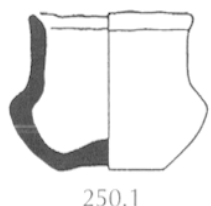

250.1

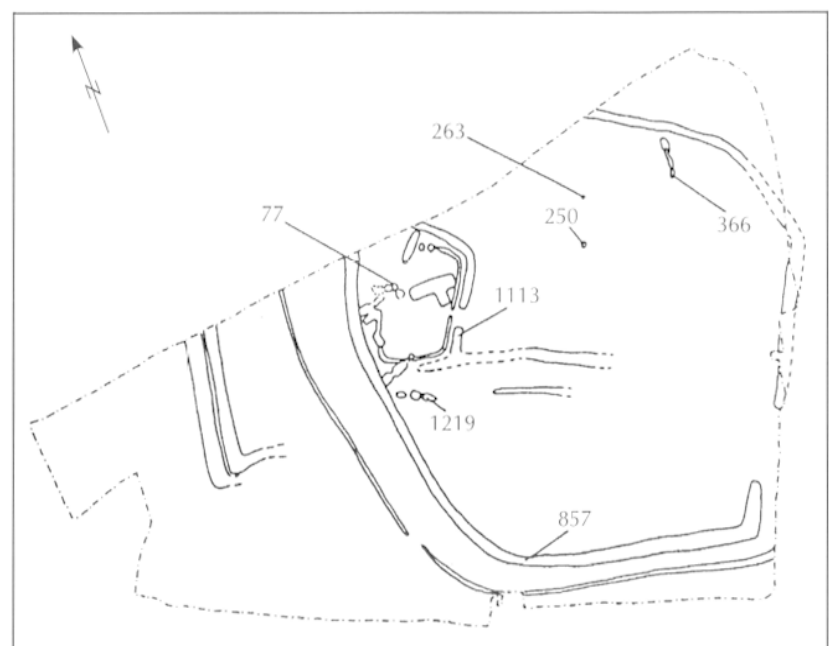

Fig. 9. Mobritier caractéristique de la phase I. 
Malgré son caractère particl, ce plan évoque toutefois, non une fortification, mais une vaste ferme (fig. 3). I.es céramiques mises au jour dans les remblais de ces excavations peuvent être attribuées au $\mathrm{V}^{*}$ et au $\mathrm{IV}^{*}$ s. avant J.-C. (fig. 9). L.e fait que certaines structures aient été remblayées probablement avant 450 prouve que les origines du site doivent être situées, si l'on tient compte d'une durée d'utilisation de ces excavations avant leur comblement, vers la fin du premier Âge du Fer.

\section{A PREMIÈRE FORTIFICATION (PHASE II)}

L'analyse de plusieurs intersections de fossés a montré que le premier bouleversement notable qu'ait connu le site s'est effectué de manière globale (fig. 10). Trois importantes lignes de défense, associant un profond fossé à section triangulaire et un rempart à poutres verticales, ont été créées de toutes pièces, entraînant l'arasement des clôtures dans toute la moitić nord de l'enclos antéricur. Deux fortifications concentriques, aujourd'hui signalées par les fossés 199 et 238 (fig. 11), cernaient un trapc̀ze d'une superficie probablement inférieure à $2000 \mathrm{~m}^{2}$. À l'angle sud-est de cet espace, une tour devait dominer l'ensemble des défenses. Une avant-cour, d'une superficic d'environ $2000 \mathrm{~m}^{2}$ et accolée à la façade est, était délimitée par un unique rempart précédé d'un vaste fossé ( $2 \mathrm{~m}$ de profondeur au nord ; 4,50 $\mathrm{m}$ à proximité de l'entrée est).

L'accès principal au site s'effectuait par une voie qui, longeant au sud cette avant-cour, pénétrait par l'intermédiaire d'une chicane dans les défenses (fig. 12). À l'issue d'un couloir délimité, vers l'ouest, par le fossé 238, vers l'est, par une ligne de potcaux, il était ensuite possible, après une nouvelle chicane, de franchir sous la super-

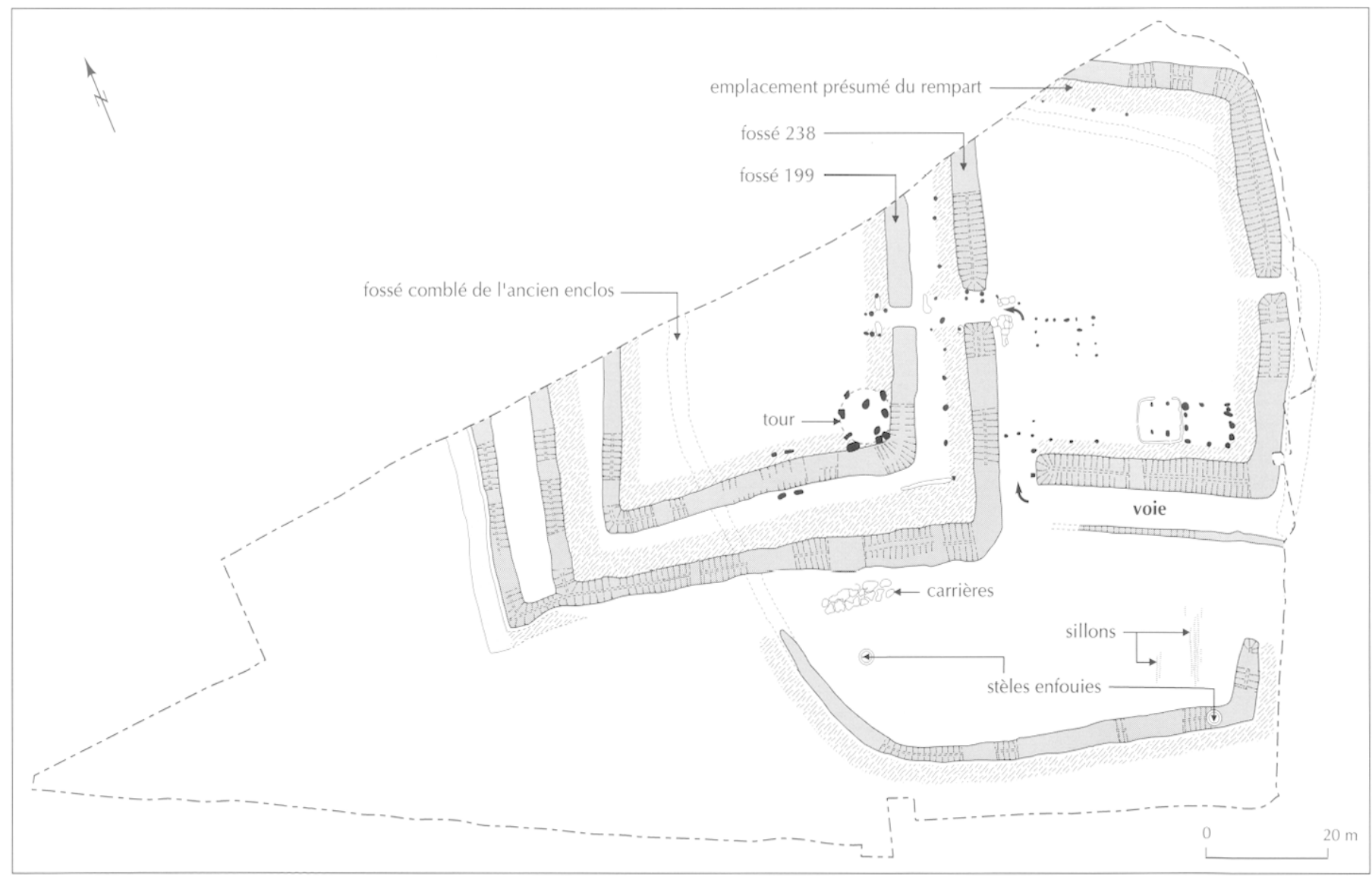

Fig. 10. Plan proposé pour le premier état de la fortification : fin du IVtr et III s. avant J.-C. (dessin M. Dupré). 


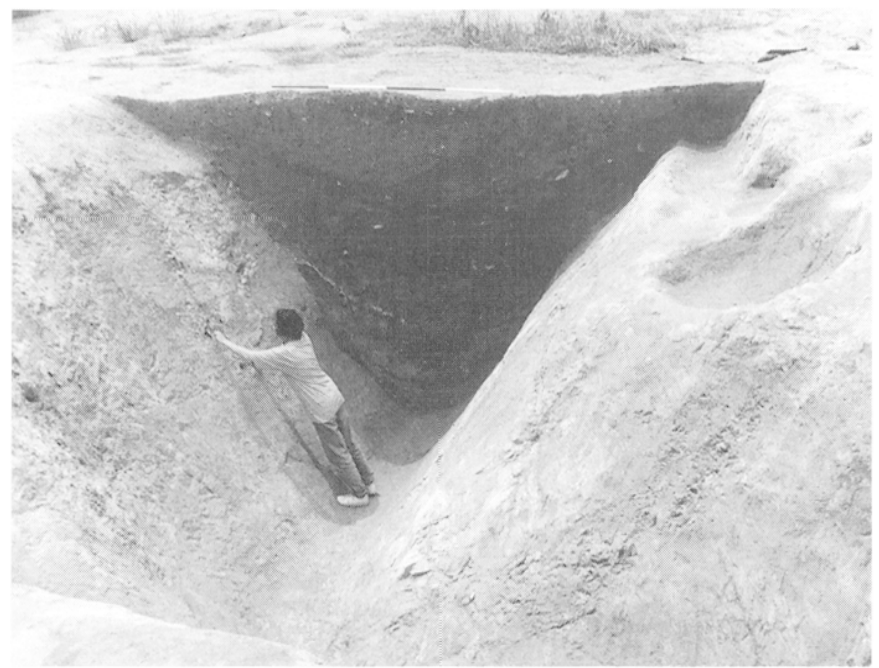

Fig. 11. Vue d'un des fossés $\left(n^{\prime \prime} 199\right)$ de la première forlification. La douve forme ici un angle ì $90^{\circ}$, an pied d'une lour fondée sur neuf potecuix. On distingue encore, à l'angle du fossé, une des vastes fosses dans lesquelles étaient implantés les supponts de cet édifice. partiellement détruite par le crensement d'un prelit fossé de parcellaire moderne.

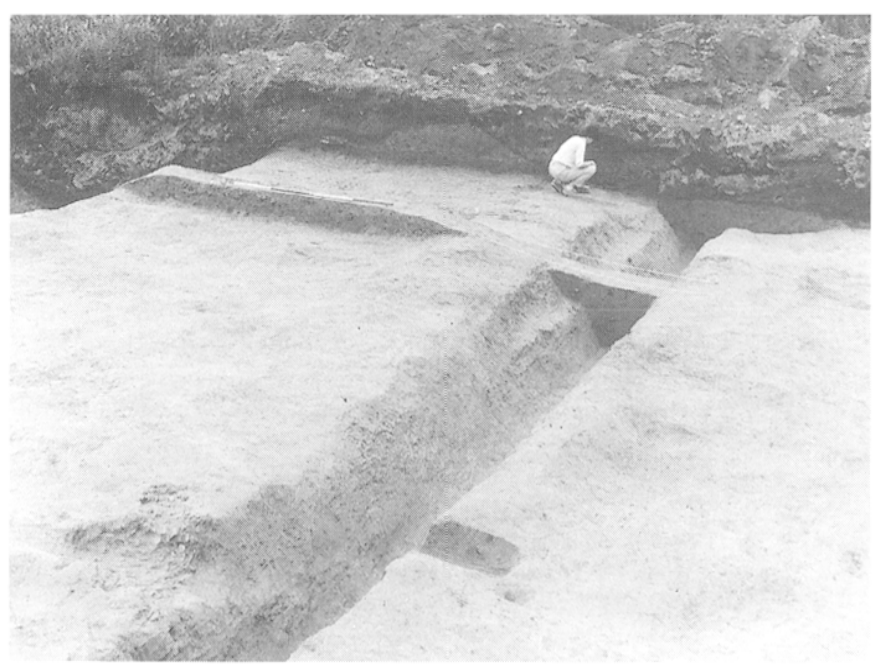

Fig. 12. Vue de la voie permollant d'acrider it la fortification comprise

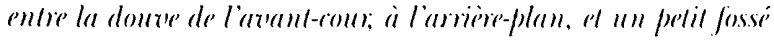

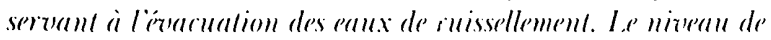
circulation, marqué par un niverau de piermille, est silue an comlact du jalon.

structure des remparts deux portes en chlilade pour accéder au corur du site.

La perception de l'occupation à l'intérieur des différents espaces ainsi délimités est encore très floue. Il est

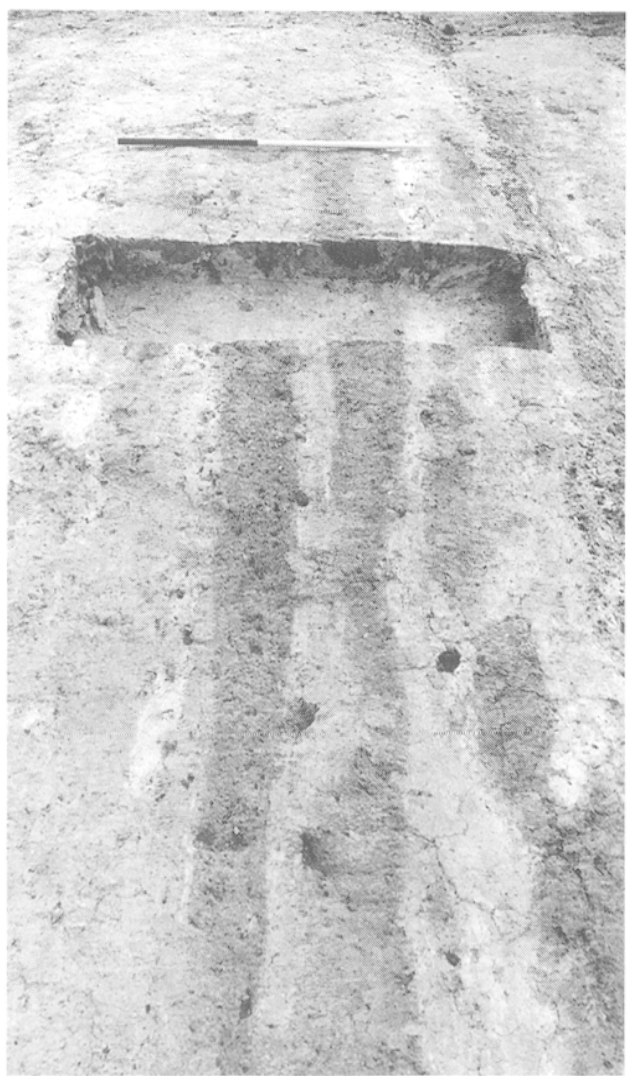

Fig. 13. Traces gémérées par un labour a laraire. Le sondage quadrangulaire realisé dans. le substrat permet d'observer le profil inferiener des sillons.

certain qu'une ou plusicurs constructions, probablement à usage d'habitation si l'on en juge par les foyers domestiques épars dans cette zone, ont continué à occuper le cocur du site. L'accumulation des excavations dans cet espace n'a pas permis, pour le moment, de discerner les plans des bâtiments contemporains de cette phase. En revanche, les emplacements de quelques édifices étaient cncore obscrvables dans l'avant-cour:

Ia nature de l'occupation du raste espace localisé au sud de la woie noest pas aisóe à cerner. La présence de traces de labours (fig. 13), orientées perpendiculairement à la voic et recoupées par les fondations ultéricures, ćroque un champ ou un jardin, délimité au sud et à l'est par lancieme clôture du site. Ia découverte de petites carrieres d'argile contemporaines au nord-est, dauns une zone qui, proche des fossés, a pu être délaisséc par la culture, ne contredit pas une telle hypothèse. 
On peut également rattacher à cette phase l'enfouissement, dans la partic sud du site, de deux stèles hémisphériques en granite à grain fin soigneusement bouchardé. Ces monuments, d'un poids respectif évaluć à $60 \mathrm{~kg}$ et plus de $200 \mathrm{~kg}$, devaient marquer auparavant un espace funćaire qui reste encore à découvrir.

Enfin, l'un des faits les plus notables qui marquent le début de cette phase est le comblement de toutes les structures souterraines encore visibles, accompagné d'un compactage des matériaux afin d'éviter les tassements ultérieurs. Certes, la désaffection de ces structures enterrées peut être due à leur position, devenuc subitement gênante lors de la réorganisation du site. Il est néammoins curicux que, pour le moment, aucun souterain plus tardif n'ait été découvert sur le site, et ce alors que nombre de ces cavités etaient encore en usage en Armorique jusqu'à Ia lène finale (Giot, 1979). On peut donc se demander s'il n'y a pas un lien, autre qu'anecdotique, entre la fortification du site et l'abandon des souterrains. D’une défense " passive ", se traduisant par l'enfouissement des denrées pondéreuses dans ces caches et la fuite des habitants vers des lieux plus sûrs, on serait passé à une défense actire arec l'édification de remparts imposants qui suggèrent la présence, à demeure, d'hommes d'armes aguerris.

Quoi qưil en soit, il est évident que le site bascule, probablement brusquement, d'une organisation de l'espace analogue à celle des "fermes indigènes " à celle d'une véritable fortification, cernée de multiples remparts et dont les accès étaient particulièrement bien défendus. Cet habitat prend alors l'allure d'une place forte qu'il gardera jusqu'à son abandon. Il faut probablement situer cette évolution fondamentale vers la fin de $\mathrm{I}$ a Tène ancicnne (fin du IV' ct début du III' s. avant J.-C.), datation retenue pour l'échantillommage de mobilier présenté sur les figures 14 et 15 .

\section{CRÉATION DE IAA BASSE-COUR, SUIVIE D'UNE MODIFICATION DE L'ORGANISATION DES DÉFENSES CONSÉCUTIVE À UN INCENDIE (PHASE III)}

I.'habitat de Saint-Symphorien, s'il conserve sa fonction de place forte ćtablie dès la fin de la lène ancienne, connaît cependant plusicurs évolutions notables.
Tout d'abord, un vaste édifice, constitué de trois ailes de bâtiments encadrant une cour, est bâti au pied des remparts (fig. 16 et 17), dans l'espace précédemment dévolu aux cultures. Sans s'attarder sur les détails, on peut néanmoins attirer l'attention sur le caractère très organisé du plan qui transparaît des fondations, un semis d'excavations délimité au nord et à l'est par une petite tranchée. L'aile nord était constituée d'un unique bâtiment, long de $21 \mathrm{~m}$ et large de $4,70 \mathrm{~m}$ environ. I a dimension des trous de potcaux (20 à $40 \mathrm{~cm}$ de diamètre en moyenne) et le diamòtre des pieux, lorsqu'il a pu être estimé (environ $20 \mathrm{~cm})$, suggerent pour cette construction la restitution d'une "longere ". I es dimensions des trous de poteaux de l'aile est sont tout autres : 60 à $150 \mathrm{~cm}$ de diamètre, pour une profondeur conservée proche de $80 \mathrm{~cm}$. Il en est de même des mensurations des pieux, lorsqu'clles ont pu etre ćtablies à partir des calages ou des taches brunes résultant du pourrissement de leur base : des madriers équarris, d'une section proche de $40 \mathrm{~cm} x$ $30 \mathrm{~cm}$. Ces indices suggèrent la restitution, pour cette aile, d'un bâtiment à étage, qui devait dominer un porche d'accès situé au centre de la construction. Iarge de $3 \mathrm{~m}$ environ, cette entrée permettait d'accéder au coeur de ce vaste édifice à partir de la voie située immédiatement au nord.

I'aile onest présente également un aspect très différent. I.es dimensions des trous de poteaux sont analogues à celles mesurées dans l'aile nord $(20$ à $40 \mathrm{~cm}$ de diamètre en moyenne), hormis dans la partie centrale du bâtiment. En effet, quatre vastes fosses, au coeur desquelles ont parfois cté retrouvées les traces de forts madriers, témoignent probablement de la présence à cet endroit d'un autre porche d'accès surmonté d'une superstructure. L'originalité des vestiges de cette aile vient principalement des petites tranchées taillées dans le schiste qui ont pu être fouillées dans ce secteur. Elles présentent deux types de profils, auxquels sont associés des remplissages différents. Certaines d'entre elles, très étroites $(10$ à $15 \mathrm{~cm})$ et aux parois presque verticales, étaient comblées de terre brun clair mêléc de pierraille. Elles semblent avoir servi de fondations à des cloisons constituées de planches épaisses. D'autres, plus larges $(60 \mathrm{~cm})$ et d'une profondeur conservée d'cnviron $25 \mathrm{~cm}$, étaient caractérisées par un fond plat, large d'environ $40 \mathrm{~cm}$, prolongé par des parois légèrement incurvées (fig. 18). Ces dernières excavations débouchent systématiquement dans de vastes fosses, d'un diamètre proche de 


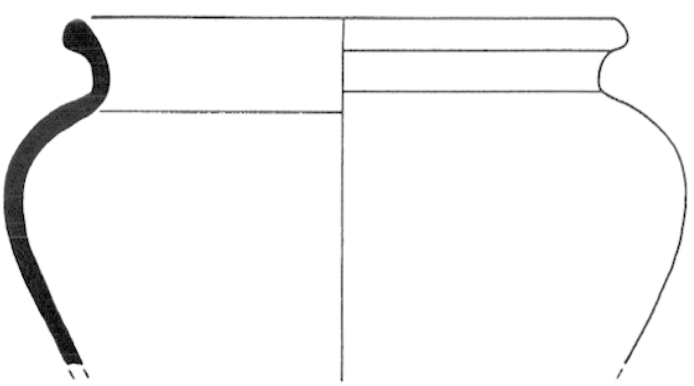

1145.1

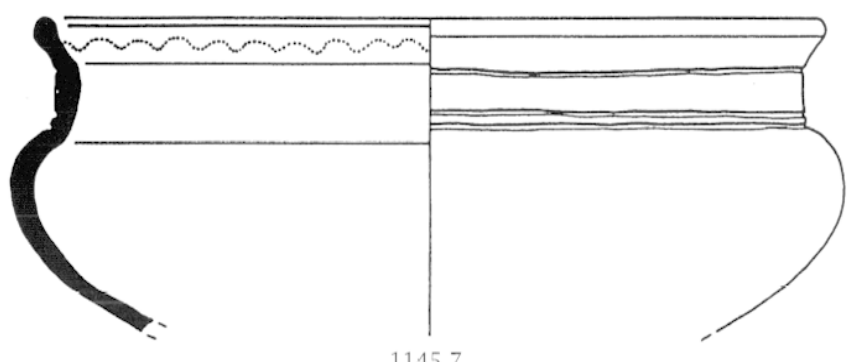

1145.7
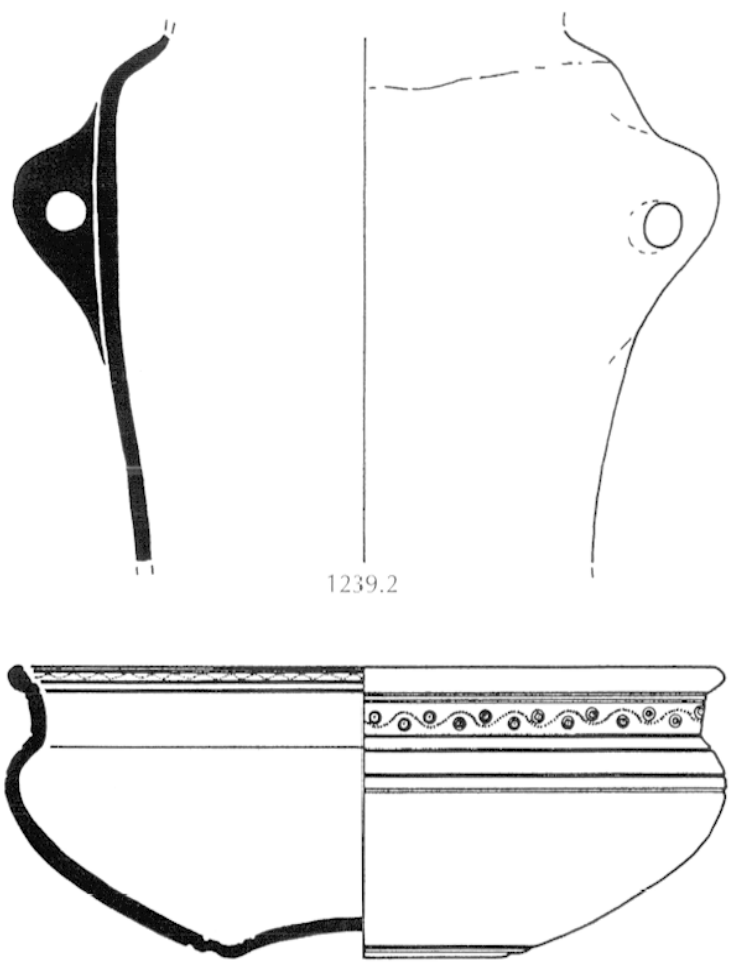

1239.1
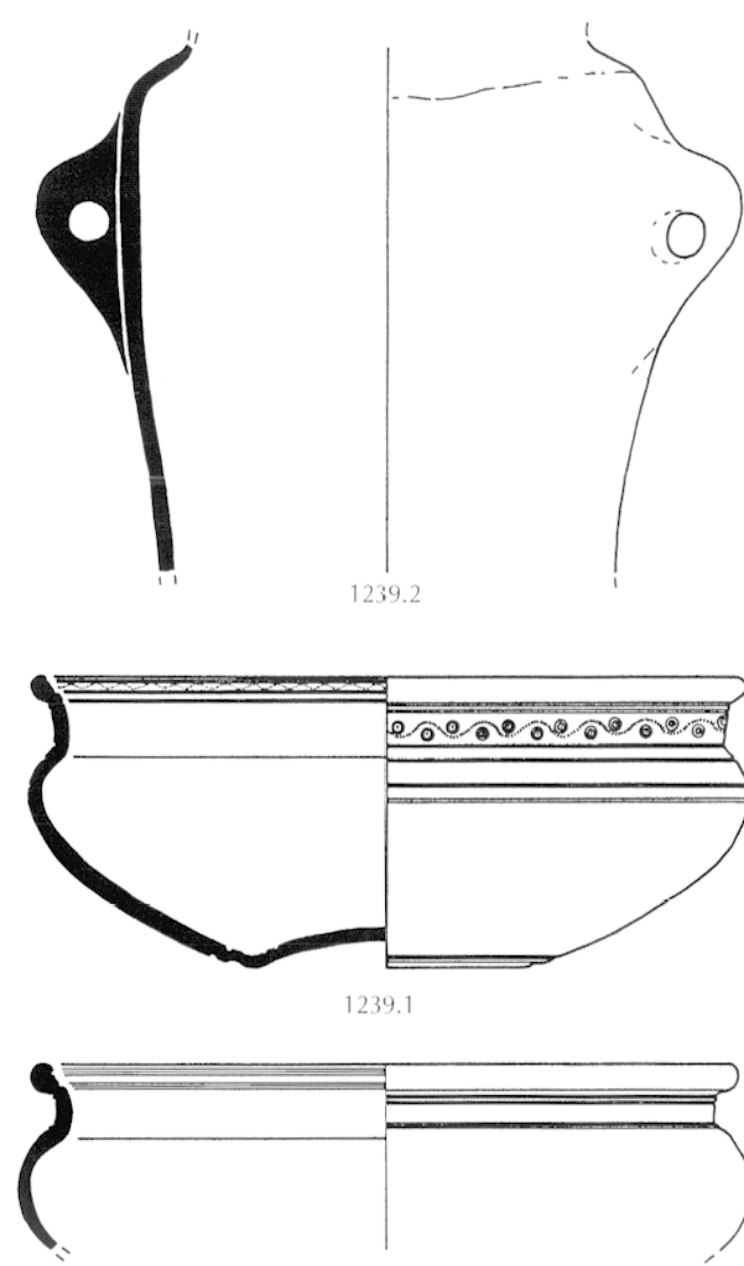
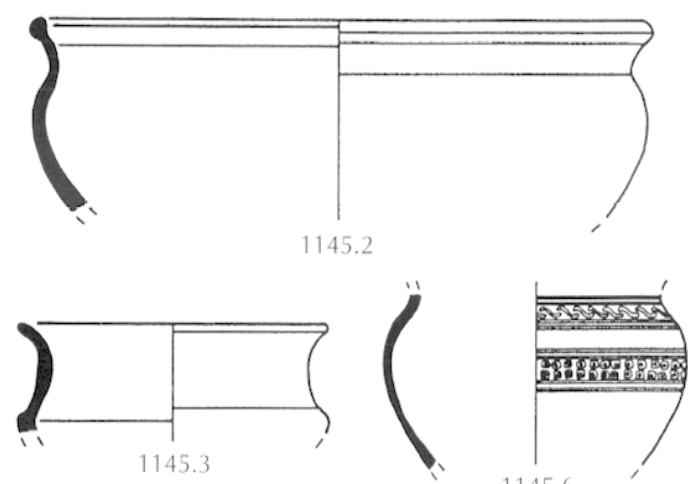

1145.6

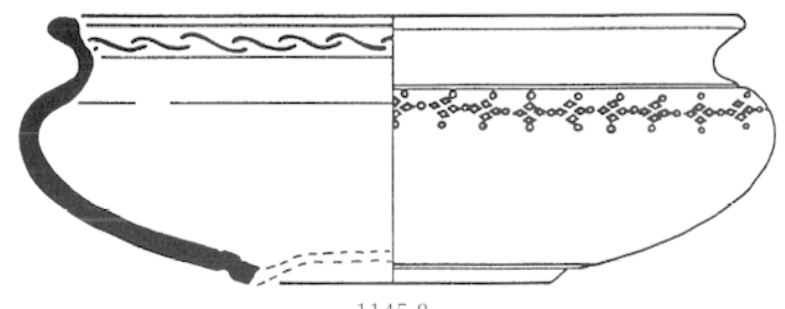

1145.8

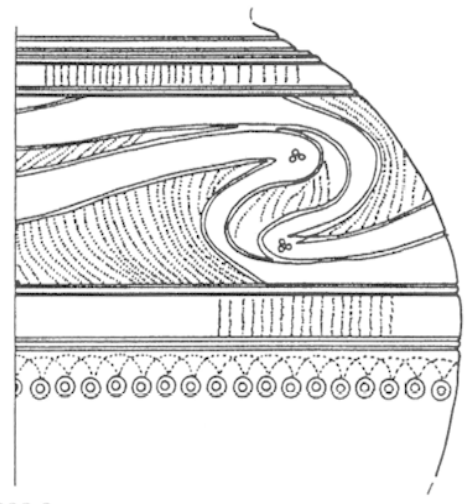

1239.3
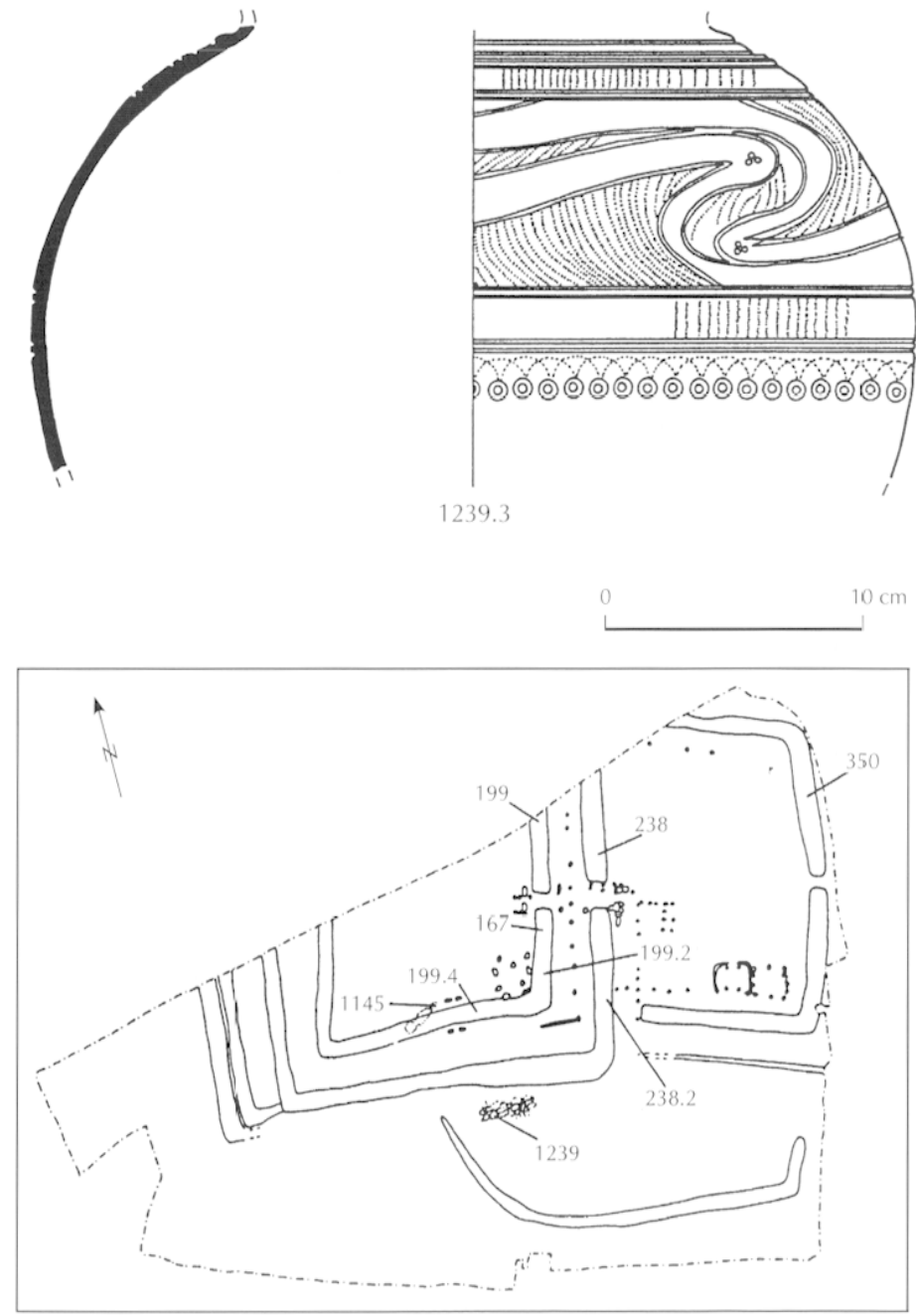

Fig. 14. Mobilier caractéristique du débul de la phase II. 


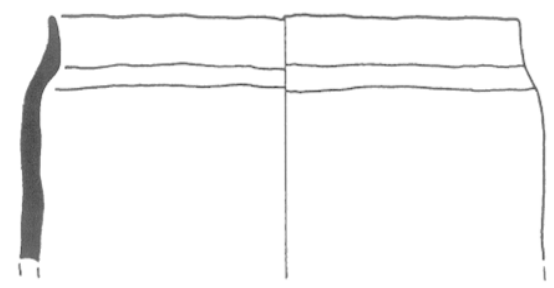

167.8

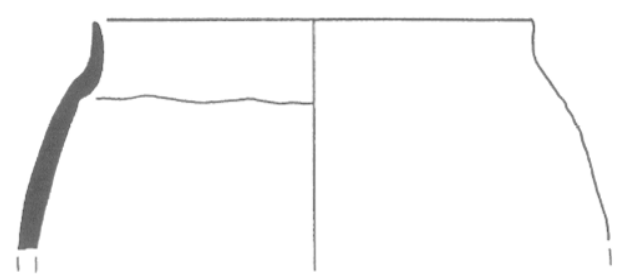

199 2c. 5

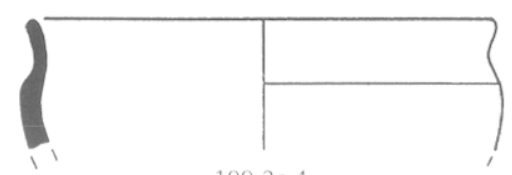

199 2C. 4

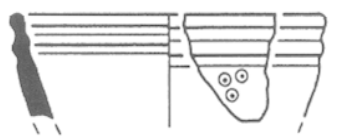

199 2c. 1

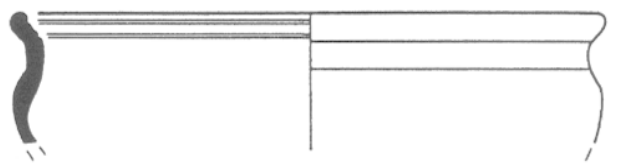

199 2c. 5

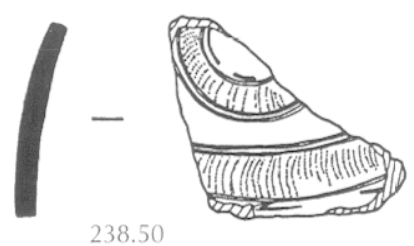

238.50 $10 \mathrm{~cm}$

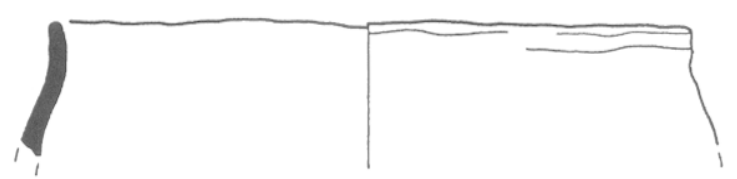

167.10

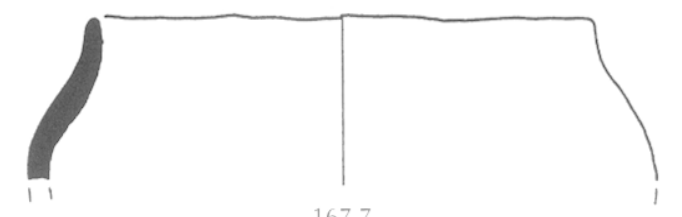

167.7

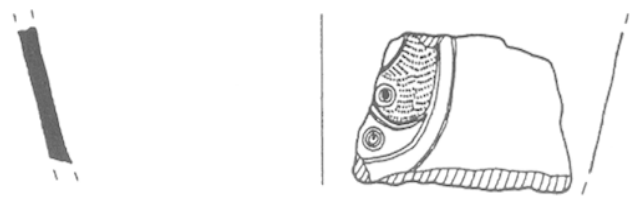

199 2c. 2

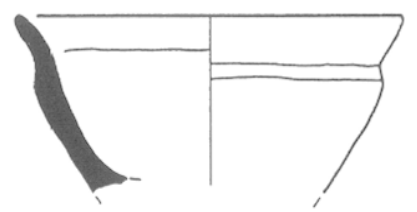

$1994 c .1$

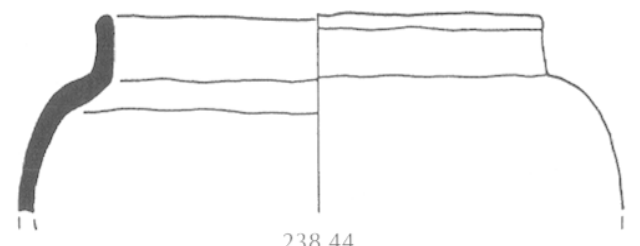

238.44

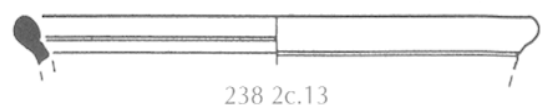

Fig. 15. Mobilier caractéristique du début de la phase II. 


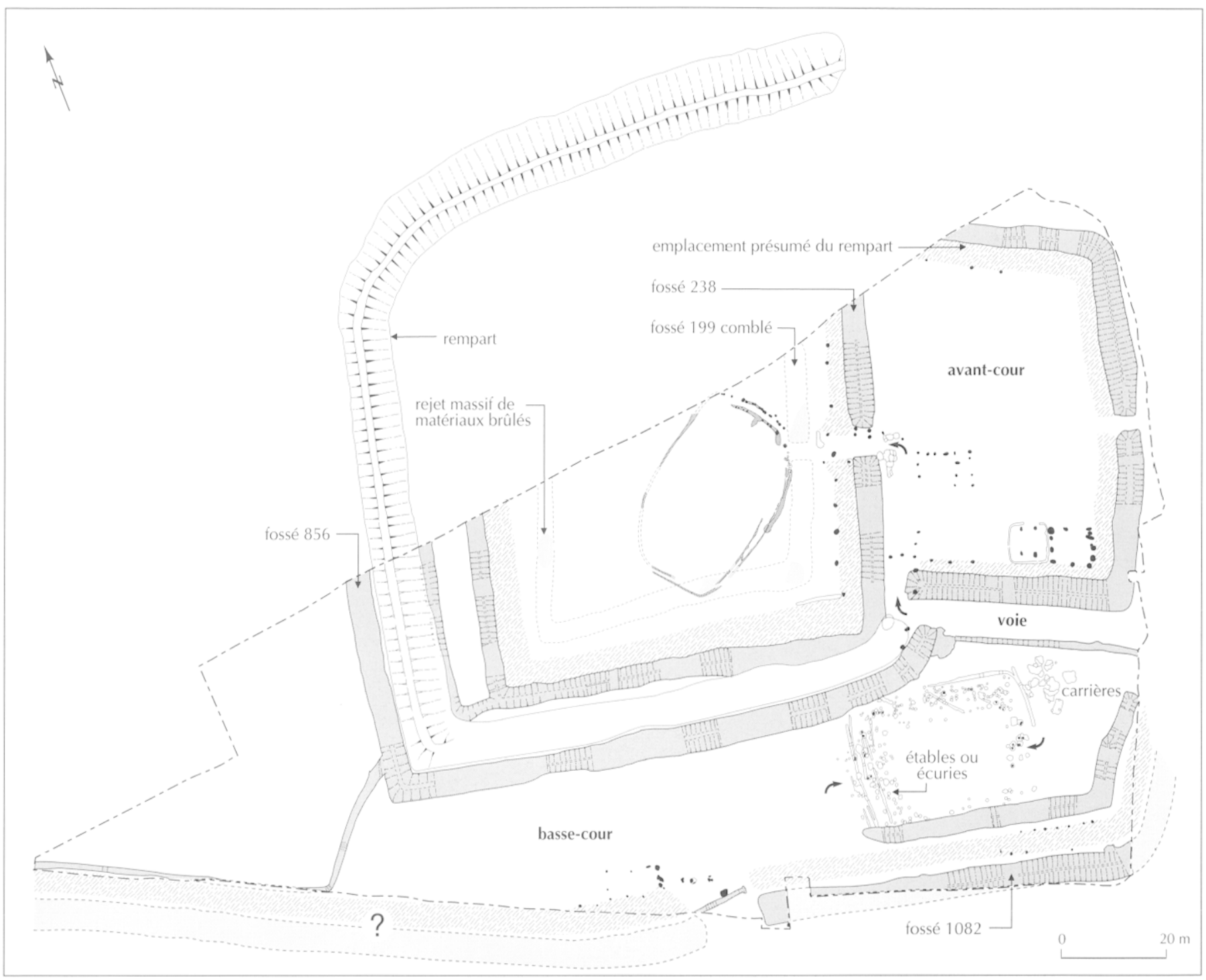

Fig. 16. Plan proposé pour la phase III : trois premiers quarts du II' s. avant J.-C. (dessin M. Dupré).

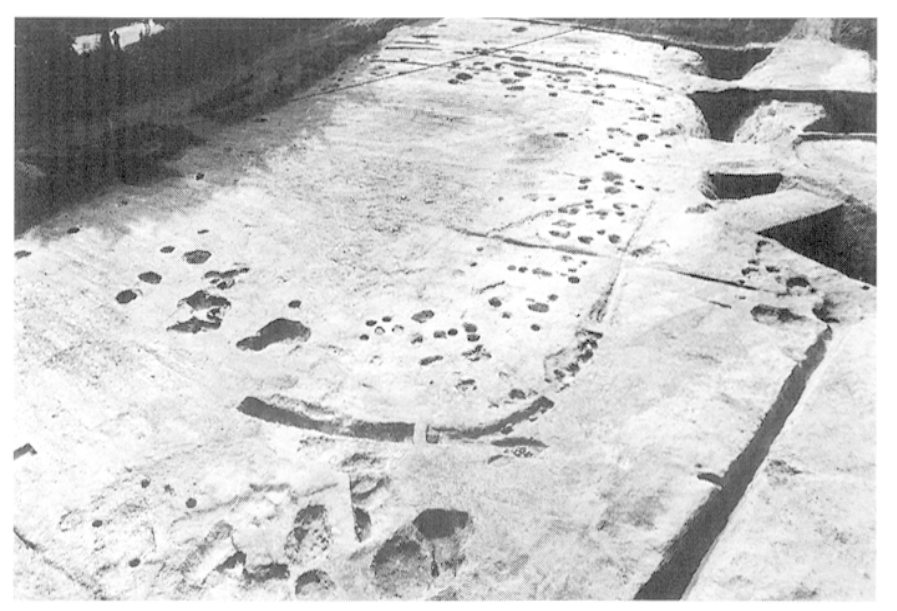

Fig. 17. Vue du vaste édifice, constitué de trois ailes de bâliments régulierement disposés autour d'une cour; bâti au cours de la phase III. La pretite tranche correspond à une fondation de palissade. Le fossé en bas, à droite du cliché, correspond au caniveau de la voie qui permettait d'accéder à l'aurant-cour. 


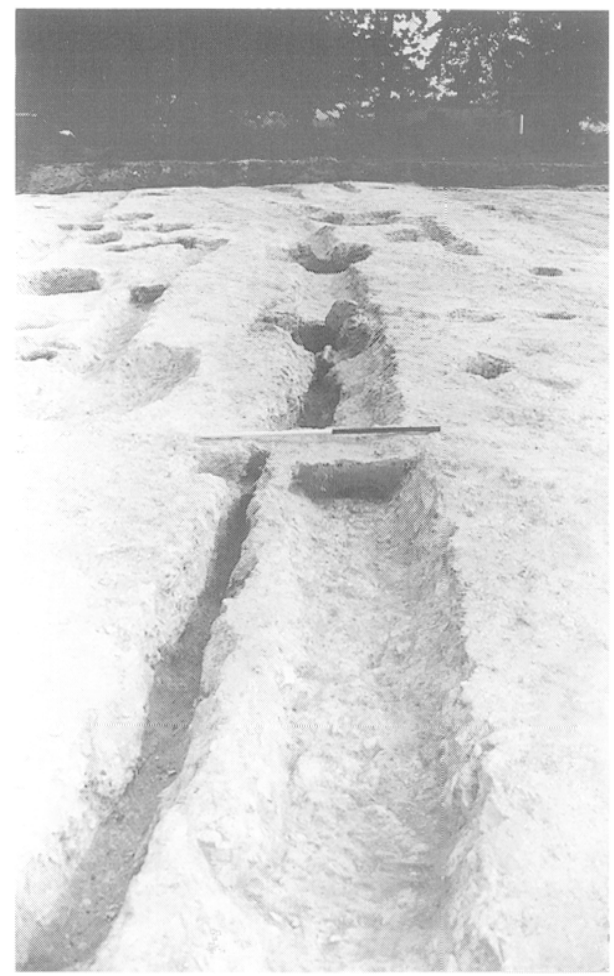

Fig. 18. A gauche, une petite tranchée, fondation d'une paroi de planches. Cefle cloison s'appuyait sur un poteau dont on discerme le calage, constitué de grosses pierres disposées en périphérie de la fosse d'implantation, vers le centre du cliché; à droite, on observe un pretit canal d'éaruation du purin qui débouchail dans une vasse fosse que l'on discerne immédiatement au-dessus du trou de poteau précédemment cité, et qui lui est postérieur:

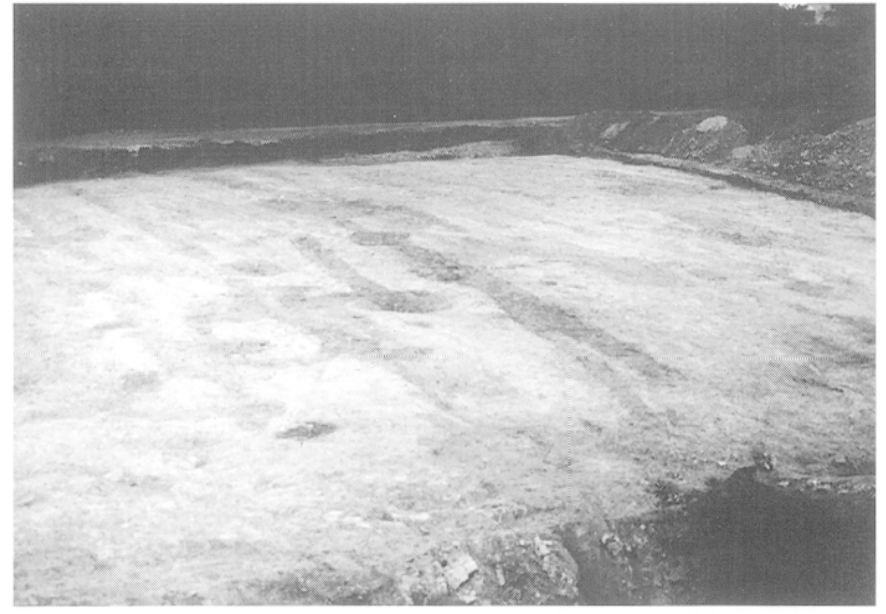

Fig. 19. Vue de l'emplacement de l'aile ouest de l'édifice, immédiatement après le décapage. I.e comblement de certaines structures, notamment des petits canaux qui débouchaient dans. de vastes fosses, apparait comme bien plus sombre que les remblais habituellement rencontrés sur le site.
$1,30 \mathrm{~m}$ pour une profondeur de $80 \mathrm{~cm}$ environ, soit $1,20 \mathrm{~m}$ à $1,50 \mathrm{~m}$ sous le niveau de l'Âge du Fer. I.e comblement de ces structures était constitué d'un sédiment brun très foncé et d'une texture très line (fig. 19). Une analyse micromorphologique, pratiquée par A. Gebhardt (1992), a mis en évidence la présence de « jus organiques lités ", ainsi qu'une sćdimentation de type «flaque " et la présence de nettoyages dans un de ces petits fossés. La mesure des taux de phosphates, pratiquée par D. Marguerie (1992), a quant à clle pu mettre en évidence, dans cette aile et particulièrement dans ces sédiments brun foncé, des concentrations très nettement supérieures à celles constatées dans les fondations des autres ailes.

La convergence entre les résultats des analyses et les particularités des vestiges permet donc d'interpréter ces petits fossés comme des canaux destinés à évacuer du purin dans de vastes fosses, où il devait ĉtre prélevé régulièrement. On s'oriente donc, nécessairement, vers la restitution d'un bâtiment, long de $14 \mathrm{~m}$ environ, destiné à abriter des animaux. La présence de parois de planches fortement fondées (25 à $30 \mathrm{~cm}$ dans le schiste, soit environ $70 \mathrm{~cm}$ à $1 \mathrm{~m}$ sous le sol de l'époque) suggère l'existence de cloisons puissantes, aptes à supporter des râteliers et la traction des attaches, ou encore le choc des sabots.

À proximité immédiate de cet édifice ont été découvertes, rejetées dans la partie d'un fossé localisé à quelques mètres au nord, de nombreuses dalles de schiste bleu, matériau qui n'a pu être prélevé qu'à quelques kilomètres du camp. Ia concentration très nette de ces blocs dans cette partie du site laisse penser que cette aile était pourvue d'un sol dallé, probablement recouvert de litière si l'on en juge par la rareté des traces d'usure visibles sur ses plaques d'ardoises, épaisses de $5 \mathrm{~cm}$ environ. L'absence d'effondrement de parois dans les canaux d'écoulement du purin peut également s'expliquer par une telle couverture de dalles, entre lesquelles devaient s'écouler les matières liquides. Tout ceci incite à proposer, pour cette ailc ouest, la restitution d'une vaste étable ou d'une écuric.

Le fossé de la ferme ancienne, qui limitait jusqu'ici l'habitat au sud, a été curé à cette époque afin de permettre l'évacuation des caux de la cour disposée entre ces trois ailes de bâtiments. Ia construction d'une ligne de défense, constituée d'un profond fossé doublé d'un rempart à poutres verticales, a permis de protéger le nou- 


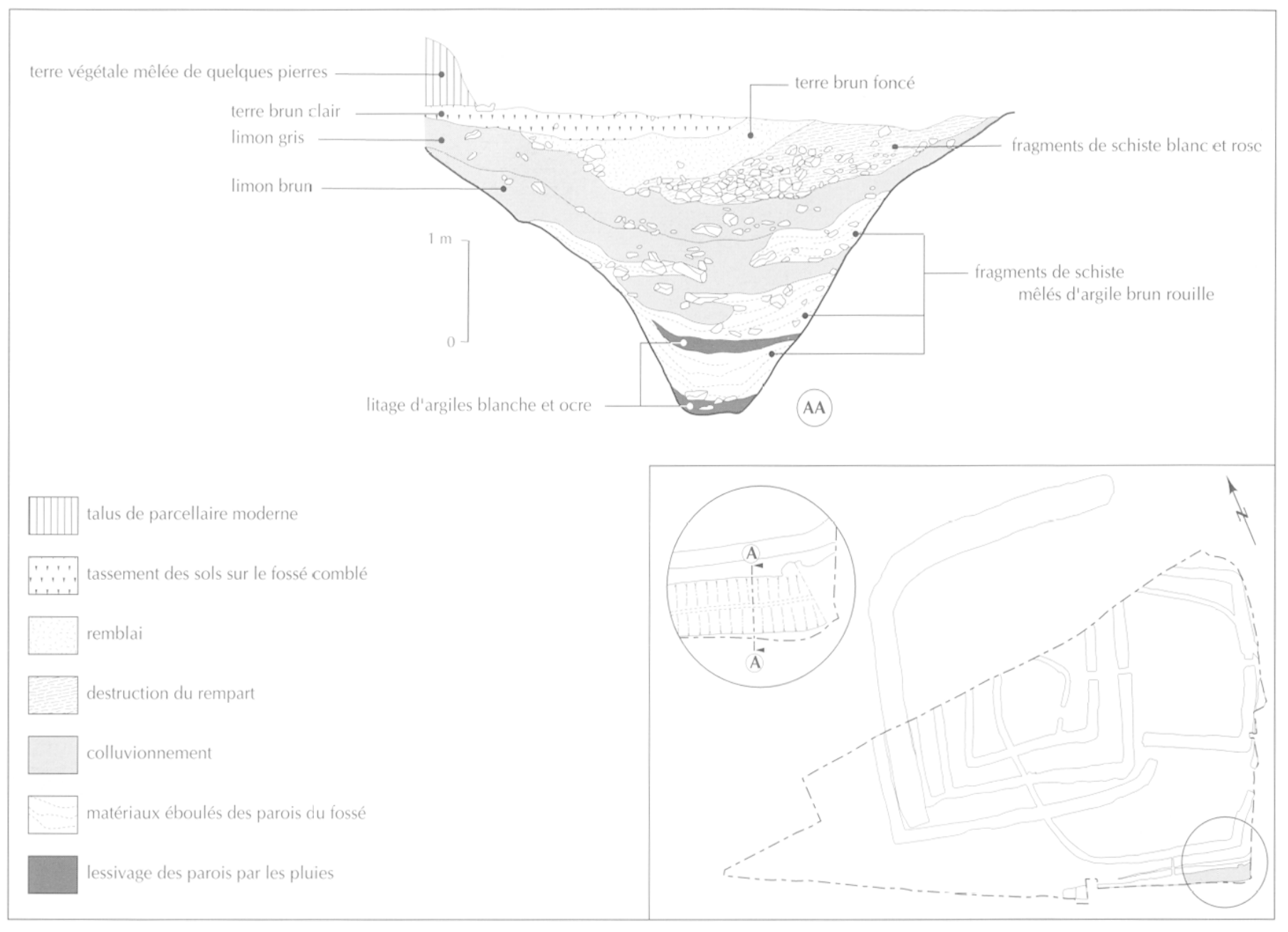

Fig. 20. Stratigrnphies de la dourer qui defendail la basse-cour, trillée dans le schiste au cours de la phase III (dessin M. Dupré).

vel édifice. Le profil des douves diffère légèrement de celles creusées durant la phase II. Il n'est plus strictement en " V " mais présente un fond plat large de $40 \mathrm{~cm}$ environ. Ia profondeur de cette excavation, taillée dans le

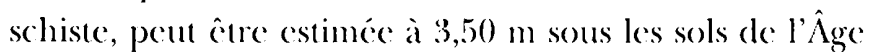
du Fer; sa largeur ćtait d'environ $6 \mathrm{~m}$ (fig. 20). L'emplacement du rempart etait marqué, sur sa face arrière, par un alignement de trous de potcaux régulicrement espacés de $2 \mathrm{~m}$ (fig. 21). On peut ĉtre certain qu'il s'agit là des fondations très arasées d'un rempart à poutres verticales selon la terminologie utilisée par (). Buchsenschut\% (Audowz, Buchsenschut\%, 1989, p. 116-117).

Quclques années ou décennies après la construction de cette basse-cour, un vaste incendie semble avoir détruit plusicurs des bâtiments situés au coeur du site.
Dans le cadre d'une restructuration générale de cet espace, l'ultime douve qui défendait jusqu'ici la partie centrale de l'habitat (fossé 199) a été combléce, pour partic à l'aide des décombres, pour partic à l'aide des matériaux provenant de la démolition des remparts adjacents (fig. 22).

I a construction d'une nouvelle ligne de fortifications, constituée du fossé 856 et d'un rempart associé, a néanmoins permis de conserver une structure de double enceinte aux défenses de la partic interne du site, d'une superficie alors portée à environ $3500 \mathrm{~m}^{2}$. Continuant une évolution constatée des la création de la basse-cour, le creusement de la nouvelle douve adopte un profil plus stable, avec des parois inclinées à $45^{\circ}$ et un fond plat, large de $60 \mathrm{~cm}$ environ (fig. 23). Elle est parallèle au fossé 238, hormis à son extrémité est. Fn effet, la présence du 


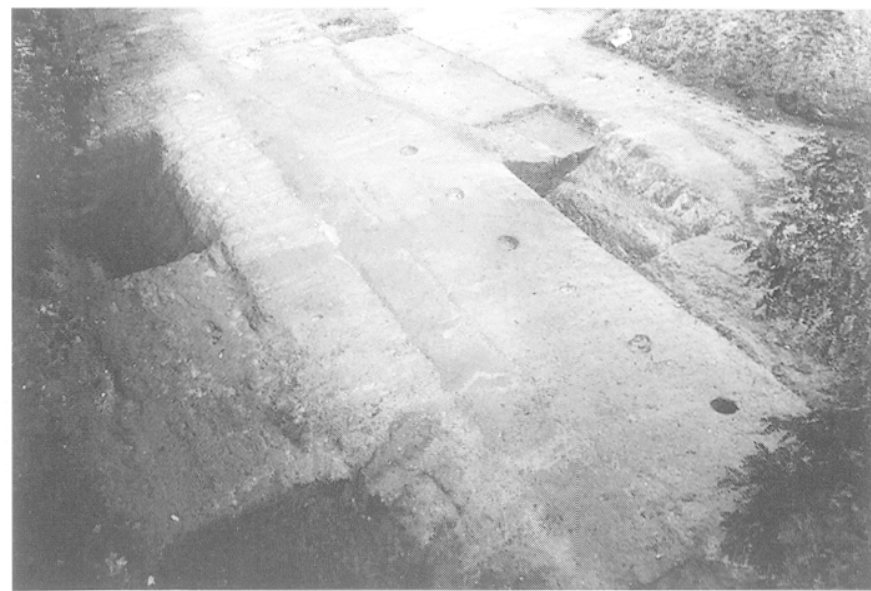

Fig. 21. Vue d'un alignement de trous de poteanx, ullime vestige du rempant à ponulres verticales qui, précédé du fossé visible à l'angle infërieur gauche du cliché, défendait la basse-soun: Les traces d'une deuxieme ligne de pieux, en bordure de la doure, ont pu, malgré l'erosion plus forte de ce secteur; être ponctuellement retrouvées.

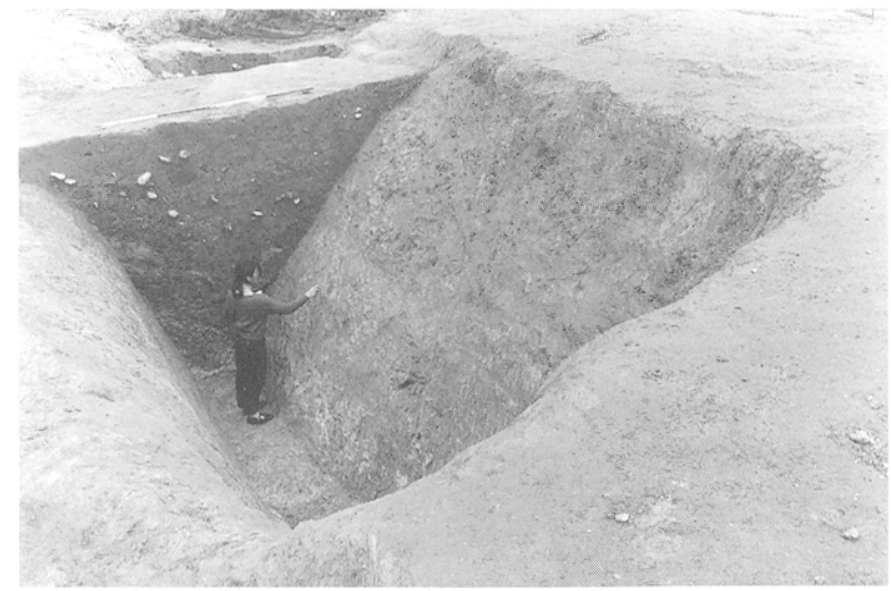

Fig. 23. Lxtrémilé est du fossé 856, douve creusée lors de la phase III pour assurer la défense du creur du site, au débouché de la voie d'acrès a l'arant-coun:

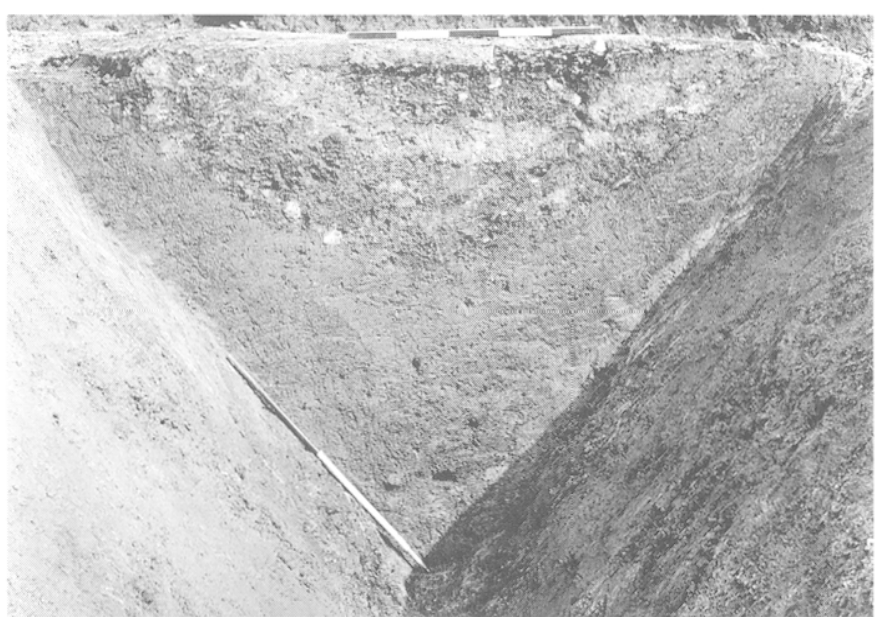

Fig. 22. Coupe dans le fossé 199, comblé au début de la phase III. Au-dessus des colluvions tapissant le fond de la douve, on note un remblai de matériaux brûlés : des fragments rougis de parois ou de plafonds constitués de bottes de pailles noyées dans de l'argile. Le volume des matériaux rejetés et la présence d'au moins quatre phénomènes de ce type avec des matériaux parfois différents (clajonnages brûlés, enduits ou non d'un badigeon blanc) montrent qu'il s'agit bien iri de déblais consécutifs à un incendie (photo) H. Paitier).

vaste édifice de la basse-cour a justifié une déviation de son tracé à cet endroit, afin d'éviter la destruction d'une partie de ces bâtiments. I.e fossé 856 se rapproche donc de l'ancienne douve, le rempart édifié en arrière venant

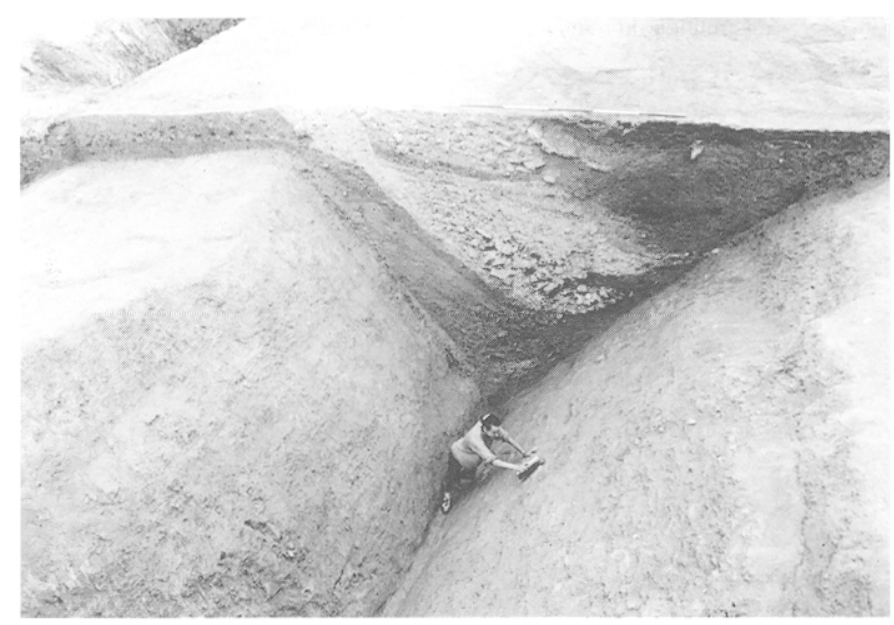

Fig. 24. Vue du fossé 238, à l'emplacement où le nouveau rempart, édifié lors de la phase III et iri constitué de blocs de schiste blanc, est venu partiellement le combler. Le fossé 856, qui venait doubler celle nouvelle ligne de défense, est discernable à l'angle supérieur gauche du cliché. La face arriere de la base de cetle levée de terre, arasée en 1968, est talutée à $45^{\circ}$. Une trace brune horizontale, visible an milieu du remblai blanchâtre, marque probablement l'emplacement d'une poutre.

partiellement la combler sur une trentaine de mètres (fig. 24).

Ce rempart n'est pas à poutres verticales, à la différence de ceux précédemment bâtis. Une puissante levée 
de terre, large de 8 à $15 \mathrm{~m}$ à la base et haute de 2,50 à $4 \mathrm{~m}$, a été édifiée à l'aide des matériaux extraits lors du creusement du fossé. Flle est venue, notamment sur la façade ouest, englober un des talus de l'habitat primitif. Une coupe pratiquéc dans ce rempart a mis en évidence la présence de deux taches d'humidité rémanente, ultimes traces des poteaux de la superstructure (fig. 25).

Ce nouveau rempart a totalement recouvert les anciennes fosses d'extraction d'argile, et de nouvelles petites carrières ont été creusées dans un délaissé situé entre la voie et la palissade délimitant, au nord-est, le vaste édifice construit dans la basse-cour. Le matériau extrait a vraisemblablement servi, entre autres, pour les activités de métallurgie du fer, du bronze et de l'or qui semblent caractériser, au moins dès cette époque, l'avantcour.

L'unique structure postérieure à cette modification des défenses et dont le plan soit discernable dans les nombreuses excavations du cœur du site est une très vaste construction. La structure de la paroi de cet édifice semble différer tout au long de son parcours. Au nordest, son emplacement est marqué par une série de trous

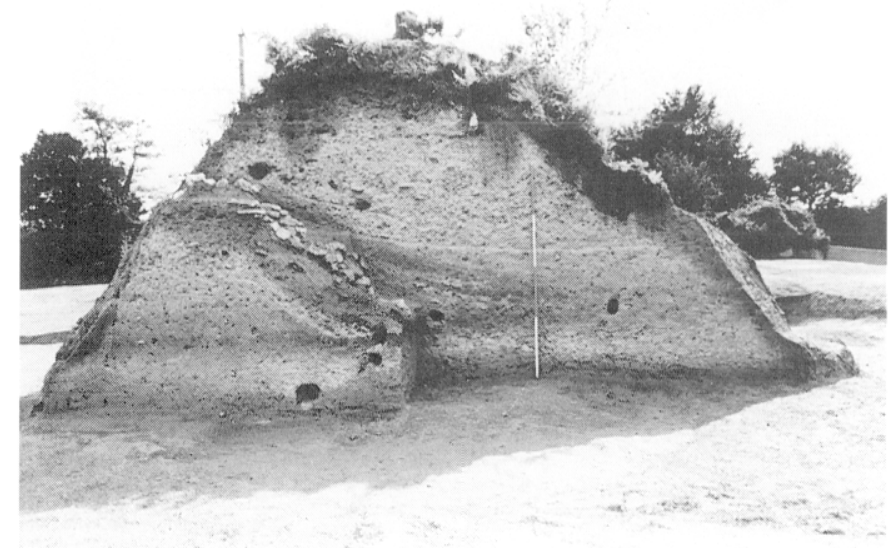

Fig. 25. Coupe du rempart doublant le fossé 856 localisé à droile du cliché. Il englobe ici un talus plus ancien, dalé de la phase I, visible dans le tiers inférieur gauche. Encore comservé sur ume hauteur de 2,50 m au-dessus des sols du II' s. avant J.-C.., situés à une cinquantaine de centimetres au-dessus de la base du jalon, il se présente sous la forme d'une acrumulation de sable et de pierraille perforée de quelques terriers de lapins. Au sommet, on distingue deux taches d'humidité rémanenté, distantes d'environ 2 met situées dans le prolongement des faces interne externe du rempart, talutees à $45^{\circ}$. Il s'agit très vraisemblablement des ultimes traces de la superstructure en bois de ce rempart. de potcaux adjacents (fig. 26). Plus au sud, une petite tranchée à fond plat, presque similaire à celle de l'édifice de la phase I, montrait encore les traces de nombreux picux accolés les uns aux autres (fig. 27). La partie de

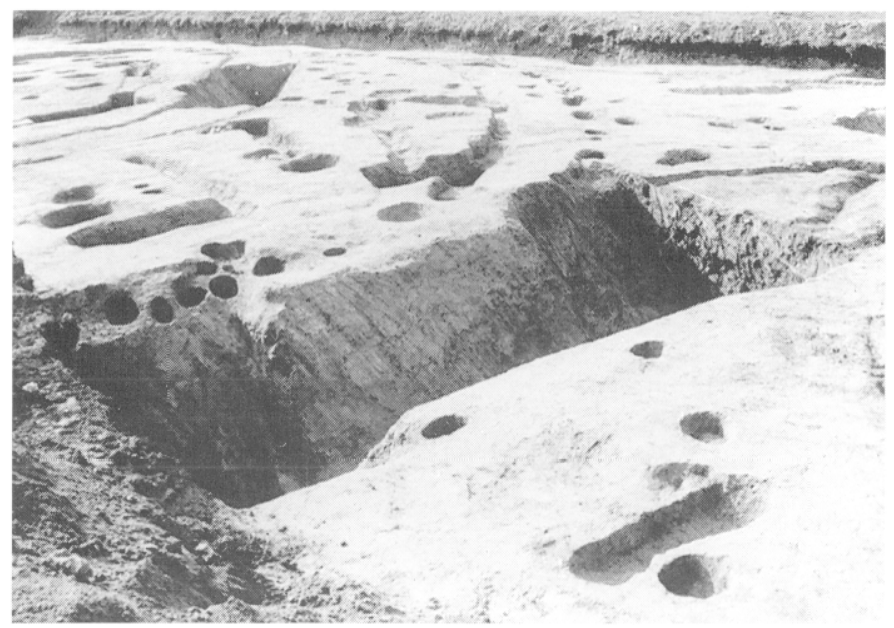

Fig. 26. Deux enfilades de trous de poteanx dessinent de vastes courbes paralliles comrespondant aux tracés des parois localisées au nord en à l'est de l'édifice bâti lors de la phase III (photo II. Paitier).

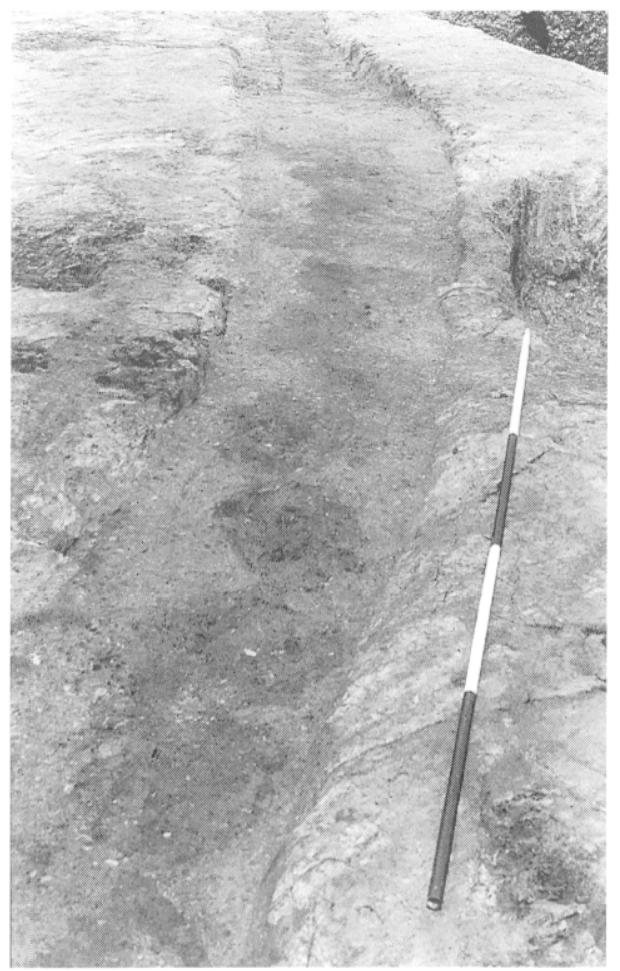

Fig. 27. Vue de détail des empreintes de poteaux apparaissant dons le remblai d'une petite tranchée, fondation de la paroi sud-est de l'édifice. 

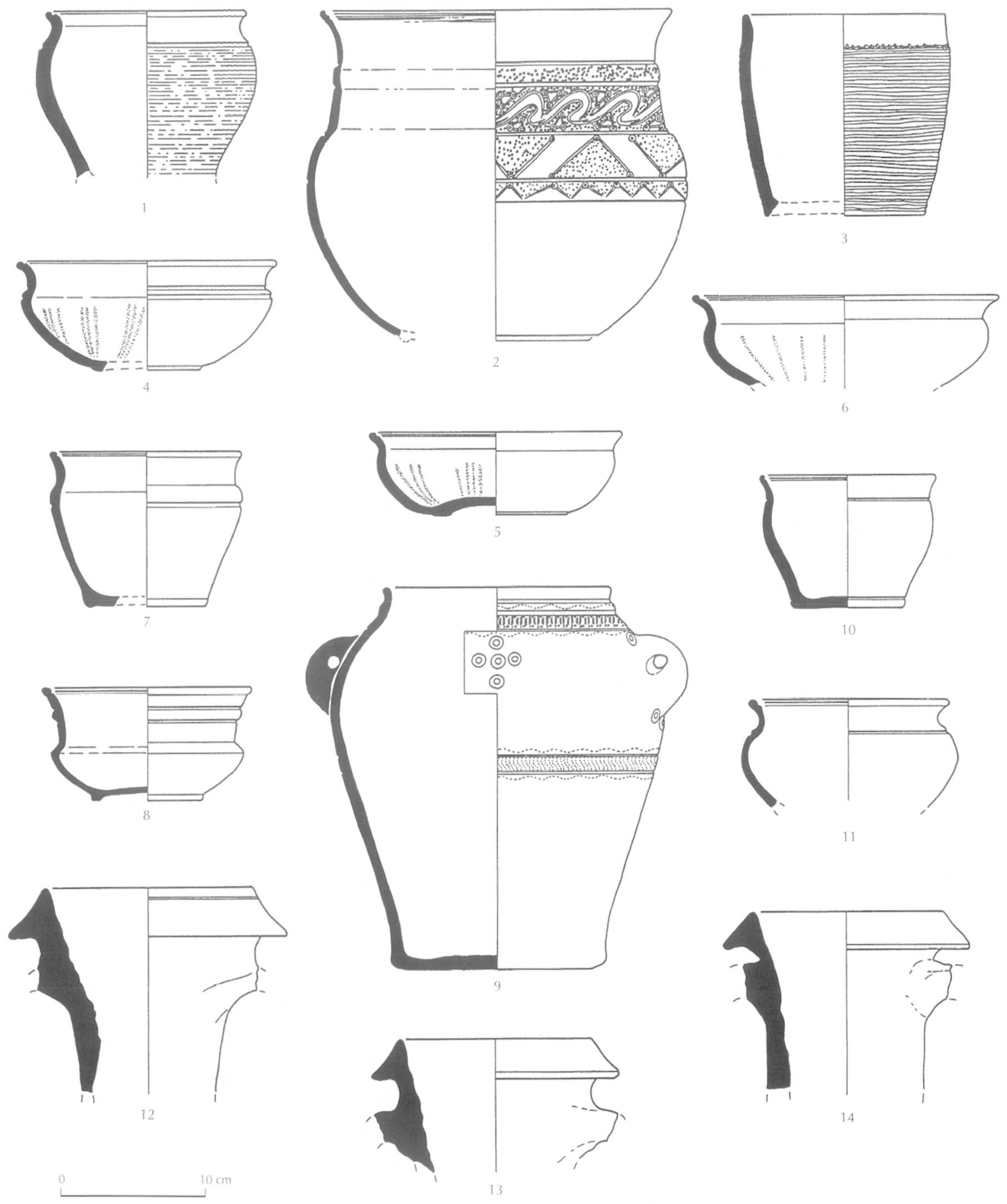

11

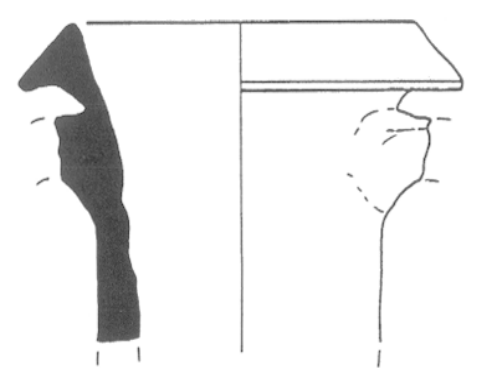

14

Fig. 28. Mobilier enfoui dans le fossé 199 lors de la restructuration des défenses du corur du sile, consécutioe à un incendie. Début de la phase III. 
l'édifice située au sud-ouest était, quant à elle, délimitéc par une petite saignée, large d'une vingtaine de centimètres et profondément ancrée dans le substrat : jusqu'à $33 \mathrm{~cm}$, soit 70 à $80 \mathrm{~cm}$ sous les sols de l'Âge du Fer. Cette tranchée, analogue à celles mises au jour à l'emplacement de l'étable ou de l'écurie, fait également penser à la fondation d'une paroi constituée de planches.

Ces différentes cloisons, situées dans l'exact prolongement l'une de l'autre, dessinent un plan régulier : un rectangle aux angles arrondis, large de $23 \mathrm{~m}$ cnviron et long de $36 \mathrm{~m}$. Il est impossible d'envisager, malgré la présence de vastes trous de poteaux au coeur de cet espace, l'hypothèse d'une unique toiture couvrant une telle superficie, supérieure à $800 \mathrm{~m}^{2}$. Les analyses architecturales futures devront plutôt tenter de restituer, à partir des nombreuses excavations relevées dans ce secteur, une série de bâtiments adossés à cette paroi et ménageant unc cour intéricure au centre de l'édifice ainsi constiucé.

Si la période de création de la basse-cour est difficile a estimer (peut-ĉtre dès la fin du III" s. avant J-(.), celle de la restructuration du coxur du site est marquée par de très abondants rejets de céramiques (fig. 28). Mêlés aux céramiques indigènes, on note, pour la premiere fois sur ce site, la présence de fragments d'amphores vinaires en

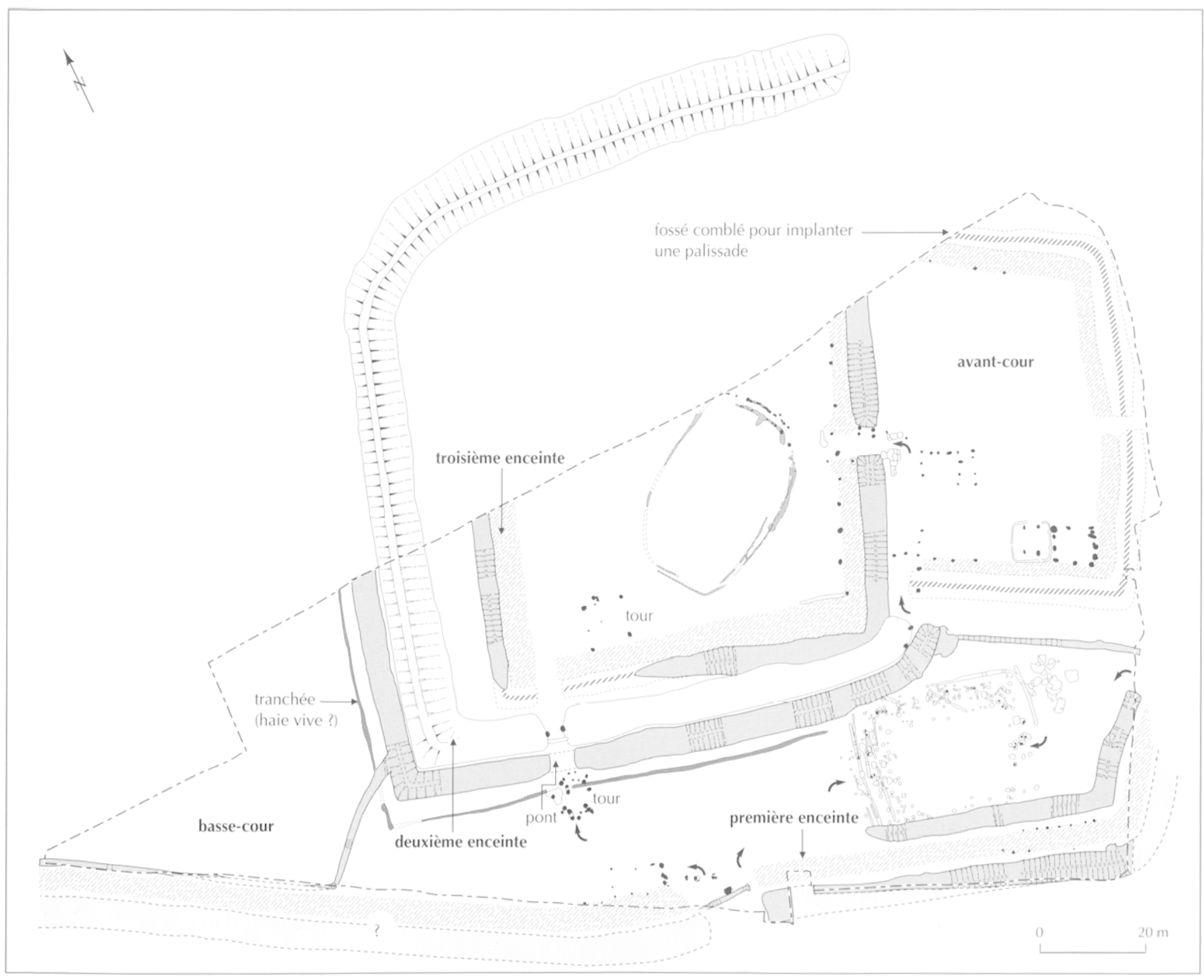

Fig. 29. Plan proposé pour la fortification dans son état terminal (phase $V$ ), arant som démantilement (dessin M. Dupré). 
faible pourcentage. I.es lèves de ces récipients ont un profil triangulaire bien marqué et décalé du col. Ies parois sont peu ćpaisses et souvent engobées de blanc. Ces caractères semblent aractéristiques des grécoitaliques antéricures aux amphores I)ressel 1. Une attribution chronologique de ces contextes au début du II" s. avant J.-C. paraît vaaisemblable.

\section{A FIN DU SITE FORTIFIÉ (PHASE IV)}

I.es modifications qui affectent ultéricurement la fortification semblent relativement modestes, et ne modifient ni sa superficie ni son organisation générale (fig. 29). Seules quelques modifications dans les défenses ont pu être identifiées. I a première consiste en un comblement du fossé de délimitation de l'arant-cour à l'aide de remblais destinés à caler une palissade à potcaux jointifs. Ce nouveau dispositif, qui précédait le rempart à poutres verticales, permettait de conserver sa valeur défensive à cette ligne de fortification, tout en évitant les risques d'accidents inhérents à la présence d'un vaste fossé à proximité de la principale voie d'accès au site.

Une deuxième modification notable consiste en la création d'une porte fortifiće à l'angle sud-ouest des défenses internes. Cet accès permettait de relier le cocur du site à la porte ménagée au milieu de la facade sud de la basse-cour. I a consuruction de cet ourrage a conduit à pratiquer une breche, sur une largeur de $3 \mathrm{~m}$ environ, dans les remparts de la deuxième et de la troisième enceintes. Maintenues par des boisages, les parois verticales de ces ouvertures ćtaient dominćes par la superstructure des remparts. I.es passages ainsi constitués étaient clos, au moins pour celui de la deuxième enceinte, par des portes pivotant sur une poutre de seuil dont la fondation a été retrouvée.

Un pont a été jeté sur le fossé de la deuxième enccinte ; celui de la troisième enceinte a été, quant à lui, comblé à l'aide d'un remblai compacté à l'emplacement du passage. Afin d'éviter l'éboulement des matériaux ainsi accumulés, une palissade a été implantée de part et d'autre de l'entrée, calée par des remblais à proximité de l'accès, simplement plantée dans les vases qui comblaient le fossé un peu plus loin. Une vaste tour, de plan carré et fondéc sur quatre poteaux distants de $4,50 \mathrm{~m}$, a ćté
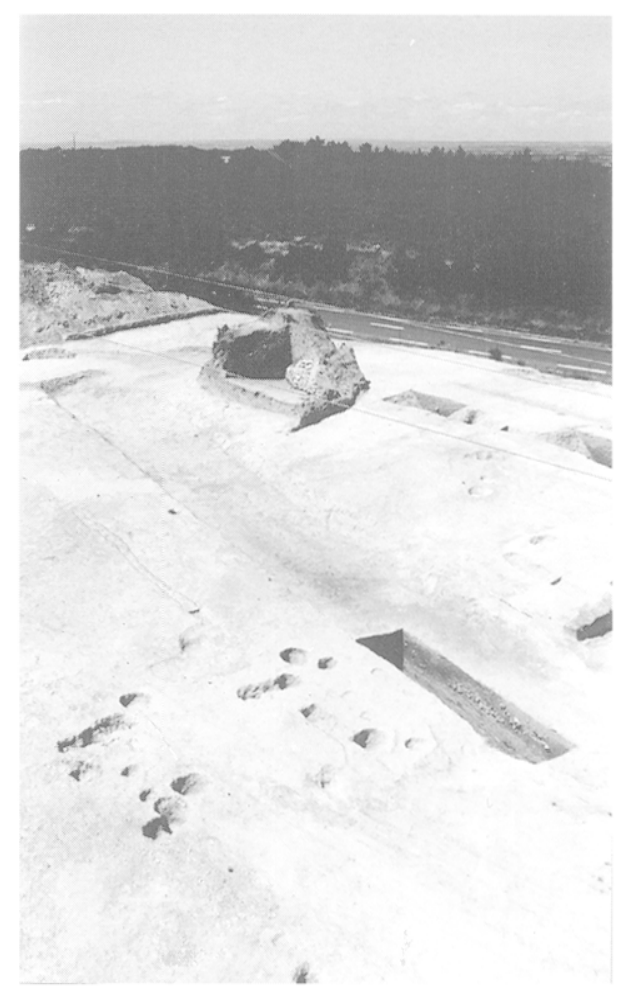

Fig. 30. Vue partielle de la porle fortifiée édifiée an cours de la phase IV. On distingue les fondations d'une lour; dessinée dans le substrat par des trous de poteanx disposés en carré el distants de 4,50 m. Cietle fortification arancée précédait un poml, dont l'emplacement est aujourd hui matérialisé par la présence d'un cône de rejets anthropiques (tessons apars, charbons de bois, petites pierres, etc.) résultant de la chute accidentelle de ces éléments à laplomb du passage au-dessus du fossé. Cé come est visible, en coupe, dans un sondage pratiqué par moitié dans. la doure aujourd hui comblée.

édifiée dans la basse-cour, en arant du pont (fig. 30). Cet ourage arancé permettait de contrôler tout accès dans le coeur du site à partir de la basse-cour. Ĺne deuxième tour, plus vaste, dominait le débouché de cet accès au coeur de la forteresse. I e percement de cette porte, accompagné de quelques comblements de douves, n’a done en rien atténué la valeur défensive de la place forte.

Ia datation de ces modifications dans les lignes de défense est fondée sur les milliers de tessons de céramiques indigènes qui ont été enfouis au cours de ces remaniements. Mêlés à de très nombreuses amphores de type Dressel $1 \mathrm{~A}$, ils peuvent être datés de la fin du II's. avant J.-C. (fig. 31 et 32). I e rejet de trois statuettes parmi les remblais de calage d'une palissade ou lors du comblement d'une salle de souterrain peut être également 


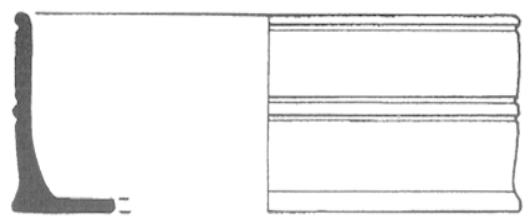

350.1

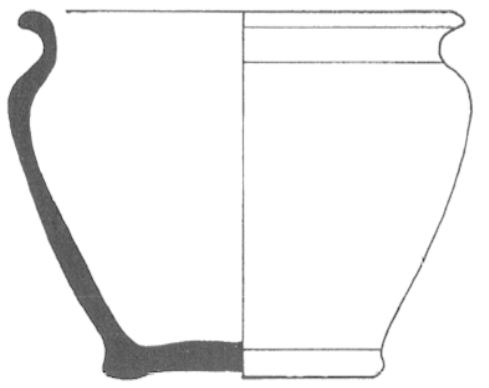

765.1

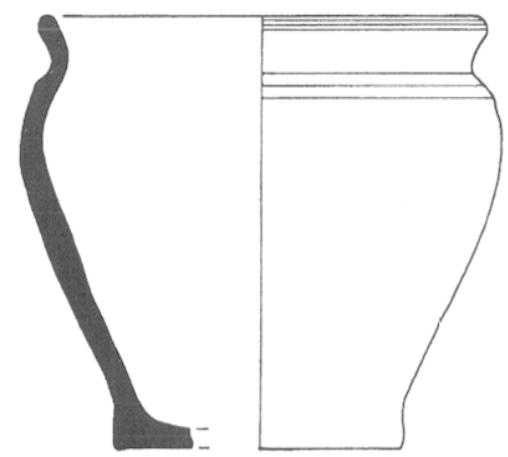

887.1

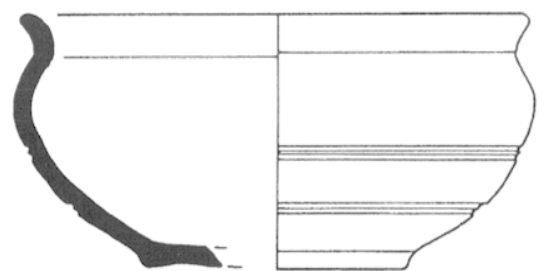

887.7

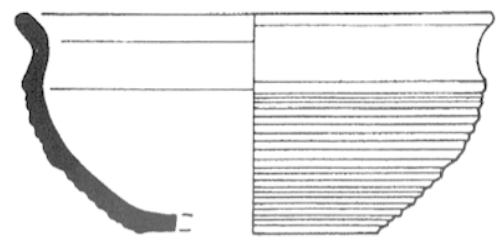

887.9
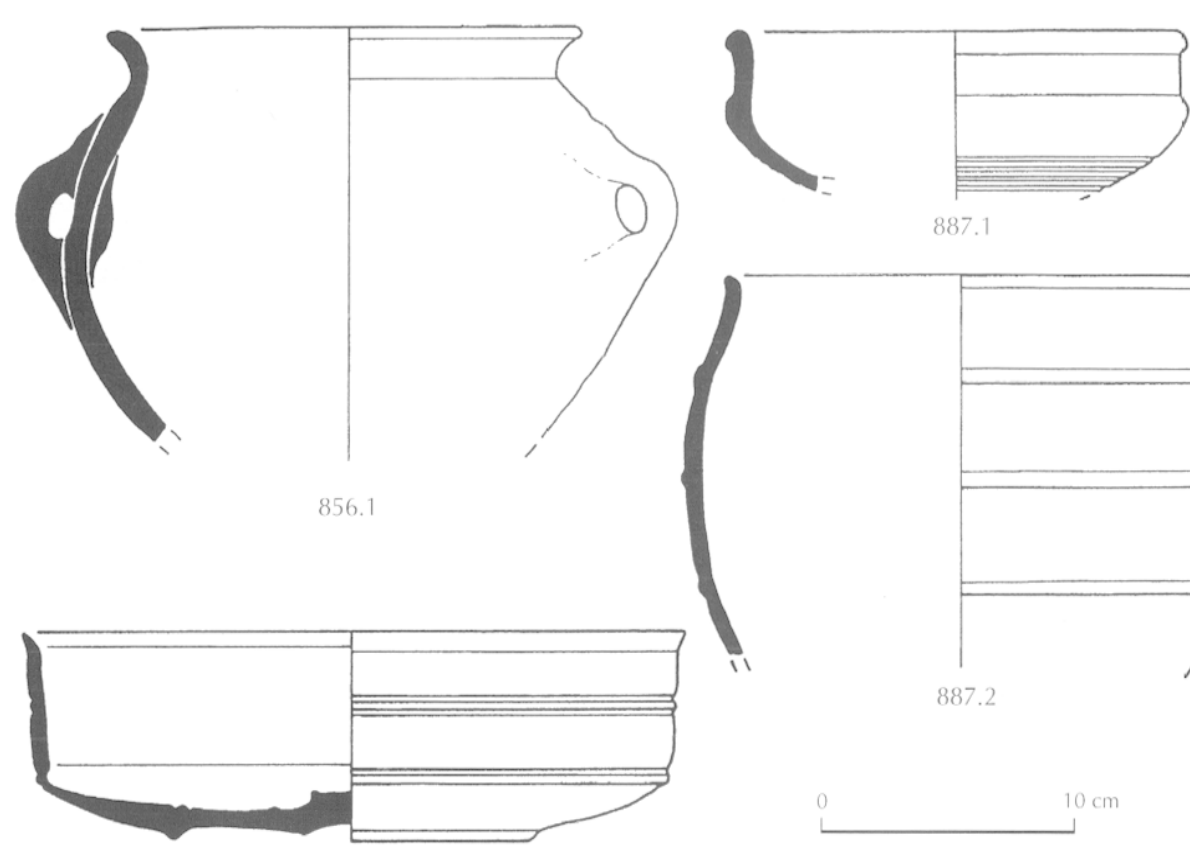

887.1

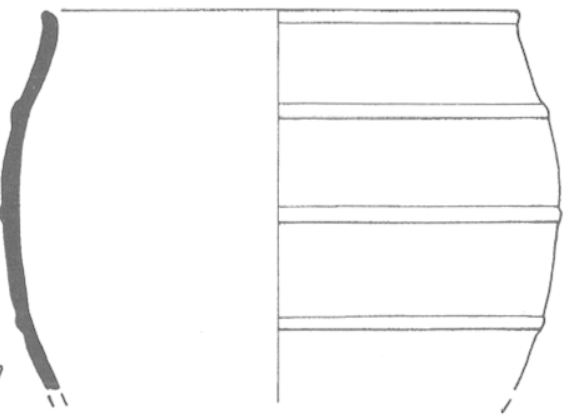

887.2

887.3

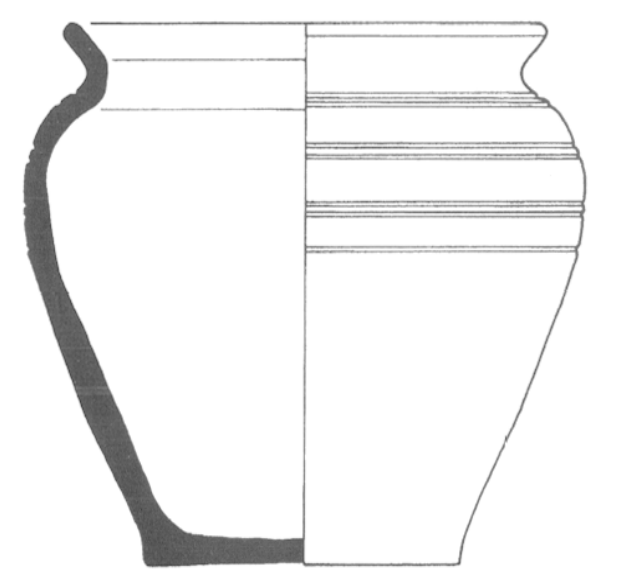

887.5
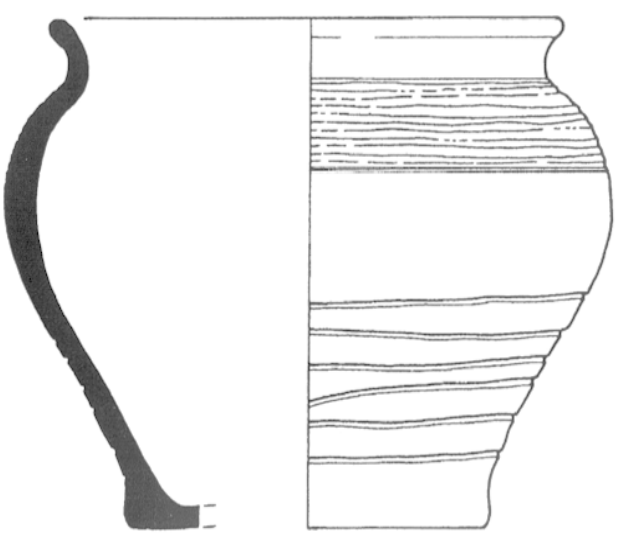

887.10
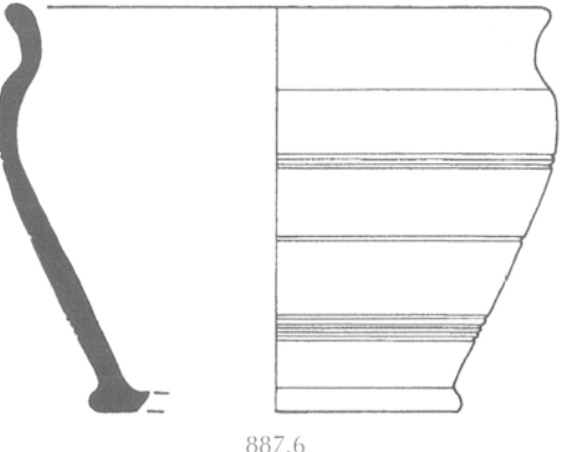

887.6

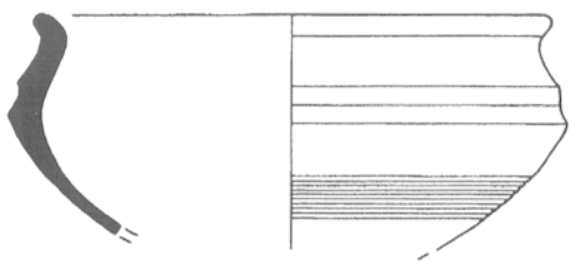

887.8

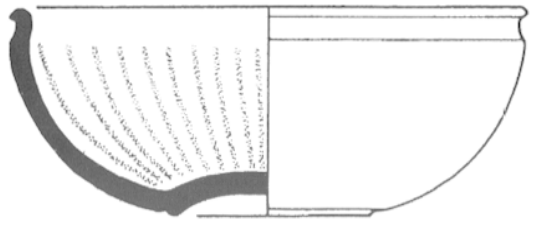

887.11

Fig. 31. Mobilier enfoui au cours de la phase $I$. 


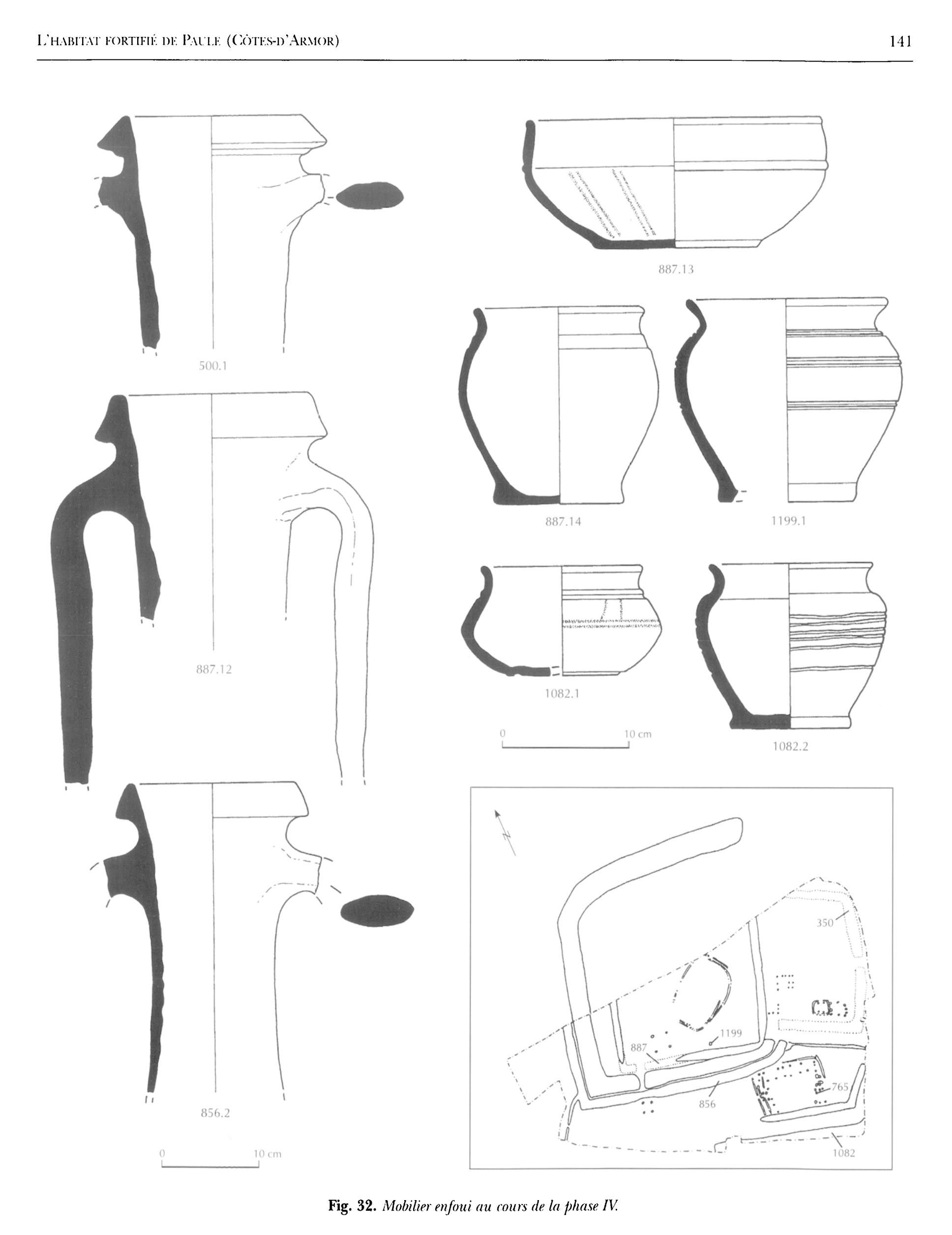



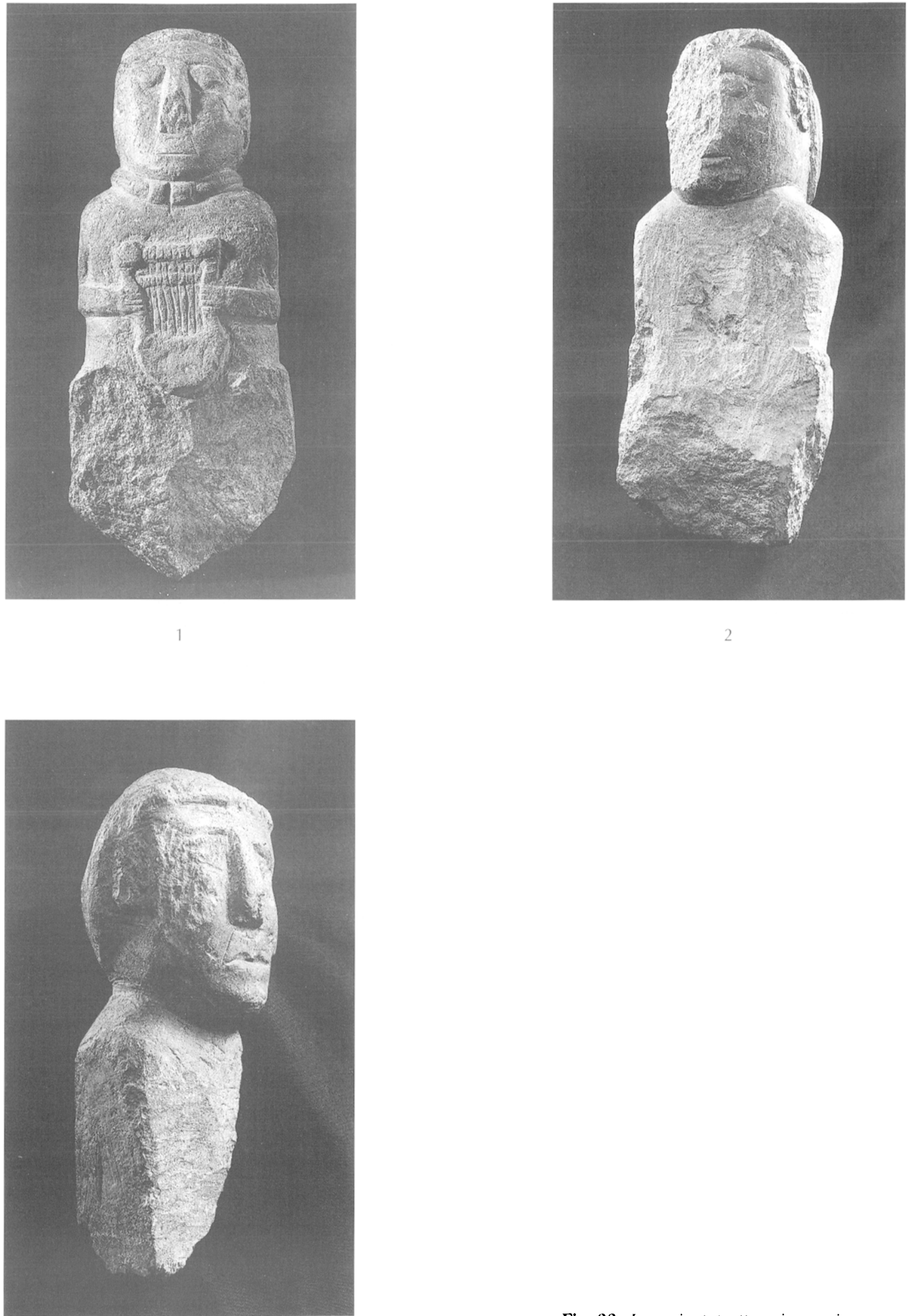

Fig. 33. I.es trois statuetles mise's ant jour sur le sile (photo /l. Paitier). 
attribué à cette période. Ces sculptures, taillées dans une roche dure, figurent des bustes de personnages émergeant de socles sommairement dégrossis (fig. 33). Lcur étude détaillée fera l'objet d'un article ultérieur.

Vers le milieu du Irr s. avant J-C., la ligne de fortification localisée à l'angle sud-est du site a été démantelée. Les boisages frontaux ont été arrachés; la masse des matériaux qui constituaient le noyau du rempart a été étalée et rejetée pour partic dans le petit fossé localisé au sud-est de la basse-cour, pour partic dans la vaste douve qui défendait cette partie du site (fig. 20). Cette opération se traduisait, dans les stratigraphies réalisées dans ces deux fossés, par une accumulation de pierraille très instable. Il ne peut donc s'agir d'un effondrement progressif ou ponctucl généré par un manque d'entretien des boisages. Détecté sur une distance mininnale de $75 \mathrm{~m}$, le cordon constitué par les matériaux du rempart dans les deux fossés a en effet une épaisseur quasiconstante, indice d'un travail systématique et non d'un affaisscment.

Il scmble que la fortification ait été désertée immédiatement après cette općration de démantèlement. En effet, aucun mobilier caractéristique de la fin de l'Âge du Fer, La Tène $\mathrm{D}_{2}$ de la chronologie établie par P. Reinecke (1902), n’á été jusqu'ici découvert sur le site. Témoignent également de cet abandon les sédiments très fins, stériles en mobilicr, qui scellent l'accumulation provoquéc par la chute de petits objets au niveau du pont (fig. 30). Il semble que ce passage se soit alors trouvé brusquement inutilisé.

\section{A PÉRIODE GALI.O-ROMAINE (PHASE V)}

Cette désertion du site durant $\mathrm{L}$ a Tène $\mathrm{D}_{22}$ est suivie d'une réoccupation limitée qui se marque essenticllement par l'arrachage des deux palissades édifiées vers la fin du II s. avant J.-C. et le creusement de deux petites tranchées à l'intérieur de l'avant-cour (fig. 34). Ces vestiges, probables fondations de clôtures, recoupent l'emplacement des anciens remparts. Ils étaient donc, à cette époque, déjà arasés. L.es petites tranchées délimitent un espace, la partic est de l'ancienne avant-cour, qui est le scul a avoir livré en relative abondance des fragments de céramiques gallo-romaines, y compris dans certains trous de poteaux.
On peut interpréter cette ultime occupation du site comme un habitat très modeste, abrité des vents d'ouest dominants par les anciens remparts et délimité par au moins deux clotures implantécs dans les petites tranchées. L'une des activités a dû être la culture ou l'élevage, le bétail pouvant être parqué dans ce qui était autrefois le cœur du site; l'autre activité consistait en la récupération des matériaux encore utilisables prélevés sur les remparts ou les édifices antérieurs à la conquête. Cette réoccupation des ruines de la place forte peut être situéc entre les ammées 10 avant et 40 après J.C.

Après le règne de Claude, le site s'est couvert d'herbes et de broussailles, puis est devenu un champ que seul distinguaient quelques talus plus imposants que de simples limites parcellaires. Au moins deux des anciens remparts effondrés ont dû rester visibles jusqu'au début du XIX's.; seules les parties oucst et nord de l'un d'entre eux ont survécu au remembrement de 1968.

\section{I.E SITE DE PAULE : POSITION ET FONCTION DANS I A HIÉRARCHIE DES HABITATS DU SECOND ÂGE DU FER}

Après avoir examiné l'évolution de ce site au cours du second Âge du Fer, il est temps de dégager les caractéristiques principales de cet habitat, puis de se poser la question de son unicité, de son caractère exceptionnel, ou, au contraire, de son aptitude à définir un type d'enceinte, la "forteresse aristocratique ", jusqu'ici non pris en compte lors de l'élaboration des schémas définissant l'organisation des territoires du second Âge du Fer.

Lors de la phase ancienne, ce site prend la forme d'un vaste enclos, délimité par un fossé doublé d'un talus et d'une superficie estiméc à $9000 \mathrm{~m}^{2}$. S'accole probablement à cette première unité un second enclos dont la superficie ne peut aujourd'hui ĉtre précisée. Si l'on compare le plan ainsi restitué à celui du seul habitat contemporain à avoir été intégralement fouillé dans la péninsule armoricaine (I.e Boisanne à Plouër-sur-Rance; fig. 35, $\mathrm{n}^{\circ} 2$ ), on a l'impression de confronter des sites de statuts différents. Certes, les techniques utilisées pour la délimitation des enclos sont identiques : un fossé d'une profondeur maximale de $2,50 \mathrm{~m}$ pour délimiter la zone habitée ; des petites tranchées, uitimes traces de la plantation de haies autour des enclos périphériques ou adjacents. Mais 


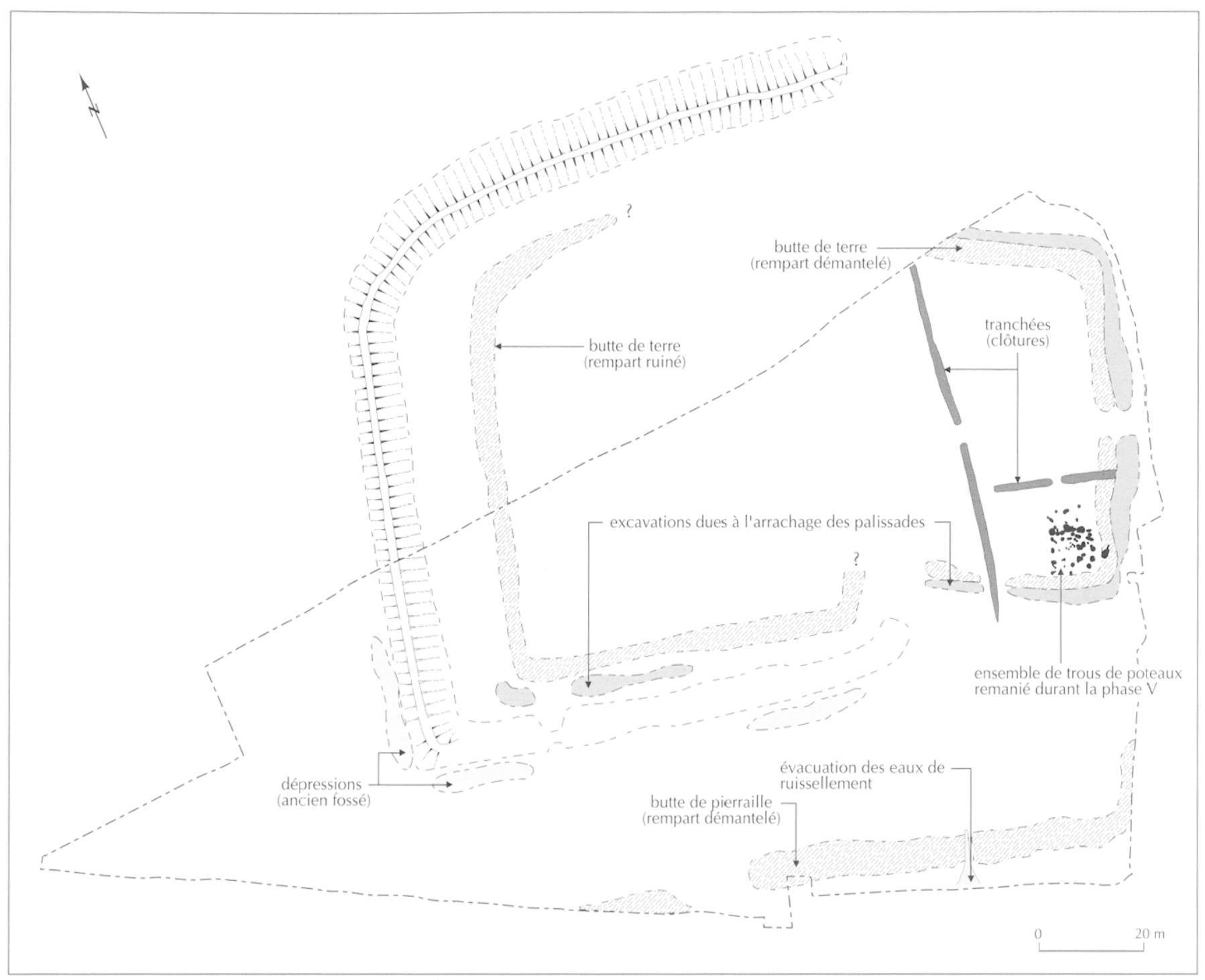

Fig. 34. Plan du site proposé pour le délnut du Irr s. après J.-C.. (dessin M. Dupré).

les superficies sont totalement différentes : $240 \mathrm{~m}^{2}$ pour l'enclos principal de Plouër-sur-Rance; $910 \mathrm{~m}^{2}$ si l'on considère l'ensemble de la surface clôturée.

L'unique bâtiment retrouvé à Plouër-sur-Rance, dont l'emplacement était marqué par six trous de poteaux, avait une emprise de $38 \mathrm{~m}^{2}$ environ, bien moindre que celle de la construction de Paule délimitée par une paroi de poteaux jointifs $\left(375 \mathrm{~m}^{2}\right)$. Ces rapports de 1 à 10 , constatés tant pour les superficies des enclos que pour celles des bâtiments, sont nécessairement significatifs d'un besoin d'espace, et donc d'un investissement en temps et en matériaux différents pour la construction de ces deux établissements.
L'élevage et l'agriculture ont dû constituer les activités majeures de ces exploitations entre lesquelles on peut néanmoins observer deux différences majeures. En effet, si l'enclos de Paule a livré les vestiges de plusicurs ateliers de tisserands, seules quelques fusaioles et les fragments de trois pesons ont été mis au jour à Plouër-sur-Rance. Dans un cas, il semble que l'on ait les traces d'une simple activité domestique, dans l'autre, celles d'un tissage abondamment pratiqué. Une seconde différence réside dans les nombreuses structures excavées (silos, probable cave ou souterrains) qui ont été creusées au cours de cette phase à proximité de la façade ouest de l'enclos de Paule. Qu'ils aient été utilisés de manière permanente ou provi- 
soire, ces lieux enfouis, probables entrepôts, témoignent d'une volonté de se doter de capacités de stockage considérables, supérieures à $100 \mathrm{~m}^{3}$. Sur le site de Plouër-surRance, rien de tel n'a pu être observé.

Sur la base de ces différences, il parât légitime de se demander si ce dernier habitat ne peut pas être considéré comme un simple établissement de défrichement (Menez, 1996), et si l'enclos de Paule, à la même période, n'a pas été conçu pour abriter un tout autre type d'établissement. R. Christlein (Christlein, Braasch, 1982) et D. Mordant (1992) ont proposé de voir, respectivement dans les sites de Bavière (fig. 35, $\mathrm{n}^{\text {(w }} 5$-7) ou l'habitat de Grisy-sur-Seine (fig. 35, $\mathrm{n}^{\circ} 4$ ), des résidences seigneuriales (Herrensitz). Une interprétation semblable pour le site de Paule paraît séduisante. Par son ampleur, sa position topographique dominante et l'ancienneté de sa fondation, cet habitat pourrait, en effet, se voir attribuer, outre la fonction d'exploitation agricole, celle de lieu de résidence d'un petit seigneur de l'Âge du Fer et de sa maisonnée. Relativisons toutefois l'importance du site de Paule au cours de cette période : son unicité en Armorique tient plus à l'avancée des recherches qu'à un réel caractère exceptionnel. S'ils restent peu fréquents en France, où la majeure partie des vastes enclos de ce type cst attribuée à La Tène moyenne ou finale, plusicurs sites analogues ont en effet été fouillés en Grande-Bretagne (fig. 35, n" ${ }^{\prime \prime} 8$-11) et également datés de la fin du premier ou du début du second Âge du Fer.

Vers la fin du IV" ou le début du III" s. avant J.-C., la structure de cet habitat est brusquement modifiée. Il devient subitement une fortification qui, d'une superficie voisine de celle de l'enclos antérieur dans un premier temps, ne cessera de s'étendre et de se modifier avant d'être démantelée dans le courant du Irr $s$. avant J.C. Cette modification dans l'aspect du site implique-t-elle nécessairement une modification profonde dans sa fonction ou son statut? Avant de répondre à cette question, tentons tout d'abord de déterminer les principales caractéristiques qui différencient cet établissement de l'exploitation antérieure ainsi que des fermes ou hameaux contemporains. Il semble qu'elles puissent se résumer aux points suivants :

- Le nouvel habitat est un site fortifié, d'une superficie comprise entre 1,5 ha (phase II) et plus de 3 ha (phases III et IV), puissamment défendu, dès l'origine, par de multiples lignes de défense. Les techniques utilisées pour l'édification des remparts et des portes, la pro- fondeur des douves et la présence de tours montrent qu'il ne s'agit pas ici d'improvisation. L'habitat antéricur n'a pas été progressivement fortifié, à l'aide de quelques matériaux et de travailleurs détournés des tâches agricoles. Il a certainement été fait appel à un corps de spécialistes qui, après avoir défini le plan de la place forte à construire, a arasé les constructions antérieures chaque fois qu'elles se révélaient gênantes pour la réalisation du projet. Le site de Paule ne peut donc être décrit comme une "ferme fortifiée" (Duval, 1991). Il semble plus juste de parler, soit d'une ferme (état 1), soit d'une forteresse (état 2).

- Comme presque toutes les fortifications protohistoriques, celle de Paule s'est implantée sur un site topographique favorable à la défense et la surveillance du territoire, en l'occurrence sur la ligne de crête occupèe par l'ancien établissement. Signalons toutefois que le relief n'est pas ici très contraignant. S'il peut concourir à la défense, il ne peut à lui seul constituer un véritable obstacle. Le plan choisi pour cette place forte a su tenir compte de la topographie, mais n'a jamais été dicté par celle-ci, comme le serait celui d'un éperon barré ou d'une enceinte de contour par exemple.

- À toutes les périodes, ce plan semble très élaboré et résulter d'une connaissance approfondie de la poliorcétique. Sa principale caractéristique est d'être constitué d'unités bien délimitées, hiérarchiquement disposées selon leur position topographique : au sommet, le « cœur du site ", suivi de l'avant-cour, légèrement plus bas sur la ligne de crête (environ 1 à $2 \mathrm{~m}$ ), puis de la basse-cour, qui se développe 3 à $5 \mathrm{~m}$ en contrebas sur les flancs de la crête. L'ensemble ainsi constitué respecte parfaitement les règles d'une défense progressive, permettant aux défenseurs de se réfugier vers le cœur du site au fur et à mesure de la prise des remparts extérieurs par les assaillants. Dans cette optique, plusieurs principes ont été respectés. Celui du commandement (Deyber, 1984) semble avoir guidé l'édification des lignes de défense parallèles. En effet, les lignes internes sont, de par la topographie, plus élevées que celles situées plus à l'extérieur. De plus, la distance entre les différents remparts est pratiquement constante et n'excède pour le moment jamais $50 \mathrm{~m}$, soit la portée utile attribuée aux armes de jet de l'époque

L'édification de tours portières (phase IV) et la présence d'accès étroits et fortifiés sous la superstructure des remparts témoignent d'un respect des règles élémen- 


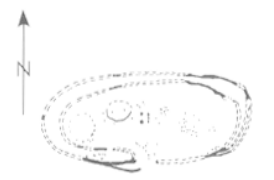

1. Staple Howe (Yorkshire) Grande-Bretagne

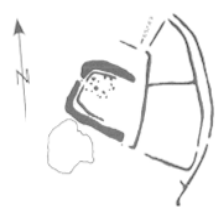

2. Plouër-sur-Rance phase ancienne

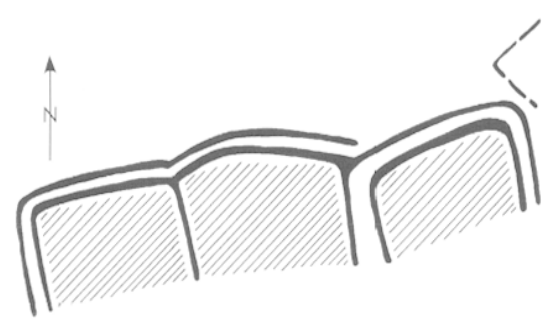

5. Landshut Hascherkeller (Bavière)

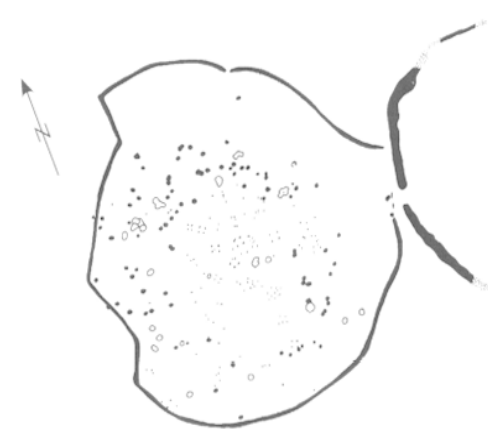

8. Gussage All Saints

(Dorset)

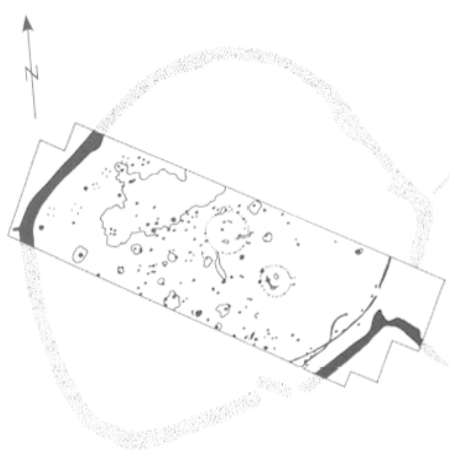

10. Little Woodbury

(Wiltshire)
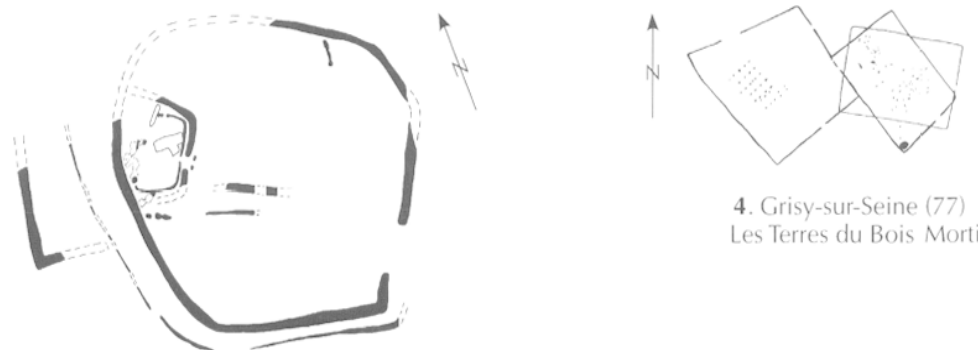

4. Grisy-sur-Seine (77)

Les Terres du Bois Mortier

3. Paule (22)

Camp de Saint-Symphorien

phase ancienne

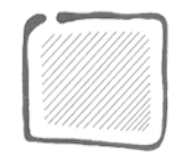

6. Langenisarhofen

(Bavière)

ALLEMAGNE

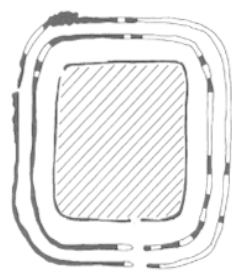

7. Aiterhofen

(Bavière)
GRANDE-BRETAGNE

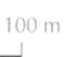

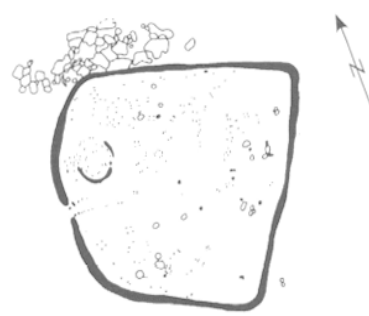

9. Winnall Down (Hampshire) phase ancienne

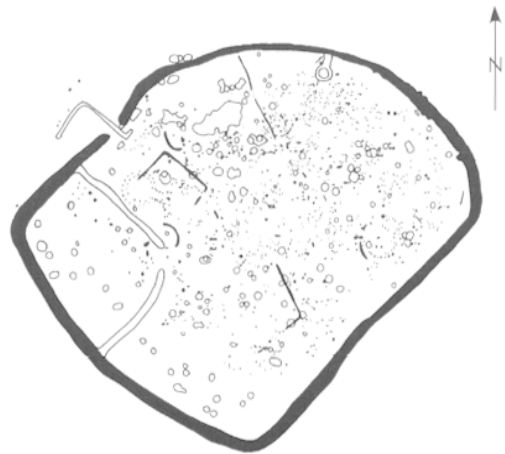

11. Old Down Farm (Hampshire)

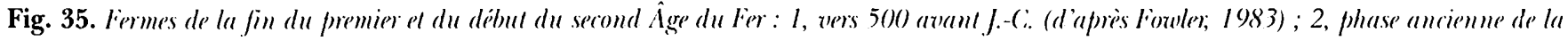

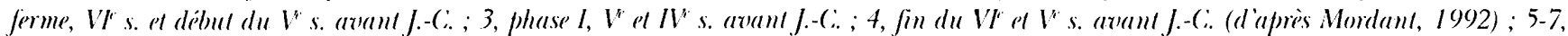

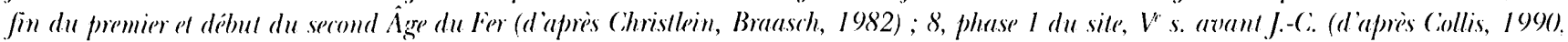

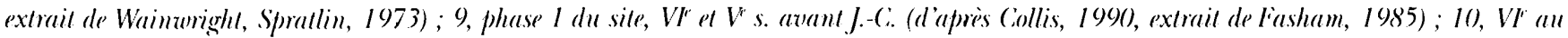

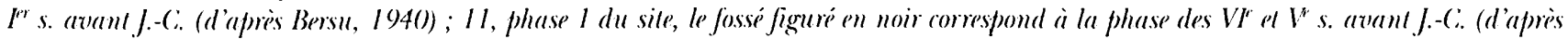
Collis, 1990, extrail de lavies, 1981). 
taires du flanquement vertical (ibidem). Enfin, la présence d'une entrée en chicane et d'un véritable chemin de défilement pour l'accès à l'avant-cour, puis au cour du site, permettait, en facilitant une frappe de flanc, de ralentir l'assaillant. Plusieurs portes, dont les fondations de la poutre de seuil ou des piédroits ont parfois été retrouvées, assuraient le contrôle des différents passages, aussi bien vers l'extérieur qu'entre les différentes parties du site. I e doublement du rempart délimitant le cocur du site montre bien que l'on souhaitait, par ce plan élaboré, rendre toute tentative de prise de la forteresse longue et extrêmement difficile, la conquête du rempart extéricur entrainant simplement le repli des défenseurs sur un noyau puissamment fortifié el de superficie plus modestc, et donc bien plus facile à tenir.

- I'intéricur de cette fortification recèle, non les vestiges d'une bourgade, mais plutôt ceux de quelques constructions éparses (dans l'avant-cour) ou de vastes édifices constituant, à eux sculs, de véritables unités (dans le corur du site et la basse-cour). I a spécificité des strucures ou du mobilier mis au jour à proximité de ces bâtiments peut nous guider dans l'interprétation des différents enclos dont est constituéc cette place forte.

Le cour du site est occupé, au moins durant les phases III et IV, par une vaste construction d'une superficie supéricure à $800 \mathrm{~m}^{2}$ et à l'architecture particulièrement élaborée. I a présence de nombreux foyers ou fours scmi-enterrés uniquement dans cette partic du site, entre autres des fours de type «polynésien " longs de $2 \mathrm{~m}$, larges d'environ $1 \mathrm{~m}$ et tapissés de pierres chauffées, suggère une utilisation domestique pour tout ou partie de cet édifice.

L'avant-cour a livré les traces d'un artisanat du métal particulièrement développé : des petits creusets de bronziers ou d'orfèves, des fragments de parois de fours vitrifiées mêlés à d'épaisses couches de cendres, enfin de nombreuses scories de bronze ou de for. I'absence de scories "cordées" ou de vestiges clairement identifiés de bas fourneaux ct la présence de battitures montrent qu'il ne s'agit pas des traces d'une activité de fabrication des métaux, mais plutôt de celle d'objets métalliques.

Dans la bassc-cour, seul le vaste édifice constitué de trois ailes de bâtiments disposées autour d'unc cour a été, pour le moment, identifié. Nous avions, dans un premier temps (Arramond et al., 1992), suggéré d'y voir une ferme, exploitation agricole implantéc au pied de la fortification. L'extension des fouilles depuis cette publica- tion et une réanalyse des vestiges de cette partie du site permettent de suggérer une nourelle interprétation. On notera en effer que, tel quil apparât aujourd'hui, ce vaste édifice constitue une unité architecturale particulièrement çaboréc, sans équivalent commu en Gaule pour cette période. Par la masse des matériaux mis en oruve (bois frequemment équarris, dalles de schiste bleu, madriers aux dimensions parfois imposantes) et l'ampleur du projet, apparemment réalisé d'un seul jet, il témoigne à lui seul de la particularité de ce site. l'identifier à une ferme, sur la seule présence de petits canaux d'évacuation du purin, semble peu crédible. Aucune des nombreuses exploitations agricoles laténiemnes jusqüici fouillées en Gaule ne semble en effet présenter, même de manière atténuće, tunc organisation similaire.

D'autres caractéristiques pouratent être plus révélatrices de la fonction de cet édifice. (On remarquera tout d'abord qu'il est implanté à proximité immédiate des principales portes aujourd'hui identifiées sur le site. De plus, il semble constituce une unité autonome, un espace clos auquel on ne pourait accéder quen empruntant deux porches surmontés soit d'une tour, soit d'un étage. On signalera enfin que la scule aile non bâtie, le sud de la cour, présente les traces d'un alignement de trous de poteaux qui, peu profonds a l'ouest, se transforment progressivement en de rastes excavations à l'est. On peut se demander si l'on n'a pas là les ultimes traces d'une rampe d'accès à l'étage de l'aile est, mais surtout au rempart délimitant la basse-cour. Si l'on ajoutc à ces particularités la présence d'un vaste édifice dallé conçu pour abriter de grands animaux, l'hypothèse d'un édifice abritant les hommes d'armes et leurs chevaux et bénéficiant d'un accès direct au rempart et aux portes de la basse-cour afin d'en faciliter la garde et la défense semble pouroir être poséc. Seule la poursuite des recherches permettra, par la validation de l'originalité de ce bâtiment dans l'ensemble de la fortification, de la confirmer.

Quoi qu’il en soit, on ne peut qu'être frappé par la stricte répartition des différentes activités qui semblent guider l'occupation de ces trois espaces précisément délimités et hiérarchisés. Une dernière particularité de ce site est l'abondance extrême, pour l'Armorique, des tessons d'amphores mis au jour : déjà plus de 5000 tessons, environ $400 \mathrm{~kg}$, et un nombre minimum de 350 cols différents. Dans l'ouest de la France, seul le village des 
Pichelots (Maine-et-Loire) peut témoigner, avec un nombre de lèvres d'amphores supérieur à 200, d'un volume d'importations comparable. La fortification de Paule se singularise donc également par les traces d'un réel commerce avec l'Italie romaine, et ce dès le début du II' s. avant J.-C., si l'on en juge par les quelques amphores de la phase III. S'agit-il des vestiges d'une abondante consommation ou d'une activité de redistribution, d'un relais commercial? L'absence de toute monnaie gauloise sur le site peut permettre, sous réserve de découvertes ultéricures, de privilégier pour le moment la première hypothèse.

Toutes ces caractéristiques contribuent déjà à donner, du site de Paule, une image fondamentalement différente de celle des habitats jusqu'ici fouillés en Armorique. Avant d'envisager une interprétation, il semble toutefois nécessaire d'examiner l'environnement immédiat de cette fortification.

On signalera tout d'abord qu'clle se situe à environ $7 \mathrm{~km}$ de la frontière présumée entre la Cité des Osismes, où elle aurait été édifiée, et celle des Venètes (fig. 36). Sa position à proximité du carrefour de deux voies semble encore plus significative. L'une d'entre elles, orientée nord-est/sud-ouest et qui longe le site au sud (fig. 37, $\mathrm{n}^{\circ} 2$ ), est un axe important qui reliait autrefois le nordest de la péninsule au sud-ouest de celle-ci. Cet axe est figuré, pour la période gallo-romaine, comme la voie

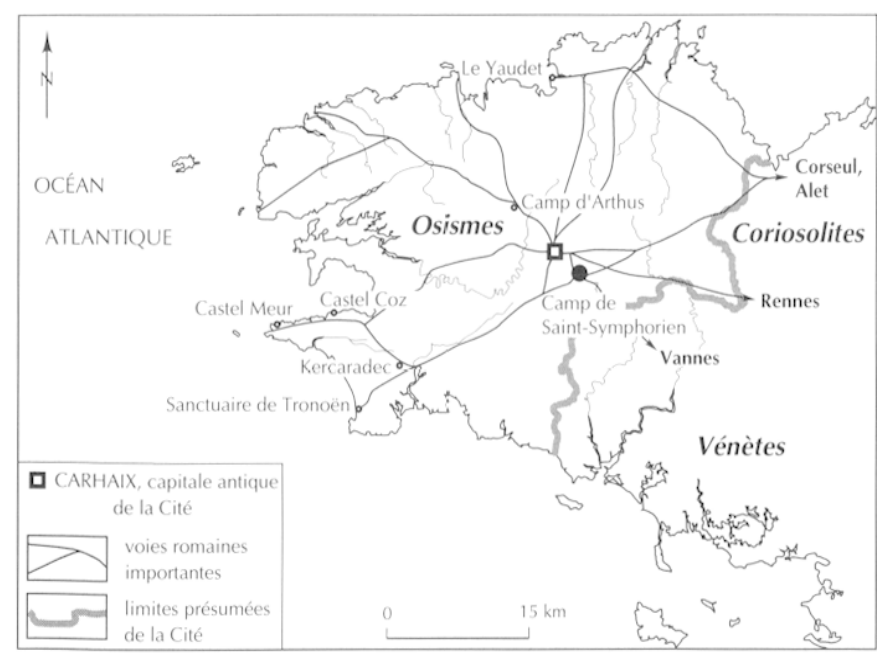

Fig. 36. Localisation du site de Paule dans la Cité des Osismes (d'après Pape, 1978) ; les principales fortifications du second $\hat{A} g e d u$ Fer attestées par les fouilles ainsi que le sanctuaire de Tronö̈n sont signalés (dessin M. Dupré). reliant Alet au sanctuaire majeur de Tronoën (Pape, 1978). L'autre, qui reliait autrefois Carhaix à Vannes, passe à proximité d'une autre enceinte (Bressilien, sur la commune de Paule ; fig. 37, n"6) et, plus au sud, près des vastes ateliers de potiers antiques de Guernevan à Glomel, fouillés par J.P. Bardel (1980).

Un autre aspect, non négligeable, est la présence de vastes tumulus à proximité immédiate de la fortification (fig. 37, no 3 et fig. 38). Ces tertres, d'un diamètre proche de $25 \mathrm{~m}$ pour une élévation conservée de $1 \mathrm{~m}$ environ, apparaissent encore sous la forme de grandes taches jaunes circulaires lorsque ces parcelles sont labourées. Ils étaient jusqu'ici attribués à l'Âge du Bronze, comme la plupart des sépultures de ce type ćtudiées en Bretagne, notamment par J. Briard (1984). Toutefois, plusicurs découvertes anciennes, et notamment celle de l'incinćration en urne couverte par une coupe à piédestal de Kergourognon à Prat dans les Côtes-d'Armor (Ciot, 1971), sont là pour nous rappeler la possible existence de tombes analogues pour le second Âge du Fer. En effet, ces vases peints datables de Ia Tène moyenne étaient recouverts par un tumulus de $39 \mathrm{~m}$ de circonférence à la base pour une hauteur maximale de $2,25 \mathrm{~m}$. On peut donc, là encore, se demander si les tertres de Paule ne correspondent pas aux sépultures de quelques personnages importants ayant occupé la forteresse voisine. Seule la poursuite des recherches permettra, peut-être, de valider ce qui demeure aujourd'hui unc hypothèse.

On signalera enfin la présence, au pied de la fortification et à proximité d'une chapelle aujourd'hui détruite, de sources importantes qui, comme le démontre une recherche récente menée par A. Provost, constituaient le point d'approvisionnement principal de l'aqueduc de Carhaix, capitale antique des Osismes située à une dizaine de kilomètres à vol d'oiseau (fïg. 37, n" 5).

L'accumulation de toutes ces caractéristiques suffir à démontrer la spécificité du site découvert à Paule. $\grave{A}$ la différence de la plupart des fortifications protohistoriques fouillées en Gaule, il ne s'agit manifestement pas, malgré une superficic comparable à celles d'autres places fortes de l'Âge du Fer (fig. 39, $n^{\prime \times 1}$ 12, 13), d'un habitat groupe : un hameau ou une bourgade plus importante abritée derrière ses remparts. L'organisation qui se dessine au travers des vestiges, et notamment la hiérarchie verticale que l'on constate entre les divers espaces fortifiés, ressemble fort à celle de certains 


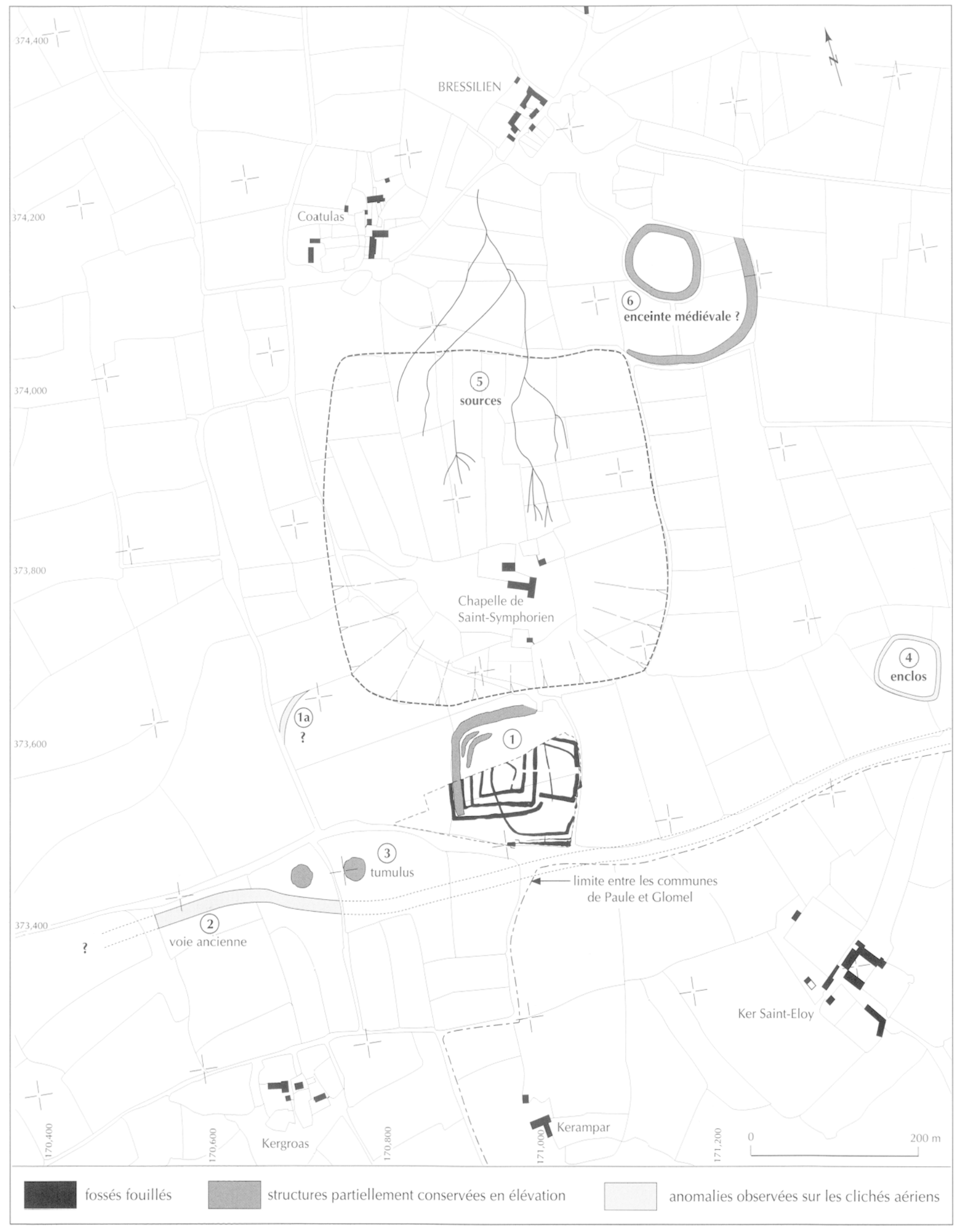

Fig. 37. La forlification et les sites archéologiques connus à proximité, implantés sur un extrait du cadastre napoléonien (dessin M. Dupré). 


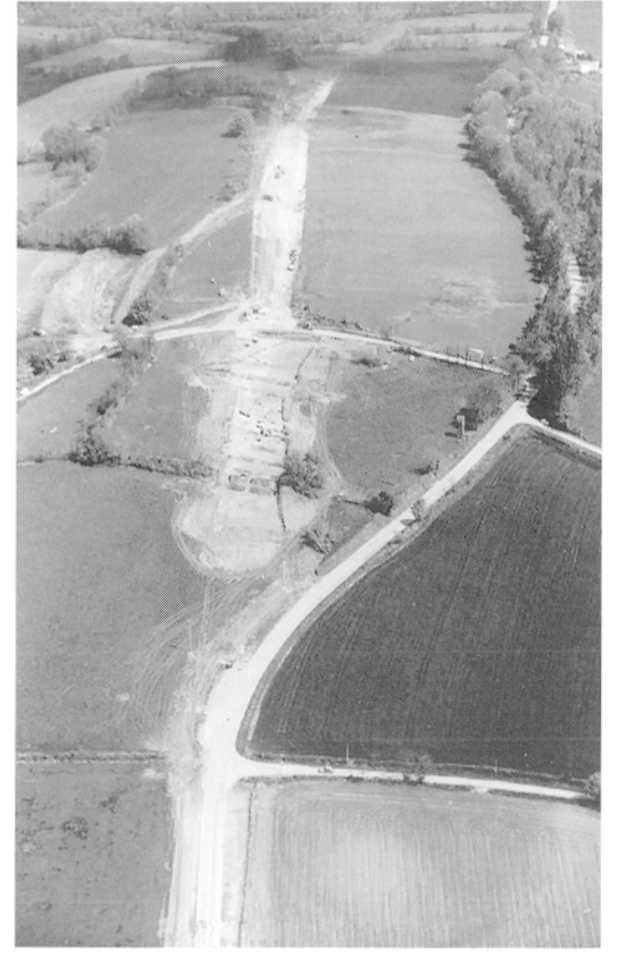

Fig. 38. Lue arienue du site à lïsue de la fouille de 1988. An premier plan, dans le champ labouré, la grande tache claire correspond ì limplacement diun tumulus.

châteaux forts médiévaux. (é site diffère donc fondamentalement des oppida contemporains, d'une superficie généralement supéricure à 15 ha et à l'intérieur desquels les vestiges d'un habitat dense, de type "proto-turbain ", ont été retrouvés.

Il pourrait, en revanche, se révéler représentatif d'un type de site jusqu'ici rarement fouillé : des fortifications, d'une superficic plus modeste, inférieure à 10 ha, qui parsement une partic de l'kurope celtique. J. Waldhauser propose, à partir d'une étude restreinte au territoire de la Bohême, de les définir à partir des critères suivants (Waldhauser, 1984) :

- "localisation presque toujours à un emplacement de hauteur, stratégiquement exposé,

- superficic des parties intericures de 0,3 à 9,3 ha (le plus souvent 0,4 à 3,2 ha),

- présence de la culture matérielle de la période ITCDl ", soit approximativement entre 300 et 80 avant J.-C.

Il suggère de les interpréter comme « le siège de communautés peu nombreuses (privilégiées ?) de la population celtique [...], ayant pour fonction le contrôle de communications commerciales, terrestres et fluviales, de l'Hinterland économique et des ressources de matières premières $[\ldots]$ ". L Les vastes oppida et ces fortifications de superficies plus modestes auraient pu, selon lui, « jouer, au moins particllement, un rôle semblable à celui des cités et des châteaux dans la période la plus tardive du Moyen Âge ».

A. Deyber, à partir d'une étude menée sur le nord-est de la France, oppose également les oppida à un deuxième type de fortifications " de moins de 10 ha de superficie, toujours implantées sur des hauteurs et habitées au moins de La Tène C2 à La Tène Dl, sinon jusqu'à La Tène D2 " (Deyber, 1984). Il propose également d'y voir "les sièges de communautés peu nombreuses ", assurant le contrôle de voies de communications. Poussant l'analyse plus loin, il remarque que "la carte des points chauds des deux conquêtes romaines de la Gaule suggère un lien étroit avec celle de l'habitat groupé fortifié de petite et moyenne importance. Les régions où il est répandu correspondent en effet avec celles qui furent les plus difficiles à soumettre, et elles peuvent passer, à juste titre, pour de véritables foyers de résistance. Il n'est pas douteux que, sans exercer les multiples fonctions des grands oppida, ces lieux fortifiés n'en constituaient pas moins des centres de commandement dont les décisions n'étaient pas contestées. Ces sites peuvent-ils passer pour les résidences fortifiées de l'aristocratic ? Nous serions tentés de le croire, d'autant qu'il existe en Iorraine et en Alsace une tradition évidente entre les lieux fortifiés de l'Âge du Fer et les châteaux médiévaux, les seconds pérennisant souvent les premiers aux mêmes emplacements".

Ce bipartisme entre quelques oppida et de nombreuses fortifications de superficies plus réduites, ćtabli à partir de l'étude de deux régions vastes et bien distinctes, semble pouvoir également s'appliquer au Iimousin (Ralston, 1992). Fin est-il de même en Armorique ? lin Bretagne, R. E. M. Whecler (Wheeler, Richardson, 1957) proposait une organisation hiérarchisée entre les capitales de province (le camp d'Arthus à Huelgoat pour les (Osismes), les enceintes secondaires (Kercaradec à Quimper : fig. 39, n"3) et les petits châteaux côticrs (Castel Cor à Beuzce-(ap-Sizun : lig. 39, n"2). Unc ćude plus récente (Maguer, 1996), limitée pour le moment au Finistère, ne remet pas fondamentalement en question ce schéma. Elle a néanmoins permis de recenser un nombre insoupçonné de petites enceintes attribuables à 


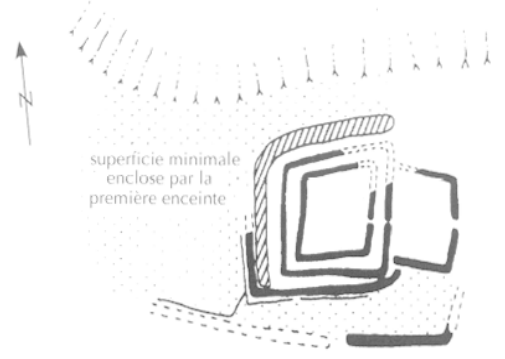

1. Paule (22)

Camp de Saint-Symphorien

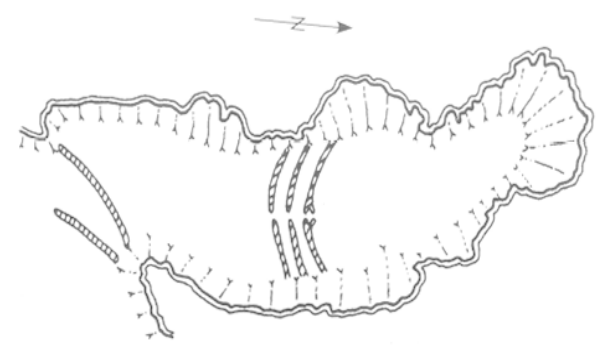

2. Beuzec-Cap-Brun (29)

Castel Coz

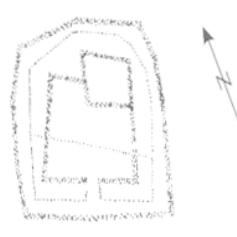

6. Taupont (56)

La Ville Corbin

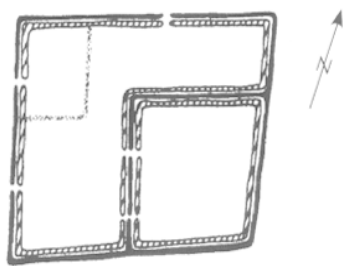

10. Rannée (35

Ligne Anne
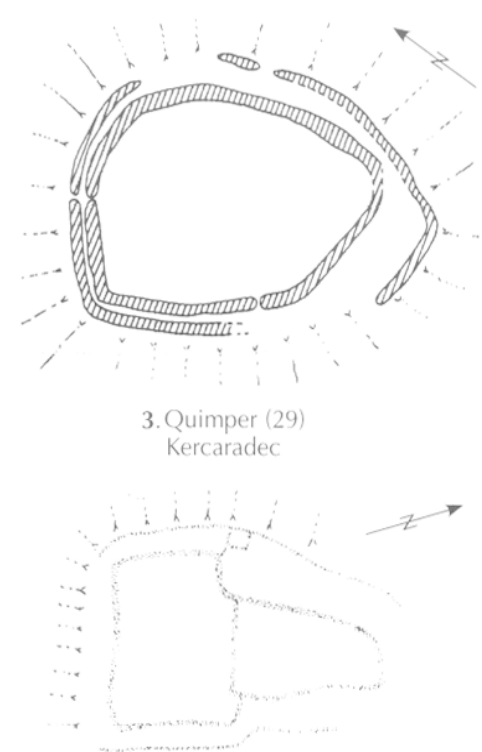

7. Livré-sur-Changeon (35)

Le Chemin

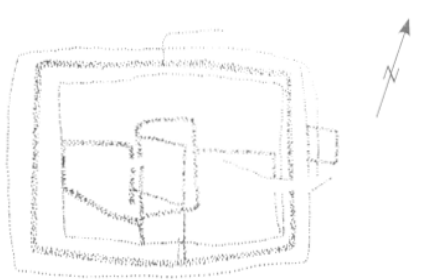

11. Ménéac (56

Couesmélan

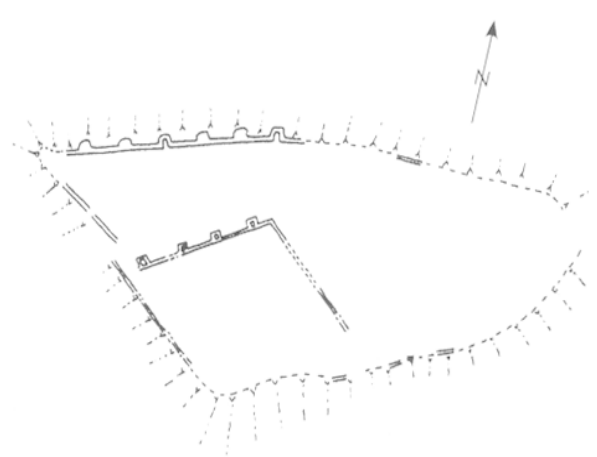

12. Entremont

(Bouches-du-Rhône)

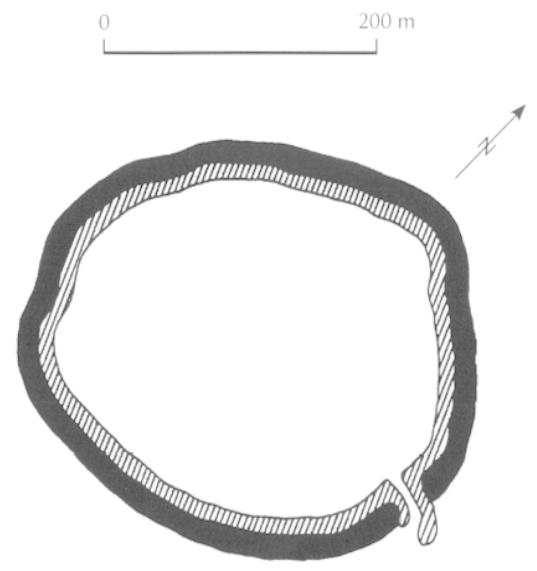

13. Danebury (Hampshire)

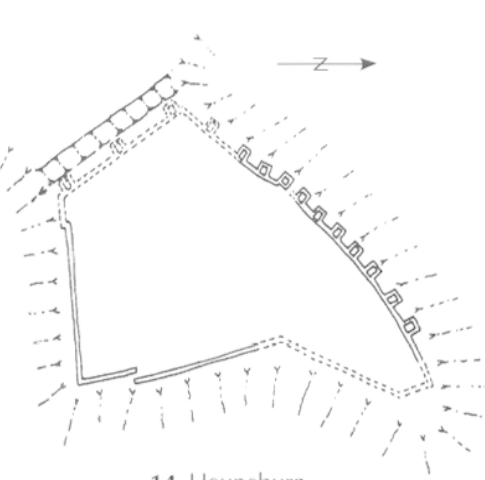

14. Heuneburg Baden Wurtenberg

Fig. 39. Mise en parallele du site de Paule et de quelques habitats enclos armoricains el de trois places fortes de la fin du fremier et du second Âge du Fer: 1, complété d'après les décapages de 1996; 2, d'après Wheeler et Richardson (1957), figurant un plan réalisé par R. F. Le Men en 1869 ; 3, d'après Wheeler et Richardson (1957); 4, d'après Le Bihan et al. (1990); 5, d'après Menez (1996); 6, site inédit découvert én prospection árienne par M. Cautier; 7, d'après Leroux (1990); 8, d'après Tanguy (1988); 9, d'uprès Bréart (1992), cliché de (;. Leroux; 10, d'après Meuret (1993); 11, site inédit découvert par M. Cautier ; 12, d'après Arcelin et al. (1990); 13, d'après Cunliffe (1983) ; 14, d'après Bittel et al. (1981). 
l'Âge du Fer, fréquemment quadrangulaires, el qui conduisent à relativiser la répartition essentiellement côtière jusqu'ici proposéc pour ces fortifications de dimensions restreintes (Wheeler, Richardson, 1957, fig. 1). Avec une superficic cstimée à plus de 3 ha pour son extension maximale, la forteresse de Paule est l'une des enceintes les plus vastes de cette catégoric.

On notera également le lien qui semble unir, au moins sur une partie de l'Armorique, ces forteresses quadrangulaires aux grandes exploitations agricoles du second Âge du Fer. Certaines de ces fermes, détectées en grand nombre en Bretagne et dont la superficie est le plus souvent voisine de $5000 \mathrm{~m}^{2}$ (fig. 39, $11^{\prime \prime \prime} 4-6$ ), couvrent en effet, dans de rares cas, des superficies comparables à celle de la forteresse de Paule. Simplement encloses, et non fortifièes, clles présentent néanmoins des plans constitués de parcelles quadrangulaires accolées ou emboîtées, analogues à ceux de certaines fortifications (fig. 39, n"10). Les prospections aćriennes ont parfois permis de détecter, sur la partie la plus élevée de ces fermes, un enclos quadrangulaire d'une superficie semblable au cocur du site de Paule et délimité par un fossé nettement plus large que ceux des autres enclos (fig. 39, no 9).

De rares fouilles, comme celle réalisćc par D. Tanguy sur le site de Kerven Teignouse à Inguiniel (Morbihan) ou par F. Mercier et E. Mare sur le site du I Iaut-Soulage à Bauné (Maine-et-Loire), confirment la présence de tels enclos défendus par une douve associée à un rempart au coeur de certaines des fermes les plus vastes. Les prospections aćriennes réalisées en Bretagne ou en Mayenne par G. Leroux, P. Naas et M. Gautier ont également permis de détecter des enclos d'une superficie de plusieurs hectares qui semblent, cette fois, intégralement délimités par des fossés très larges, plus proches des douves de Paule que des fossés, larges de 2 à 3 m, classiques dans les fermes armoricaines.

Il semble donc bien que, parmi les enclos de type "ferme indigène" du second Âge du Fer détectés ou fouillés dans le Grand-Ouest, certains aient été particllement ou intégralement délimités par des lignes de fortifications, marques d'un statut social probablement plus affirmé. I e groupe des cnclos fossoyés, jusqu’ici abusivement désignés par le terme de fermes qui reflète mal une diversité aujourd'hui bien établic, recouvre donc en partie celui des forteresses aux superficies modestes, de là 4 ha, détectées en abondance dans la péninsule armoricaine.

Tout indique donc que le camp de Saint-Symphorien peut, dans une large mesure, être considéré comme caractéristique d'un ensemble de sites dont l'existence a été pressentic dans plusieurs régions de l'Europe celtique, mais qui n'ont jusqu'ici été que rarement fouillés. Voir dans ces forteresses les résidences des personnages qui ont dominé la société du second Âge du Fer, environnés de leurs clients, de leurs guerriers et de leur maisonnée, semble, si l'on en juge par les premiers résultats de la fouille du site de Paule, crédible. Ia poursuite des recherches deva done s'attacher, plus qu'à valider cene hypothèse qui paraît désormais bien ćtablie, à distinguer les rythmes de l'évolution de cet habitat et l'inscrire dans son enviromnement géographique et historique. En associant à cette démarche de foullle extensive la réalisation d'inventaires sur les enceintes de la péninsule armoricaine, accompagnés de campagnes de sondages pour valider les typologies établies, il devrait être possible de dépasser le cadre du modèle théorique comme celui de l'étude de site pour aborder, avec quelques ćléments tangibles, le problème de la formation des territoires de l'Armorique celtique. 


\section{BIBLIOGRAPHIE}

Arcelin P., Congies G., Willaume M. 1990 : Entremont, in : Vovage en Massalie, 100 ans d'archéologie en Gaule du Sud, Marseille/Aix-en-Provence. Musées de Marseille/Edisud, p. 100-111.

Arramond J.-C., Le Potier C.

1990): Paule, Saint-Symphorien, habitat de l'Âge du Fer. in : Duval A.. Le Bihan J.-P.. Menez Y. (éds.), Les Gaulois d'Armorique : la fin de l'Âge du Fer en Europe tempérée, Actes du XII Colloque de I'Association Française d’Étude de l’Âge du Fer, Quimper, mai 1988. 3“ suppl. à la Revue Archéologique de l'Ouest. p. 153-155.

Arramond J.-C.. Mrinez Y., Le Potier C. 1992 : Le Camp de Saint-Symphorien à Paule. Archéologie et travaux routiers départementaux. Musée d'Histoire, Saint-Brieuc, 71 p.

A(D)OC\% F., Buchshenschutz O.

1989 : Villes, villages et campagnes de l'Europe celtique. Bibliothèque d’Archéologie, Paris, Hachette, 362 p.

BARIDEL J.-P.

1980) : Glomel. Guernevan : fours de potiers, Archéologie en Bretagne. 4' trimestre, p. 35-37.

BERSU G.

1940 : Excavations at Little Woodbury, Wiltshire, part I : the settlement revealed by excavation, Proceedings of the Prehistoric Society, 29. p. 206-213.

Bittel K., Kimmig W.. SCHiek S.

1981 : Die Kelten in Baden-Wiirttemberg, Stuttgart, Konrad Theiss Verlag, 533 p.

Blanchet J.-Cl., Buchsenschutz O., Meniel P.

1983 : La maison de La Tène moyenne de Verberie (Oise), « Le Buisson Campin », in : Les Celtes dans le nord du Bassin parisien. Actes du V: Colloque de
l'Association Française d’Étude de l'Âge du Fer, Senlis, 30-31 mai 1981. I'r suppl. à la Revue Archéologique de Picardie, p. 96-126.

BRÉART B.

1992 : Archéologie aérienne : 30 ans de découvertes, Archéologia, 283, oct. 1992, p. 54-61.

BRIARD J.

1984 : I.es tumulus d'Armorique, l'Âge du Bronze en France. 3, Paris. Picard, 297 p.

\section{BLCHSENSCHLTZ O.}

1981 : L'apport des habitats à l'étude chronologique du premier siècle avant J.-C.. in : l'Âge du Fer en France septentrionale, Actes du III Colloque de l'Association Française d'Étude de l'Âge du Fer, Châlons-sur-Marne, 1979, Mémoires de la Société Archéologique Champenoise. 2, p. 331-337.

Christl.hin R., Braasch O.

1982 : Das unterirdische Bayern, Stuttgart, Konrad Theiss, $275 \mathrm{p}$.

COLlis J.

1990 : L’impact des processus d'urbanisation sur les sites ruraux : le cas d'Owslebury. Hants. Angleterre, in : Duval A., Le Bihan J.-P., Menez Y. (éds.), Les Gaulois d'Armorique : la fin de l'Âge du Fer en Europe tempérée, Actes du XII Colloque de l'Association Française d'Étude de l'Âge du Fer, Quimper, mai 1988, 3' suppl. à la Revue Archéologique de l'Ouest, p. 209-222.

CUNLIFFE B.

1983 : Danebury; Anatomy of an Iron Age Hillfort, Londres, Batsford, $192 \mathrm{p}$.

Davies S. M.

1981 : Excavations at Old Down Farm. Andover -II- Prehistoric and Roman. Proceedings of the Hampshire Field Club, 37, p. 81-164.
Deyber A.

1984 : Structures et fonctions des fortifications de l'Âge du Fer dans le nord-est de la France (régions ChampagneLorraine-Alsace), in : Les Celtes en Belgique et dans le nord de la France, les fortifications de l'Âge du Fer, Actes du VI' Colloque de l'Association Française d'Étude de l'Âge du Fer, Bavay et Mons, 1982, n" spécial hors série à la Revue du Nord, p. 215-236.

Duval A.

1991 : La société celtique au Irr siècle avant J.-C., in : Les Celtes, Catalogue d'exposition, Venise 1991, p. 487.

FASHAM P. J.

1985 : The Prehistoric Settlement at Winnall Down, Winchester, Gloucester, Hampshire Field Club Monograph, 2.

FowI.tR P.

1983 : The Farming of Prehistoric Britain. Cambridge University Press, $127 \mathrm{p}$.

Galltiek du MotTay J.

1883: Répertoire archéologique du département des Côtes-du-Nord, I. Société Historique et Archéologique des Côtesdu-Nord, Saint-Brieuc, 251 p.

\section{Gebhardt A}

1992 : Camp de Saint-Simphorien (Paule, Côtes-d'Armor), Rapport d'étude micromorphologique, 9 p., inédit.

Giot P.-R.

1971 : Ombres et lumières sur la chronologie de la céramique armoricaine de l'Âge du Fer, Annales de Bretagne, LXXVIII, p. 73-92.

1979 : L'Âge du Fer, in : Giot P.-R., Briard J., Pape L. (éds.), Protohistoire de la Bretagne, Rennes, éd. OuestFrance, p. 215-360.

Giot P.-R., MoR7.Adec H.

1992 : Utilisation préhistorique de la « métahornblendite " de Pleuven (Finistère) : 
des haches néolithiques à la statuette gauloise de Paule (Côtes-d'Armor), étude pétro-archéologique, Comptes rendus de l'Académie des Sciences de Paris, 315, série 2, p. 1215-1221.

Giot P.-R., LF:Cerf Y., OnNéE Y.

1971: Céramiques armoricaines de l'Âge du Fer: II, Travaux du Laboratoire d'Anthropologie de l'Université de Rennes, 18 p., 72 pl.

Giot P.-R., LF Roux C.-T., ONné Y. 1968 : Le souterrain de Bellevue à Plouegat Moysan, in : Céramiques armoricaines de l'Âge du Fer, Travaux du Laboratoire d'Anthropologie de l'Université de Rennes, 41 p., 63 pl.

HARMOIS A.-L.

1909 : Imventaire des déconvertes archéologiques du département des Côtes-duNord. Mémoires de la Société d'Émulation des Côtes-du-Nord, XLVII, 272 p.

LA CHENEIIIERR: G. IH:

1884 : Deuxième inventaire des momuments mégalithiques compris dans ié département des Côtes-du-Nord. Saint-Brieuc. $32 \mathrm{p}$.

\section{LF: BIHAN I.-P.}

1984 : Villages gaulois et parcellaires antiques au Braden en Quimper, Cahiers de Quimper antique, 1, 264 p.

Le: Bihan J.-P., Bardel. J.-P., Menez, Y., TANGUY D.

1990 : Les établissements ruraux du second Âge du Fer en Armorique, in : Duval A., Le Bihan J.-P., Mene\%. Y. (éds.), Les Gaulois d'Armorique : la fin de l'Âge du Fer en Europe tempérée. Actes du XII Colloque de l'Association Française d'Étude de l'Âge du Fer, Quimper, mai 1988. 33 suppl. à la Revue Archéologique de l'Ouest, p. 97-113.

Ll: Bihan J.-P., Dairk: M.-Y., Carril: P., GoupIl. F.

1987 : Le hameau de La Tène finale du Braden II à Quimper (Finistère), Revue Archéologique de l'Ouest, 4, p. 67-89.

Ll: Potier C., Arramoni) J.-C.

1989a : Le dieu barde, Connaissance des Arts, 444, février 1989, p. 62-63. 1989b : Paule, Saint-Symphorien (Côtes-duNord), in : Archéologie de la France, 30) ans de découvertes, Catalogue d'exposition, Paris, éd. de la Réunion des Musées nationaux, p. 281.

1990): L'établissement de Paule, VI"-l" siècle av. J.-C., in : Paule, pierre de mémoire, 5 siècles de civilisation celte. livret-guide, Musée d'Histoire de SaintBrieuc, p. 16-17.

\section{LEROUX G.}

1990 : Le passé v'u du ciel - les révélations archéologiques de la sécheresse de 1989 de Hante-Bretagne, fascicule d'exposition, $16 \mathrm{p}$.

Maguer P.

1996 : Les enceintes fortifiées de l’Âge du Fer dans le Finistère, Revue Archéologique de l'Ouest, 13, p. 103-122.

MARGiUERIE: D.

1992: Le camp du second Âge du Fer de Saint-Symphorien (Paule. Côtesd'Armor). Rapport d'étude anthracologique et de mesure des taux de phosphate. 16 p.. inédit.

Massy J.-L.. Manthi. E.. Me.vili. P.

1986 : La nécropole gauloise de Tartigny (Oise), Revue Archéologique de Picardie, 3/4. p. 13-81.

\section{MENEL $Y$.}

1988 : Pluguffan - Keriner - sondage sur un habitat datable de la transition La Tène finale-Gallo-romain précoce, in : Audouze F., Buchsenschut\% O. (éds.), Architectures des âges des Métaux : fouilles récentes, Dossiers de Protohistoire 2, Paris, Errance, p. 111120.

1994 : Les enclos de type "ferme indigène" en Bretagne : quelques réflexions issues de treize ans de fouilles, in : Les installations agricoles de l'Âge du Fer en Ilede-France, Études d'Histoire et d'Archéologie, IV, Paris, Presses de l'École normale supéricure, p. 255-276.

1996: Une ferme de l'Armorique gauloise: Le Boisanne à Plouer-sur-Rance (Côtesd'Armor), Documents d'Archéologie Française, 58, Paris, éd. de la Maison des Sciences de l'Homme, 217 p., 34 pl.
MESNARD M.

1962 : Recherches archéologiques, Bulletins et Mémoires de la Société d'Émulation des Côtes-du-Nord, XC, p. 9-12.

MELRI:T J.-C.

1993 : Peuplement, pouvoir et paysage sur la marche Anjou-Bretagne, des origines alu Moven Âge, Société d'Archéologie et d'Histoire de la Mayenne, suppl. $n^{\circ} 4$, Laval, $656 \mathrm{p}$.

\section{MORIDANT D.}

1992 : La Bassée avant l'Histoire, Archéologie et gravières en Petite-Seine, Association pour la Recherche Archéologique en Ile-de-France, Nemours, $143 \mathrm{p}$.

PAPE L.

1978 : La Civitas des Osismes à l'époque gallo-romaine. Université de HauteBretagne, Paris, C. Klincksieck, 541 p.. $74 \mathrm{pl}$.

Py M.

1978 : L'oppidum des Castels à Nages (Gard) : (fouilles 1958-1974), XXXV: suppl. à Gallia, Paris, éd. du CNRS. 362 p., 148 ill.

RALSTON I. B. M.

1992 : Les enceintes fortifiées du Limousin: les habitats protohistoriques de la France non méditerranéenne, Documents d'Archéologie Française, 36, Paris, éd. de la Maison des Sciences de l'Homme, $190 \mathrm{p}$.

\section{REINFCKE: P.}

1902 : Zur Kenntis der La Tène denkmaler der Zone nord wärts der Alpen, Festschrift zur Feier des 50 jährigen Bestehens des Römisch-Germanischen Zentral Museums. Mainz, p. 53-109.

SCHWAPPACH F.

1989 : Stempelverzierte Keramik von Armorica, in : Festschrift Dehn. Fundherichte aus Hessen, Beiheft 1 , p. 213-293.

TANGUY D.

1988 : L'habitat du second Âge du Fer de Pluvigner (Morbihan), in : Audouze F., 
Buchsenschut\% O. (éds.). Architecture des âges des Métaux: fouilles récentes. Dossiers de Protohistoire, 2, Paris. Errance, p. 71-80.

\section{Vendries C., Alimasson P.}

1990 : La statuette de Paule, in : Paule, pierre de mémoire, 5 siècles de civilisation celte, livret-guide, Musée d'Histoire de Saint-Brieuc, p. 6-9.
Waiswriciht G.. SpratliN G. M.

1973 : The Iron Age Settlement of Gussage All Saints, Antiquity. 47. p. 109-127.

\section{WALDHAUSER $\mathbf{J}$.}

1984 : Les fortifications celtiques de la période L.T.C.-D1 en Bohême. Oppida et castella, in : Les Celtes en Belgique et dans le nord de la France, les fortifications de l'Âge du Fer, Actes du VF
Colloque de I'Association Française d'Étude de l’Âge du Fer. Bavay et Mons, 1982. $n^{\circ}$ spécial hors série à la Revue du Nord. p. 265-270.

WHEEl.ER M.. RICHARISON K. M. 1957 : Hill-Forts of Northern France. Reports of the Research Committee of the Society of Antiquaries of London. XIX. p. 32-38. 